$$
\begin{aligned}
& \text { UNIVERSIDADE DO ESTADO DE SÃO PAULO } \\
& \text { ESCOLA POLITÉCNICA } \\
& \text { DEPARTAMENTO DE ENGENHARIA QUÍMICA }
\end{aligned}
$$

FÁBIO COFFANI DOS SANTOS DE SIQUEIRA

\title{
ESTUDO DE ÓLEO PESADO ENVOLTO EM ÁGUA UTILIZANDO FERRAMENTA CFD
}




\title{
UNIVERSIDADE DO ESTADO DE SÃO PAULO ESCOLA POLITÉCNICA DEPARTAMENTO DE ENGENHARIA QUÍMICA
}

\section{FÁBIO COFFANI DOS SANTOS DE SIQUEIRA}

\section{ESTUDO DE ÓLEO PESADO ENVOLTO EM ÁGUA UTILIZANDO FERRAMENTA CFD}

\begin{abstract}
Dissertação apresentada à Escola Politécnica da Universidade de São Paulo como parte dos requisitos para a obtenção do título de Mestre em Ciências, Programa de Engenharia Química
\end{abstract}




\title{
UNIVERSIDADE DO ESTADO DE SÃO PAULO ESCOLA POLITÉCNICA DEPARTAMENTO DE ENGENHARIA QUÍMICA
}

\section{FÁBIO COFFANI DOS SANTOS DE SIQUEIRA}

\section{ESTUDO DE ÓLEO PESADO ENVOLTO EM ÁGUA UTILIZANDO FERRAMENTA CFD}

\begin{abstract}
Dissertação apresentada à Escola Politécnica da Universidade de São Paulo como parte dos requisitos para a obtenção do título de Mestre em Ciências, Programa de Engenharia Química
\end{abstract}

Área de concentração:

Engenharia Química

Orientador:

Prof. Dr. Ardson dos Santos Vianna Jr. 
Este exemplar foi revisado e corrigido em relação à versão original, sob responsabilidade única do autor e com a anuência de seu orientador.

São Paulo, de fevereiro de 2015.

Assinatura do autor

Assinatura do orientador

\section{Catalogação-na-publicação}

Siqueira, Fábio Coffani dos Santos

Estudo de óleo pesado envolto em água utilizando ferramen-

ta CFD / F.C.S. Siqueira. -- versão corr. -- São Paulo, 2015.

$72 \mathrm{p}$.

Dissertação (Mestrado) - Escola Politécnica da Universidade de São Paulo. Departamento de Engenharia Quimica.

1.Escoamento bifásico 2.Modelo de mistura 3.Simulação 4.Fenômenos de transporte I.Universidade de São Paulo. Escola Politécnica. Departamento de Engenharia Química Il.t. 
Dedico este trabalho aos meus Pais, Eliane e Marcelo, à minha avó, Ernesta e a toda minha família que, com muito carinho e apoio, não mediram esforços para que eu chegasse até esta etapa de minha vida. 


\section{Agradecimentos}

Ao meu orientador e amigo, Prof. Dr. Ardson dos Santos Vianna Jr., pela dedicação e pelo entusiasmo com que orientou esse trabalho;

Ao Prof. Dr. Deovaldo Moraes Jr. que nos anos de convivência contribuiu para meu crescimento científico e intelectual;

Ao Engenheiro Cláudio Neves Borges da RPBC, pelo apoio e exemplo;

Aos meus amados pais, irmãos, namorada e demais familiares pelo carinho e incentivo dado ao longo desse período;

Aos nobres colegas da Universidade de São Paulo, sobretudo ao Eng ${ }^{\circ}$. Rodrigo de

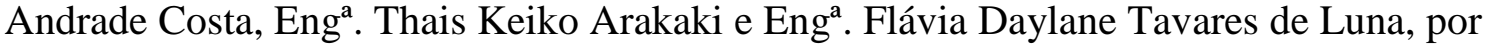
todo apoio dado durante essa etapa. 
O entusiasmo é a maior força da alma. Conserva-o e nunca te faltará poder para conseguires 0 que desejas.

Napoleão Bonaparte 


\section{RESUMO}

A descoberta de petróleo na camada do Pré-Sal fez com que a Petrobras envestisse cerca de 240 bilhões de dólares. Uma etapa crítica desta indústria é o transporte de petróleo, que envolve o sistema água-óleo. O objetivo do presente trabalho é estudar uma corrente água-óleo em um tubo reto e em uma curva, com o intuito de gerar perfis de velocidades, pressões e densidades em CFD. Para as simulações desenvolvidas foram considerados: fluxo 3D, escoamento turbulento na fase óleo e escoamento laminar na fase água, isotérmico e incompressível. Foram realizados estudos nos estados estacionário e transiente. Foi desenvolvido o estudo de convergência da malha. As ferramentas do Phoenics utilizadas para representar a interação entre as fases foram o IPSA e o Algebraic Slip. O IPSA resolve as equações de Navier-Stokes para cada fase. No Algebraic Slip, postula-se que existe um meio contínuo em que existem vários componentes da fase dispersos, podendo estes ser gotas, bolhas ou partículas sólidas. A turbulência foi avaliada utilizando os modelos $\mathrm{K}$ $\varepsilon$ padrão e o K-w, porém só houve redução considerável dos resíduos para o K$\varepsilon$ Padrão. As densidades geradas nas simulações em CFD foram comparadas visualmente com os resultados experimentais obtidos em trabalho anterior para fluxo multifásico. As quedas de pressão obtidas em simulação foram comparadas com os dados da literatura, onde foi possível observar a grande redução da perda de carga ao utilizar a técnica de envolver o óleo com um anel de água na tubulação. As simulações realizadas com o modelo Algebraic Slip, e o modelo de turbulência foram consideradas como validadas.

Palavras Chave: Multifásico, Água-Óleo, CFD, PHOENICS, Óleo Pesado 


\begin{abstract}
With the discovery of oil in the pre-salt layer, Petrobras was encouraged to invest about 240 billion dollars. A critical point of this industry is the oil transport, which encompasses oil-water system. The objective of the present work is to study the flow of water and oil into a tube and an elbow, in order to generate distributions of velocity, pressure and density by using a CFD tool. To develop simulations the following is assumed: 3D flow, turbulent flow in oil phase and laminar flow in water phase, isotherm and incompressible flow. Steady-state and transient studies have been done. The mesh convergence has been carried out. The IPSA and Algebraic slip were the Phoenics tools that were used to represent the phases interaction. The IPSA solves the Navier-Stokes equations for each phase. In the Algebraic Slip model, one assumes that a continuum mean exists where the other components are dispersed, which can be bubbles or solid particles. The turbulence was evaluated by using $\mathrm{K}-\varepsilon$ standard and $\mathrm{K}-$ $\omega$ models; however, the considerable reduction of residue to the $\mathrm{K}-\varepsilon$ Standard was observed. The densities modeled by CFD were visually compared to the experimental results that were obtained in a previous work for a multiphase flow. The simulations of head loss were compared to literature data, and it can be seen a big difference between the head loss that was obtained by using water and that no using water. The simulations of Algebraic Slip model and the use of turbulence model were considered as validated.
\end{abstract}

Keywords: Multiphasic, Water-Oil, CFD, PHOENICS, Heavy Oil. 


\section{LISTA DE FIGURAS}

Figura 1 - Anuário Estatístico......................................................................

Figura 2.1 - Diferentes padrões de escoamento bifásico..................................

Figura 2.2 - Diferentes padrões de escoamento bifásico................................. 5

Figura 3.1 - Duto com Rifting...................................................................... 7

Figura 3.2 - Corte transversal do padrão anular............................................ 9

Figura 3.3 - Representação das variáveis no escoamento anular......................10

Figura 3.4 - Malha ortogonal...................................................................... 14

Figura 3.5 - Malha não-ortogonal............................................................ 14

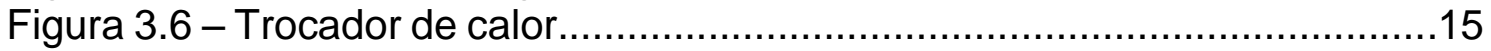

Figura 3.7 - Malha ortogonal 40x15 ...................................................... 15

Figura 3.8 - Malha não-ortogonal 40x15 ..............................................15

Figura 3.9 - Campo de velocidades da malha ortogonal.................................16

Figura 3.10 - Campo de velocidades da malha não-ortogonal........................16

Figura 3.11 - Malha estruturada não-ortogonal..........................................16

Figura 4.1 - Fluxo estratificado com gotas....................................................23

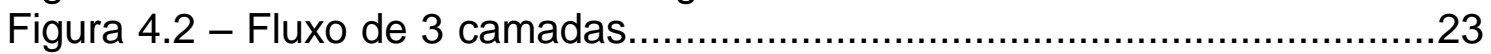

Figura 4.3 - Fluxo mistura estratificada.......................................................24

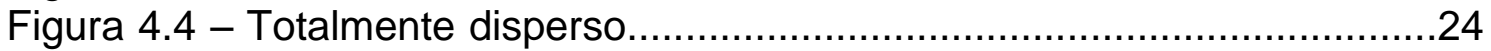

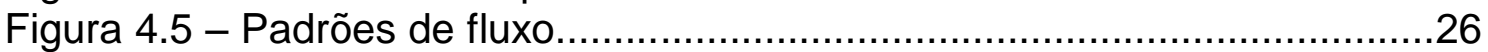

Figura 4.6 - Fluxo estratificado...............................................................

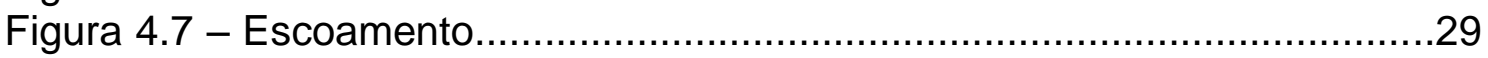

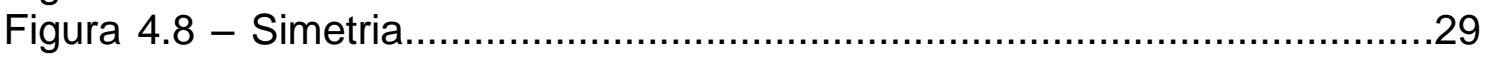

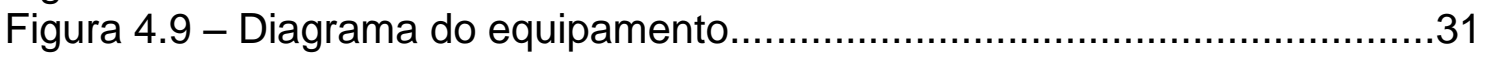

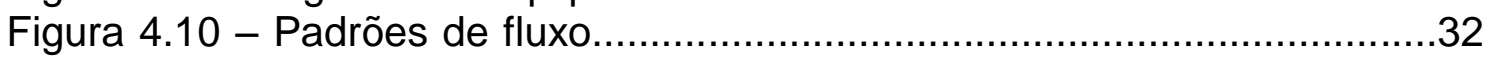

Figura 5.1 - Planta em escala de laboratório do sistema multifásico...................41

Figura 5.2 - (A) Trecho Inferior; (B) Trecho Superior; (C) Trecho Vertical...........42

Figura 5.3 - (A) Trecho Inferior; (B) Geometria Completa..............................42

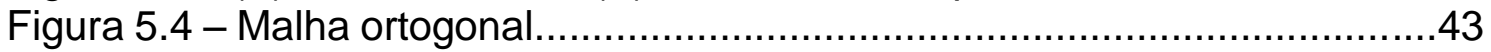

Figura 6.1 - Gráficos de acompanhamento da simulação...............................46

Figura 6.2 - (A) Isosuperfíce de Velocidade k- $\varepsilon$; (B) Isosuperfíce de Pressão k- $\varepsilon$;

(C) Isosuperfíce de Velocidade k- $\omega$; (D) Isosuperfíce de Pressão k- $\omega . . . \ldots \ldots . . . .47$

Figura 6.3 - A) Plotagem das Velocidades do modelo $k-\varepsilon$; B) Plotagem das

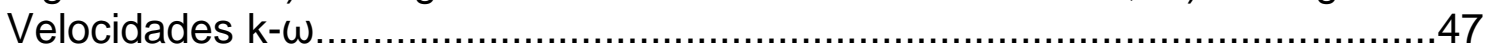

Figura 6.4 - (A) Simulação das densidades na curva; (B) Foto do Trecho Curvo

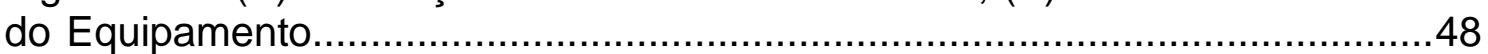

Figura 6.5 - (A) Simulação das densidades no trecho reto; (B) Foto do

Escoamento no trecho reto.....................................................................48

Figura 6.6 - Gráficos de monitoramento da simulação......................................49

Figura 6.7 - Isosuperfíce de Pressão..........................................................49

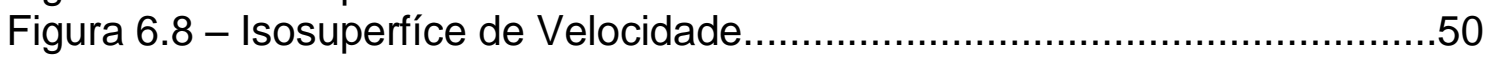

Figura 6.9 - Isosuperfíce de Densidade...............................................50

Figura 6.10 - Gráficos de acompanhamento da simulação após 1000 Steps.....51

Figura 6.11 - Isosuperfíce de Pressão.....................................................52

Figura 6.12 - Isosuperfíce de velocidades...............................................53

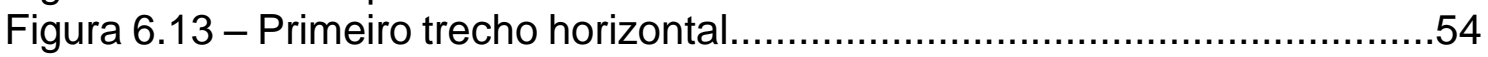

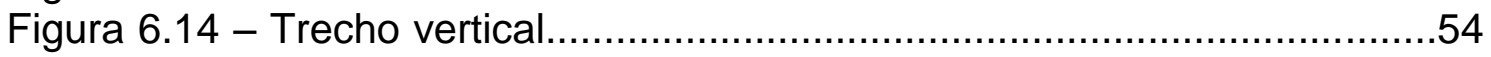


Figura 6.15 - (A) Trecho Horizontal Superior; (B) - Trecho Horizontal Inferior....55

Figura 6.16 - Isosuperfíce de densidade ...................................................56

Figura 6.17 - Vista do eixo $X$ do tubo vertical em diferente instantes...................57

Figura 6.18 - Isosuperfíce de velocidade ................................................57

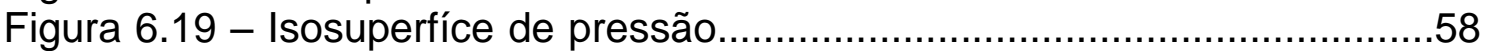

Figura 6.20 - Isosuperfíce de densidade ..................................................59

Figura 6.21 - Isosuperfíce de velocidade ..................................................60

Figura 6.22 - Queda de Pressão com valores para fluxo de óleo.......................61

Figura 6.23 - Queda de pressão modelo multifásico.......................................61

Figura 6.24 - Curva e trecho horizontal superior.............................................62

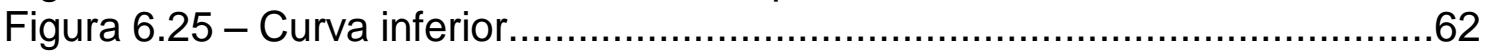

Figura 6.26 - Isosuperfície de densidade................................................63

Figura 6.27 - Vista do eixo $X$ do tubo vertical em diferentes instantes................64

Figura 6.28 - Tubo vertical em operação.....................................................64

Figura 6.29 - (A) Linhas de Fluxo eixo Y (B) Linhas de Fluxo eixo X..................66 


\section{LISTA DE TABELAS}

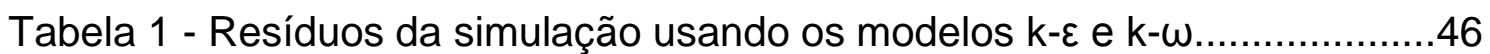

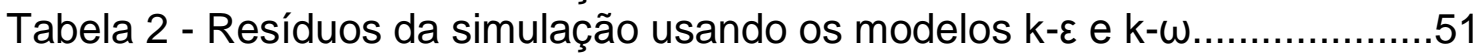

Tabela 3 - Resíduos da simulação usando o modelo k-E...............................59 


\section{Lista de Abreviações}

ASLP - Algebraic Slip Model

CFD - Computacional Fluid Dynamics

MDF - Método das Diferenças Finitas

CHAM - Concentration, Heat and Momentum Limited in Winbledon

EP - Épsilon (Referente ao modelo de turbulência K-Épsilon)

MVF - Método dos Volumes Finitos

MEF - Método dos Elementos Finitos

OM - Ômega (Referente ao modelo de turbulência K-Ômega)

PARSOL - Partial Solids Teratment

PHOENICS - Parabolic, Hyperbolic or Eliptic Numerical Integration Codes

Series

PWIM ou PWI Method - Pressure Weitghted Interpolation Method

SEM - Scalar Equation Method

VOF - Volume of Fluid Method

HOL - Height Of Liquid

GENTRA - General Tracking 


\section{Lista de Símbolos}

$\nabla$ - Operador diferencial

$\Psi$ - Variável Arbitrária

$f^{*}{ }_{n e w}$ - Valor da solução da equação de volume finito após aplicação da relaxação

\langle\rangle -média

$f_{\text {new }}$ - Valor da solução da equação de volume finito do Step atual

$f_{\text {old }}$ - Valor da solução da equação de volume finito do Step anterior

$\dot{m}$ - Taxa de transferência de massa por volume

$\vec{n}$ - Vetor normal

$\mu_{t}-$ Viscosidade turbulenta

A - Coeficiente do Centróide ou Área da seção transversal

a - Coeficiente de volume finito

B - Força de campo em função da massa

$\mathrm{C}_{d}$ - Coeficiente de arraste

$\mathrm{C}_{\mathrm{f}, \mathrm{i}}-$ Fator de atrito interfacial

D - Soma de $\mathrm{k}$ com $\dot{m}$

d - Diâmetro da tubulação

f - Função genérica de segunda ordem

F - Função marcadora

$F_{d}$ - Força de Arraste

Fs - Força deslizamento

g - Gravidade

h - Espaçamento de grid

$h_{f}-$ Espessura de fluido

$h_{L}-$ Espessura de líquido

$\mathrm{J}$ - Tensor genérico de segunda ordem

J - Variável de difusão

$\mathrm{K}$ - Energia Cinética de Turbulência

$\mathrm{N}$ - Número total de Fases

$P$ - Erro da Pressão

p - Pressão

Rc - Fluxo de deposição

$\mathrm{R}_{\mathrm{D}}$ - Fluxo de atomização

Re - Número de Reynolds

$\mathrm{S}$ - Perímetro do tubo

$S$ - Termo Fonte

$S$-Termo Fonte

$S_{G}$ - Perímetro molhado pela fase gás

$S_{I}$ - Perímetro da interface

$S_{L}$ - Perímetro molhado pela fase líquida

$\mathrm{t}$ - Tempo

$T$ - Tensor das tensões

$U$ - Erro da Velocidade

u, V - Velocidade

$\mathrm{V}_{\mathrm{A}, \mathrm{z}}$ - Velocidade da gota Atomizada

$V_{D, z}-$ Velocidade da gota depositada

$x$ - Dimensão Espacial 
y - Dimensão Espacial

$\alpha$ - Fração Volumétrica

$\beta$ - Coeficiente de Fourier para Erro

$\Delta$ - Variação

$\varepsilon$ - Dissipação turbulenta

$\theta$ - Número de ondas

$\mathrm{K}$ - Coeficiente de Arraste de Interface

$\Pi$ - Coeficiente de erro

$\omega$ - Dissipação turbulenta específica

$\rho$ - Densidade

\section{Subscrito/Sobrescrito}

e, w - Faces Leste e Oeste do elemento de controle respectivamente

E, W, P - Nós Leste, Oeste e Central

K, L - Índice Espacial

h, i, j - Índice Fásico

LW - Interface Parede Líquido

I - Interface entre fluidos

LE - fluido no núcleo

LF - fluido no filme

$G$ - fase gás

p - Partícula

C - núcleo

(i) - Expoente

' - Correção

ר, - Estágios Intermediários 


\section{Sumário}

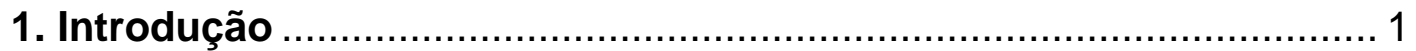

2. Objetivos Gerais e Específicos .............................................. 2

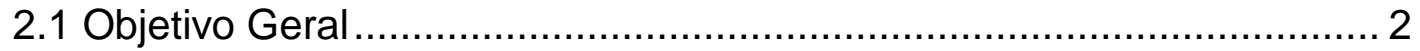

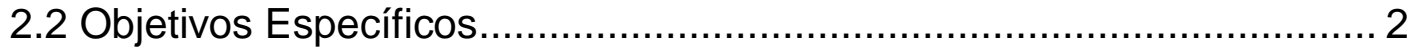

3. Fundamentos Teóricos ……………………........................... 3

3.1 Conceitos Básicos do Escoamento Multifásico ……………………...... 3

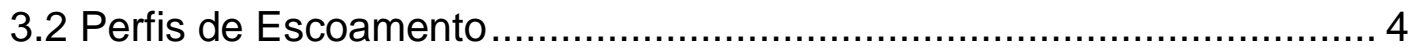

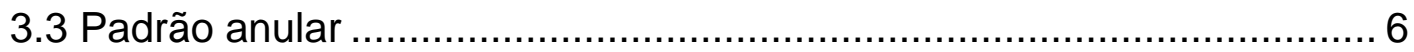

3.4 Equação Geral da Conservação .................................................... 7

3.5 Equações de transporte Locais e Instantâneas ................................. 8

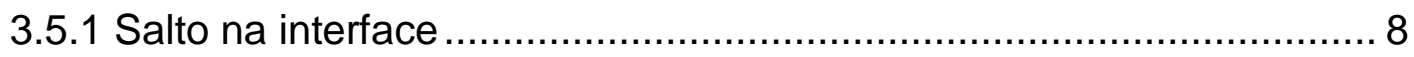

3.6 Modelo de padrão anular ou dois fluidos 1D...................................... 9

3.6.1 Equação de transporte para o escoamento anular ........................... 11

3.6.2 Fator de atrito interfacial .............................................................. 12

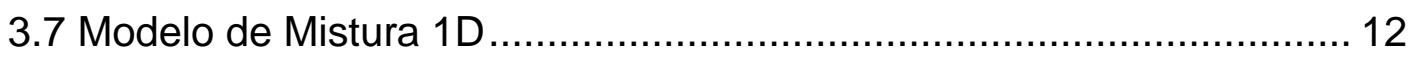

3.8. Método de Discretização ............................................................. 13

3.8.1. Método dos Volumes Finitos (MVF) ......................................... 13

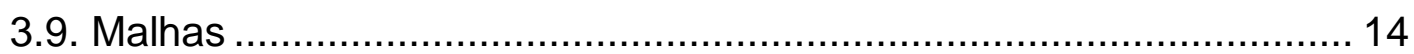

3.9.1 Malhas Ortogonais e Não-Ortogonais........................................... 14

3.9.2 Malhas Estruturadas e Não-Estruturadas ...................................... 16

3.10. CFD - Computational Fluid Dynamics .......................................... 17

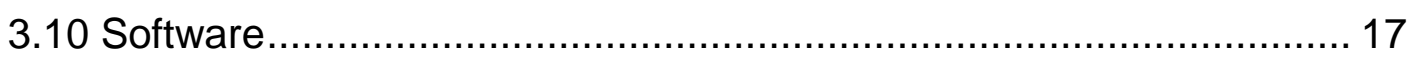

3.11 Modelos Multifásicos no PHOENICS ............................................... 18

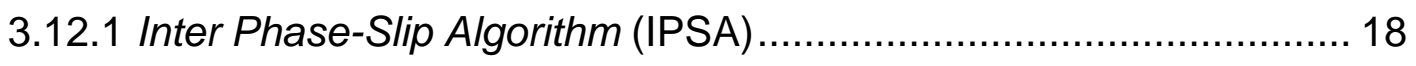

3.12.2 Algebraic Slip Model (ASLP)..................................................... 18

3.12.3 Scalar Equation Method (SEM).................................................. 18

3.12.4 Height Of Liquid (HOL) .......................................................... 19

3.12.5 General Tracking (GENTRA) ................................................... 19

3.13 VOF - Volume Of Fluid Method ..................................................... 19

3.14 - Modelos de Turbulência.............................................................. 20

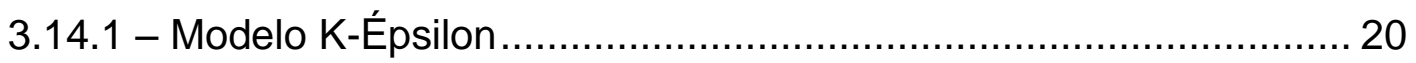

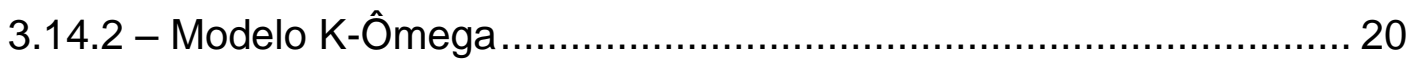

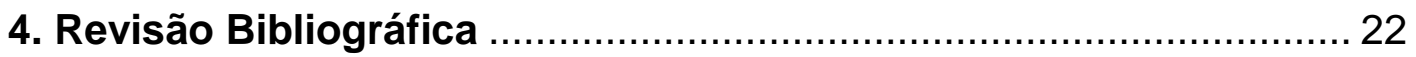


4.1 Flow Structure in horizontal oil-water flow (Angeli P., Hewitt G.F.; 2000)

4.2 Methods for multiphase computational fluid dynamics (van Wachem

B.G.M., Almstedt A.E.; 2003). 25

4.3 Numerical study of stratified oil-water two-phase turbulent flow in a horizontal tube (Gao et al.;2003) 25

4.4 Study on oil-water two-phase flow in horizontal pipelines (Xu X.; 2007)

4.5 Modelling of stratified gas-liquid two-phase flow in horizontal circular pipes (Sampaio P. A. B., et al.; 2008)...

4.6 Numerical study of dispersed oil-water turbulent flow in horizontal tube (Walvekar R.G., et al.; 2009)

4.7 Study on oil-water two-phase upflow in vertical pipes (Mydlarz-Gabryk K., et al. 2014) 30

4.8 A Fourier analysis of the IPSA/PEA algorithms applied to multiphase flows with mass transfer (Miller T.F, Miller D.J. 2003)............................. 32

4.8 Algebraic Slip model in Phoenics (Spalding, 1992) .......................... 37

4.8.1 Princípios básicos do modelo ..................................................... 37

4.8.2 Cálculo da velocidade de deslizamento .......................................... 37

4.8.3 Implementação no PHOENICS .................................................... 38

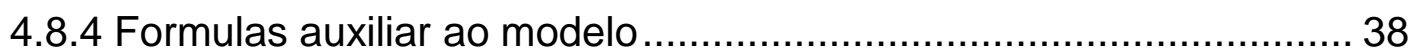

4.9 The Volume of Fluid (VOF) Method (Hird C. W., Nichols B. D. 1981).. 38

5. Materiais e Métodos...................................................................... 40

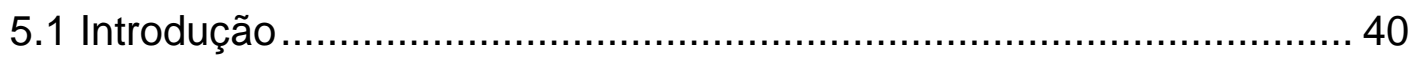

5.2 Unidade Experimental................................................................ 40

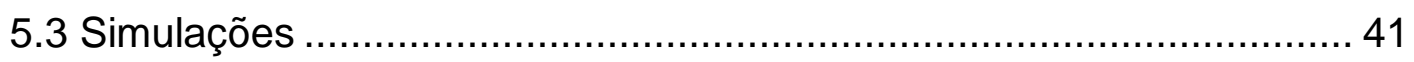

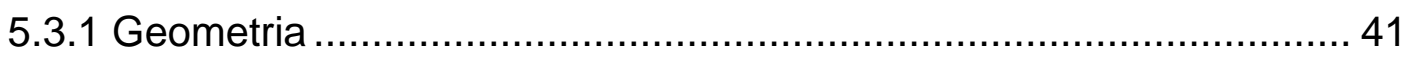

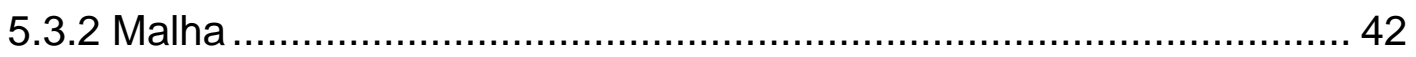

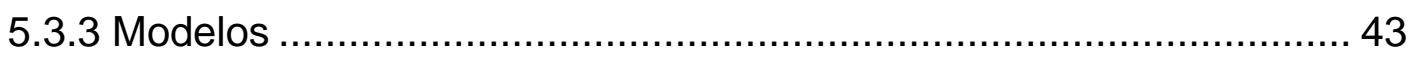

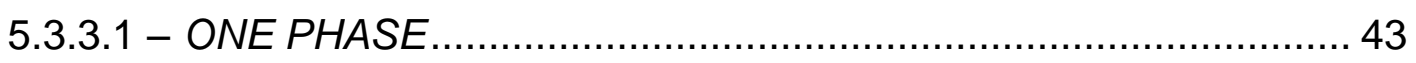

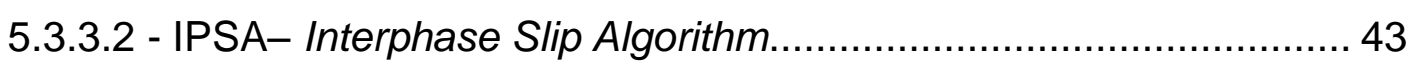

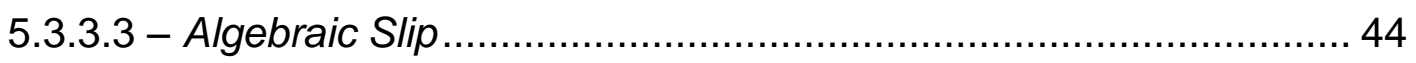

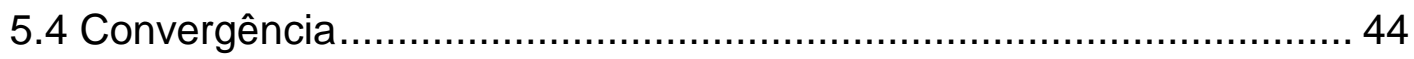

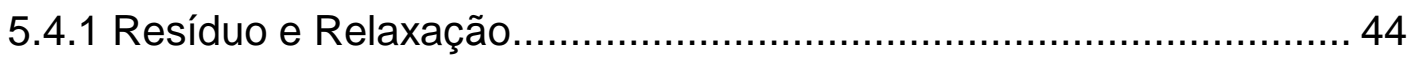

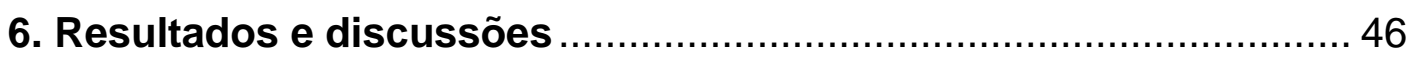

6.1 Trecho reto mais uma curva ....................................................... 46

6.1.1 - Resultados das Simulações..................................................... 46 


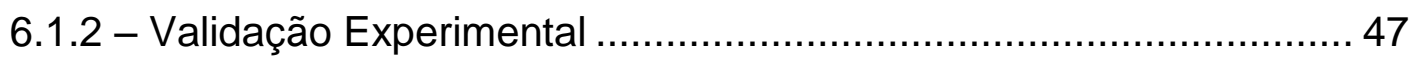

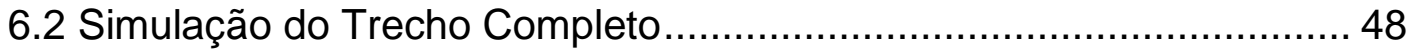

6.2.1 - Resultados da simulação para o modelo IPSA .............................. 48

6.2.2 Resultados da simulação para o modelo Algebraic Slip ..................... 51

6.2.3 Estudo da perda de carga............................................................. 59

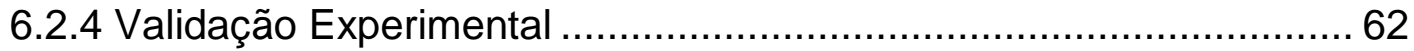

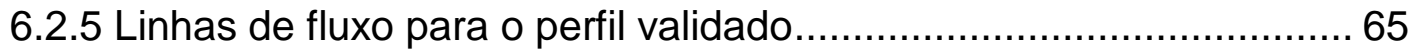

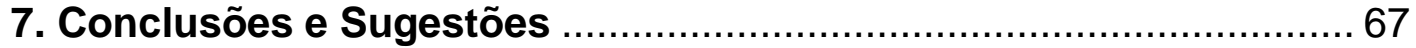

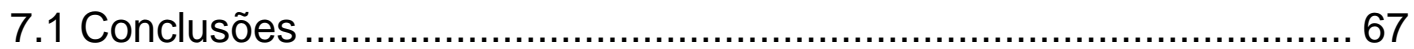

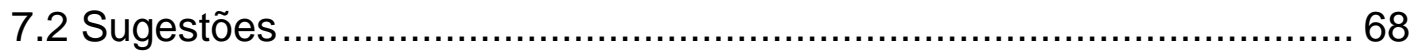

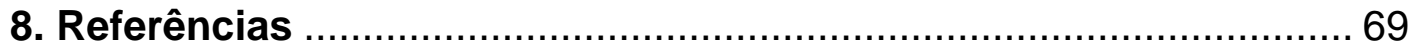




\section{Introdução}

CFD "Computacional Fluid Dynamics"é o nome dado para a ferramenta numérica e computacional que obtém soluções para as equações de conservação de grandezas físicas e permite predizer o comportamento de fluxos de gases e líquidos. A prática apresenta baixo custo, já que não requer a construção de experimentos ou plantas piloto (Spalding, 1996). Com o auxílio dessa ferramenta este trabalho visa o estudo de uma corrente multifásica onde há o escoamento de água-óleo, procurando reproduzir o padrão conhecido como "Core Annular Flow", onde um anel de água envolve o óleo pesado. Existem registros de patentes com o intuito de reproduzir este fluxo desde 1904, porém a primeira linha de importância foi somente construída em 1970 pela SHELL, com aproximadamente 38 quilômetros de extensão e ficou em operação por 12 anos (Joseph, et al 1997).

Alguns trabalhos prévios já foram feitos tratando da modelagem de condições de operação como perda de carga e fração volumétrica (Kaushik, et al, 2012). Os presentes estudos apresentaram que o fluxo é estável para certas faixas de velocidades e que produz Perdas de Carga relativamente baixas, sendo assim uma possibilidade de redução de custos.

No Brasil com a descoberta de petróleo na camada do Pré-Sal nas regiões dos estados de São Paulo, Rio de Janeiro e Espirito Santo, tem feito com que a Petrobras invista cerca de 240 bilhões de dólares, até 2017, para que haja a produção de 1 milhão de barris/dia (Petrobras, 2014), onde um trabalho visando o estudo de transporte água-óleo de grande importância para a situação atual do país. Para ilustrar tais afirmações a Figura 1 apresenta as bacias de óleo pesado no Brasil e suas respectivas produções.

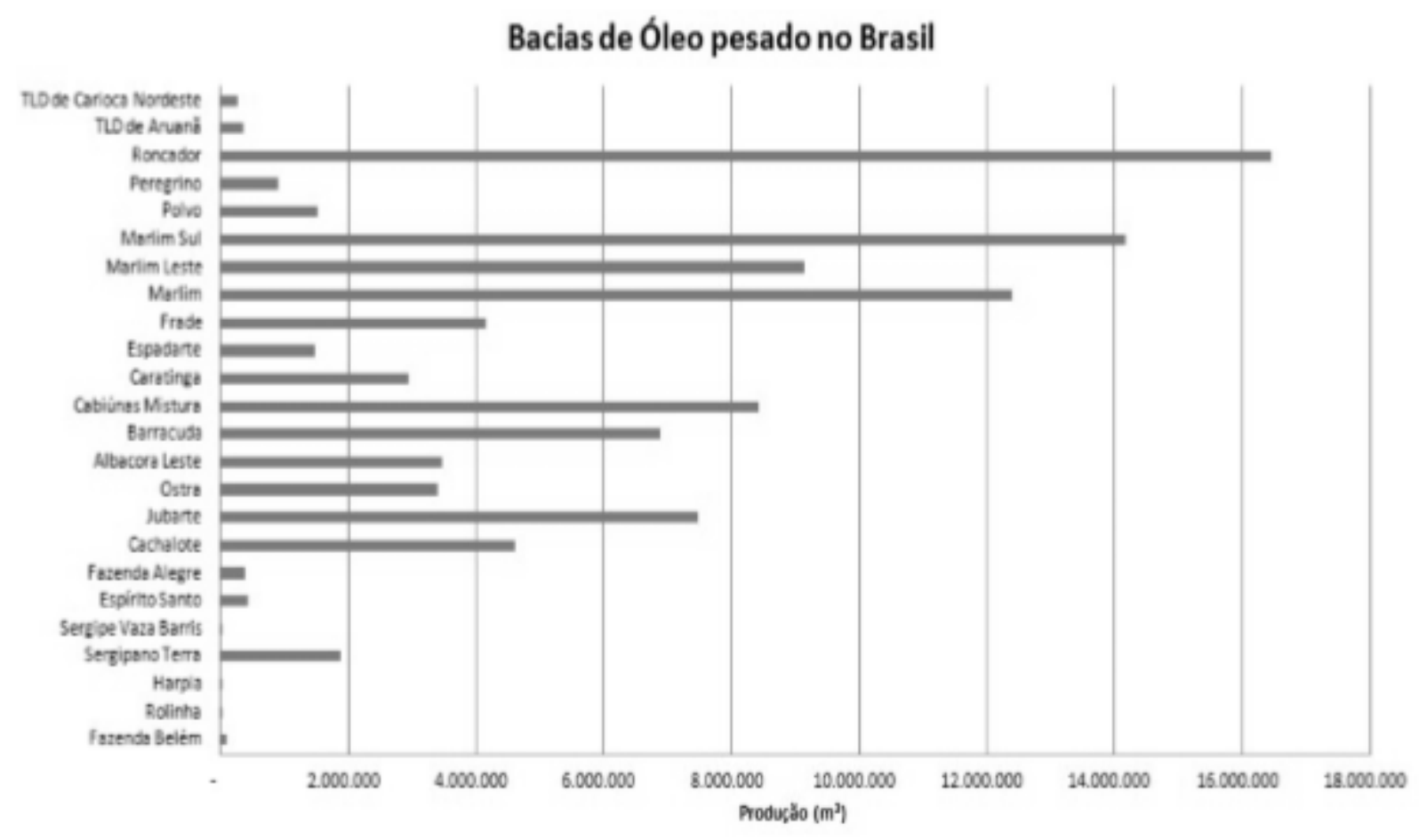

Figura 1 - Anuário Estatístico. 


\section{Objetivos Gerais e Específicos}

\subsection{Objetivo Geral}

Este trabalho visou, como objetivo geral, estudar uma corrente multifásica Água - Óleo no Software de CFD Phoenics, com o intuito de gerar perfis de escoamento e validá-los experimentalmente.

\subsection{Objetivos Específicos}

Os objetivos específicos do trabalho foram:

a) Entender o Escoamento Multifásico

b) Avaliar modelos numéricos e malha para resolução do problema utilizando o Software de CFD Phoenics;

c) Gerar perfis de velocidade, pressão e densidades para o escoamento multifásico estudado;

d) Validá-los experimentalmente 


\section{Fundamentos Teóricos}

\subsection{Conceitos Básicos do Escoamento Multifásico}

De acordo com Rosa (2012), escoamento multifásico é quando mais de uma fase está escoando simultaneamente. Por fase subentende-se uma região do espaço delimitada por uma interface de espessura infinitesimal, que encerra em seu interior material com composição química homogênea, propriedades de transporte e de estado definíveis e que é separável por processos mecânicos. $O$ termo fase é comumente utilizado como sinônimo do estado da matéria.

Com intuito de facilitar a compreensão e destacar a abrangência da área de escoamentos multifásicos, Rosa (2012) os classificou de acordo com as fases envolvidas: gás-líquido, gás-sólido, líquido-sólido e líquido-líquido, evidenciando as aplicações industriais e em fenômenos naturais.

Sistemas gás-líquido: $O$ movimento de bolhas alongadas de gás em um meio líquido é um exemplo de escoamento gás-líquido que ocorre com frequência na área de produção de petróleo. Esses escoamentos podem ocorrer em linhas verticais, horizontais e inclinadas, e envolvem uma coluna de produção e a linha de transporte que conecta o poço ao separador. O escoamentos de gás e líquido também ocorrem na indústria de geração de energia (nuclear, fóssil e geotérmica), em geradores de vapor, em condensadores; em sistemas de atomização aplicados a combustão, combate a incêndio, ou agricultura na forma de gotas de líquido dispersas no gás; em fenômenos naturais tais como a nucleação de gotas de chuva; em questões de segurança na indústria nuclear simulando acidentes por perda de refrigerante onde a ebulição junto ao gasoduto que, pela presença de condensados, pode formar um padrão anular onde uma camada de condensado escoa junto à parede enquanto que no núcleo predomina a fase gás transportando gotas de condensado.

Sistemas gás-sólido: Material sólido disperso numa fase contínua gasosa é o tipo mais frequente de escoamento gás-sólido. Esse tipo de escoamento engloba o transporte pneumático e leitos fluidizados com grande aplicação industrial. Ele também é encontrado em equipamentos de separação, tais como ciclones e precipitadores eletrostático utilizados em controle de poluição, indústria química, de cimento de alimentos e agroindústria; em escoamentos naturais onde sólidos são transportados na atmosfera, tais como transporte de areia do Saara para Europa e região Amazônica ou em escoamento em regime granular que controla a formação de dunas em desertos e em leitos de rios e mares. Escoamentos granulares ocorrem quando as forças entre partículas e partícula-gás são mais importantes do que as forças atuantes na fase gás. Há também aplicação na área de combustão de sólidos onde carvão é disperso na forma de pequenas partículas para aumentar a eficiência de queima em aquecedores e geradores de vapor. Por último, quando o sólido permanece estacionário, o problema reduz o escoamento num meio poroso onde a força viscosa na superfície das partículas sólidos é o principal mecanismo que controla o movimento da fase gás. Esse tipo 
de escoamento também é considerado um escoamento multifásico com aplicações em trocadores de calor com leito fixo, regeneradores de calor, processos de filtração, e em rochas porosas encontradas nos reservatórios de gás natural e petróleo.

Sistema líquido-líquido: Dois líquidos imiscíveis assumem diversas configurações dentro da tubulação devido à diferença de viscosidade e de densidade. Este tipo de escoamento pode ocorrer em elevação de óleo pesado onde água é injetada e se desloca junto à parede para que no núcleo escoe o óleo de forma a causar uma significativa redução de atrito se comparado com o escoamento monofásico de óleo. Havendo dissipação de energia no sistema líquido-líquido, seja por ação de um agitador ou pela diferença de velocidades, eventualmente obtêm-se emulsões líquido-líquido. As emulsões líquido-líquido são formadas naturalmente no processo de extração do petróleo e como produto manufaturado na indústria química. Além disso, a maioria dos fluidos biológicos, incluído o sangue, pode ser considerada uma emulsão. Outras aplicações de sistemas líquido-líquido ocorrem em processos de extração ou separações de líquidos na indústria química.

Sistemas multifásicos: $O$ agrupamento em sistemas bifásicos como exposto acima é uma conveniência, pois, em situações reais, é frequente a ocorrência de múltiplas fases, tais como escoamentos de óleo-água-gás frequentes na produção de petróleo ou de gás no escoamento sólido-líquido, como ocorre em transporte de gás natural com ocorrência de areia e condensado. Apesar da teoria desenvolvida para os modelos de dois fluidos e de mistura dar suporte para escoamentos multifásicos, suas aplicações ainda são raras e os desenvolvimentos nesta área baseiam-se na experiência prática e empírica. Novas técnicas experimentais alias a recursos computacionais estão permitindo avanços nesta área ainda carente de pesquisa básica e fundamental.

\subsection{Perfis de Escoamento}

Rosa (2012) diz que o grau de complexidade não está restrito somente ao tipo de acoplamento entre as fases. De fato, um modelo que capture o comportamento físico dos termos da interface é também necessário para conhecer como as fases estão distribuídas espacialmente no escoamento, sua dimensão característica e sua densidade de área interfacial. As propriedades geométricas da interface, por sua vez, dependem das vazões das fases, do diâmetro e da inclinação da tubulação e das propriedades de transporte das fases. Na figura 2.1 um escoamento vertical ascendente de uma mistura de ar e água para demonstrar qualitativamente como as propriedades topológicas da interface mudam com a variação da vazão. 


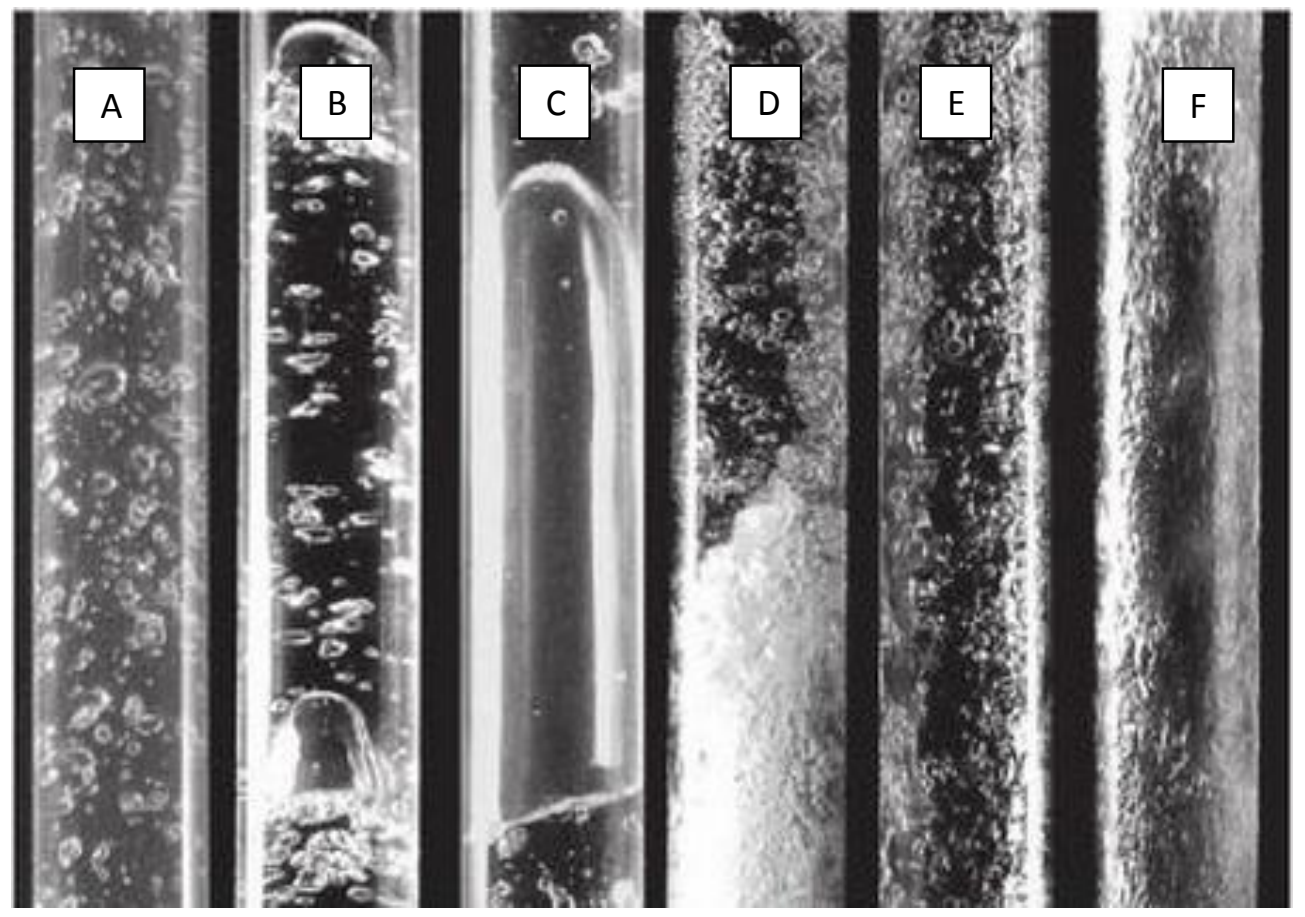

Figura 2.1 - Diferentes padrões de Escoamento Bifásico: (a) bolhas (bubbly); (b) capa esférica (spherical cap); (c) golfadas (slug); (d) golfadas instáveis ( unstabble slug); (e) semianular (semiannular); (f) anular (annular).

Uma forma prática de referenciar as características qualitativas das diferentes distribuições das interfaces é associá-las a diferentes nomes. Estes nomes são denominados por padrão ou regime do escoamento e têm por função associar a uma palavra todas as características geométricas de um específico arranjo das interfaces. Rosa (2012), as referência como bolhas (bubbly)(Fig. 2.1a), capa esférica (spherical cap) (Fig. 2.1b), golfadas (slug (Fig. 2.1c), golfadas instáveis (unstabble slug) (Fig. 2.1d), semianular (semi-annular) (Fig. 2.1e), anular (annular) (Fig. 2.1f). Joseph et al. (1997) também realizaram o estudo dos diversos padrões de escoamento bifásico em tubulações horizontais e verticais e os classificaram (inclusive os perfis intermediários) conforme a Figura 2.2.

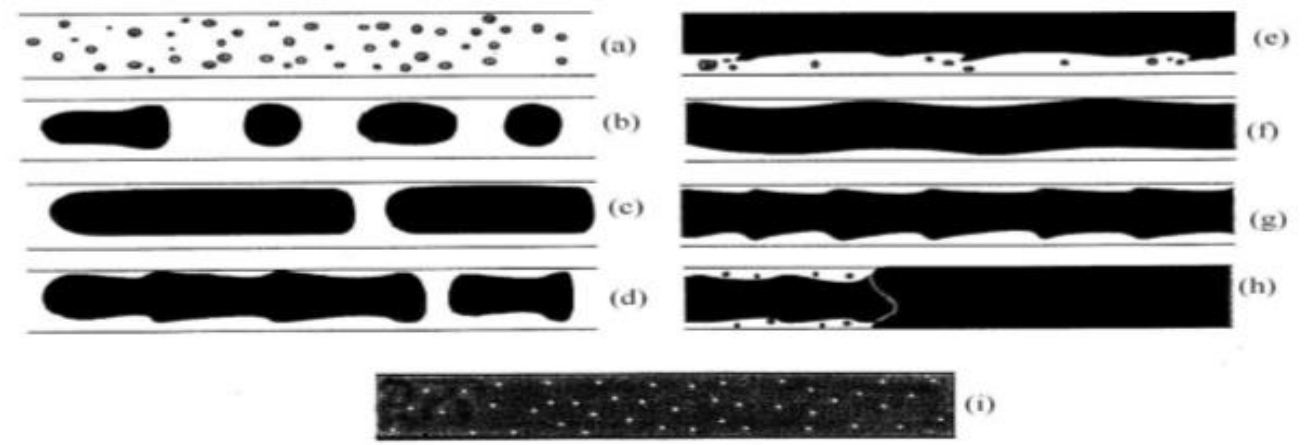

Figura 2.2 - Padrões de Escoamento Bifásico: (a) Dispersão de óleo em água; (b) Gotas alargadas ou esféricas; (c) Bolhas Alongadas; (d) Pistonado; (e) Estratificado; (f) Anular; (g) Core - Flow ou Bamboo Wave; (h) Wavy Core Annular Flow com dispersão de bolhas; (i) Mist flow. 
Infelizmente, não há um completo consenso na utilização dos nomes para identificação dos padrões. As características de cada padrão são descritas a seguir, de acordo com a nomenclatura adotada por Rosa (2012).

O padrão bolhas representa dois tipos de distribuições: bolhas monodispersas e bolhas discretas. As bolhas monodispersas apresentam forma esférica, tamanho uniforme, trajetórias retilíneas e não possuem interação com as bolhas vizinhas. As bolhas discretas (Figura 2a) possuem tamanhos variados, formas não esféricas ou distorcidas, descrevem trajetórias em ziguezague, viajam ao longo do tubo em formas de ondas de vazio e interagem entre si, podendo apresentar coalescência.

Conforme a vazão de gás aumenta, as bolhas discretas coalescem, formando bolhas maiores com forma de uma capa esférica que tomam parcialmente ou completamente a seção transversal do tubo (Figura 2b). $O$ aumento da vazão de gás faz com que as capas esféricas coalesçam em bolhas alongadas, também conhecidas por bolhas de Taylor, que ocupam quase toda a seção transversal do tubo e possuem vários diâmetros em extensão axial. As bolhas alongadas são precedidas por pistões de líquido que podem ou não conter bolhas de gás disperso caracterizando o padrão de golfadas (Figura 2c). As bolhas escoam concêntricas ao tubo com um filme de líquido anular separando a fase gás da parede do tubo. Enquanto que a trajetória da bolha é ascendente, a velocidade média do filme de líquido ao redor da bolha é descendente.

O padrão de golfadas instáveis sucede o padrão de golfadas conforme a vazão de gás aumenta (Figura 2d). Esse padrão é caracterizado quando a forma do nariz da bolha fica distorcida, o filme de líquido está aerado e na maioria das vezes permanece em contracorrente com fluxo de gás. As bolhas de gás têm um comprimento grande, enquanto que os pistões de líquido têm comprimento reduzido, são aerados e sua integridade é frequentemente rompida pelo fluxo de gás.

O padrão semianular (Figura 2e), é usualmente empregado para identificar a transição entre os padrões golfadas instáveis e o anular. Ele é considerado uma forma degenerada do padrão anular com grande ondas interfaciais onde o filme de líquido adjacente às paredes pode apresentar mudança de direção.

O padrão anular (Figura 2f), é caracterizado por um núcleo com gás e gotas de líquido em alta velocidade envolto por um filme de líquido co-corrente que escoa junto à parede. $O$ filme de líquido é, ocasionalmente, interrompido por uma onda de perturbação. No capitulo a seguir, o estudo para este padrão será aprofundado para o fluxo com água.

\subsection{Padrão anular}

Óleos pesados são altamente viscosos e mais leves que a água, possuindo tipicamente viscosidades de 1000 Poise e uma densidade de 0,99 $\mathrm{g} / \mathrm{cm}^{3}$ na temperatura de $25^{\circ} \mathrm{C}$. Sendo assim, por diferença de densidade, a água tende a ficar nas paredes da tubulação lubrificando o fluxo. Óleos leves com 
viscosidades abaixo de 5 Poise só conseguem gerar fluxos lubrificados estáveis em emulsões água-óleo (Joseph et al., 1997)

Joseph et al. (1997), falam que a viscosidade dessas emulsões podem ser bem menores que a do óleo e podem ser independentes para grandes valores. Isso tem motivado a consideração de bombear óleo bruto pesado através de tubulações como emulsões água-óleo e apresenta uma tubulação comercial na Indonésia, que produz 40 mil barris por dia de 70\% emulsão óleoágua com $50 \mathrm{~cm}$ de diâmetro e $238 \mathrm{~km}$ de comprimento.

As indústrias de óleo têm apresentado interesse nos fluxos lubrificados com água desde 1904. Algumas patentes demonstram o esforço para se entender tal fenômeno, onde Isaac \& Speed (1904) foram os primeiros a discutir o assunto, propondo estabilizar fluxos de óleos leves através de força centrípeta gerada por tubos que passaram pelo processo de Rifling (Figura 3.1), que consiste em gerar ranhuras helicoidais nas paredes.

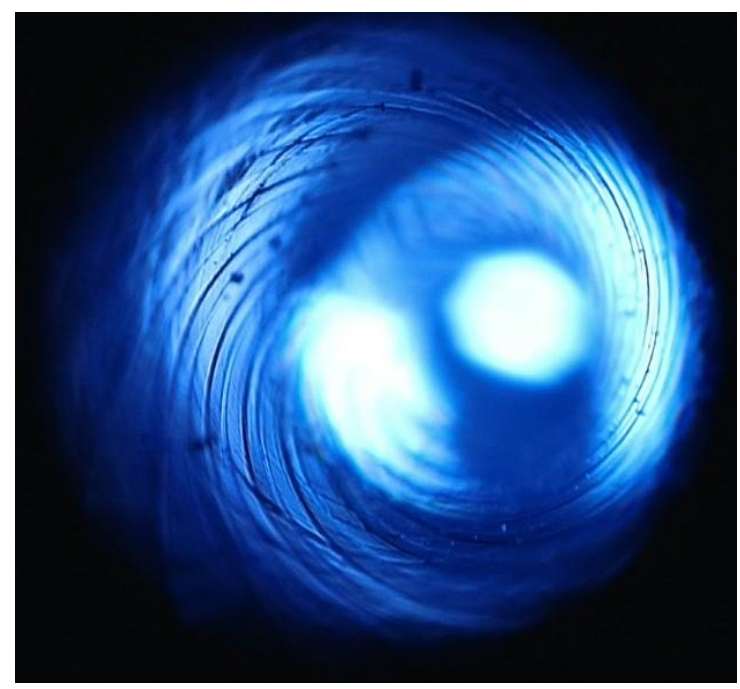

Figura 3.1 - Duto com Rifting

Looman (1916) patenteou para fluxos estratificados um método que consiste no transporte de óleo passando-os através de uma série de Water Traps localizadas na parte inferior do tubo.

\subsection{Equação Geral da Conservação}

O movimento das partículas em um meio continuamente deformável é representado por meio das equações que descrevem, matematicamente, a conservação de uma grandeza, por exemplo: massa, momento, energia, etc. Estas equações de conservação, também conhecidas como equações de transporte, estão genericamente representadas na sua forma diferencial (Rosa, 2005).

$$
\frac{\partial}{\partial}(\rho \psi)+\nabla \cdot(\rho \vec{V} \psi)=\nabla \cdot J+S
$$


Sendo $\Psi$, a grandeza a ser transportada, pode ser de natureza escalar ou vetorial; $\nabla$ é o operador diferencial que representa o divergente e $\rho$ a densidade da grandeza $\Psi$; as variáveis $\mathrm{J}$ e $\mathrm{S}$ estão relacionadas a fluxos difusivos e fontes/sumidouros relativos ao transporte de $\Psi$ (Rosa, 2005).

As equações de conservação geram um sistema de equações diferenciais que, na grande maioria das vezes, não apresenta solução analítica. As soluções numéricas envolvem a redução dos operadores diferencias a fórmulas diferença. Para isso, o volume total é dividido em pequenos elementos de volume, de forma que a equação diferencial possa ser representada por uma aproximação. Alguns conceitos são discutidos nas sessões seguintes.

\subsection{Equações de transporte Locais e Instantâneas}

Em escoamentos com uma única fase, as leis de conservação em um ponto $r$ no espaço são expressas em termos de equações diferenciais parciais desde que o ponto $r$ não pertença a uma superfície descontinuidade. Se o ponto $r$ pertencer a uma superfície de descontinuidade, as leis de conservação locais devem ser formuladas incorporando o termo de salto na interface de forma a relacionar os valores de ambos os lados da descontinuidade (Rosa, 2012).

Quando somente uma fase está presente no ponto $r$ os balanços de massa e quantidade de movimento são expressos em termos locais e instantâneas por meio das equações 2.1 e 2.2:

$$
\begin{gathered}
\frac{\partial \rho}{\partial t}+\nabla \cdot(\rho \vec{u})=0 \\
\frac{\partial(\rho \vec{u})}{\partial t}+\nabla \cdot(\rho \vec{u} \vec{u})=-\nabla P+\nabla T+\rho g
\end{gathered}
$$

Em que $\rho$ e u representam, respectivamente, a massa específica e a velocidade da fase, $\mathrm{P}$ é a pressão na fase, $\mathrm{g}$ a aceleração da gravidade e $\mathrm{T}$ o tensor das tensões.

\subsubsection{Salto na interface}

A interface é uma característica que está presente em escoamentos multifásicos. As propriedades do escoamento, tais como velocidades tensões cisalhantes e tensões normais, apresentam uma descontinuidade nos seus valores ao cruzar uma interface. Este fenômeno é representado por uma condição de salto na interface. Ela relaciona as propriedades do escoamento entre um lado e outro da interface por meios de balanços de massa, de quantidade de movimento e de energia (Rosa, 2014). A forma canônica da equação de transporte local e instantânea e sua condição de salto na interface são dadas pelas equações 3.1 e 3.2 :

$$
\frac{\partial(\rho \Psi)}{\partial t}+\nabla \cdot(\rho \Psi \vec{u})=\nabla \cdot J+\rho \vec{f}
$$




$$
\sum\left[\rho \Psi \cdot\left(\vec{u}-\vec{u}_{\text {interface }}\right)+J\right] \cdot \vec{n}=0
$$

A representação local instantânea dos balanços de massa e de quantidade de movimento é correta desde que ela seja aplicada dentro de cada fluido. Entretanto, em escoamentos multifásicos, a posição espacial das fases muda continuamente no tempo e no espaço, dificultando o emprego de um modelo para solução direta destas equações. De fato, existem simulações diretas destas equações. Porém, elas requerem grades computacionais muito refinadas capazes de capturar todas as escalas representativas do fenômeno; nessas simulações também deve-se preocupar em capturar a interface e combater a difusão numérica. Hoje, esses modelos estão no estado inicial de seu desenvolvimento, requerem intensivos recursos computacionais e ainda estão distantes de serem aplicados em problemas de engenharia (Rosa, 2012).

\subsection{Modelo de padrão anular ou dois fluidos 1D}

Rosa (2012) apresenta que o escoamento anular é caracterizado por fluxo co-corrente ascendente, onde no caso de um escoamento óleo-água, se forma um filme de água junto à parede do tubo e um núcleo central de óleo com gotas de água dispersas. O núcleo de óleo possui alta velocidade e escoa em regime turbulento. A interface apresenta ondas de pequena amplitude com padrão 3D. O movimento relativo entro o núcleo de óleo e o filme de água atomiza em gotas uma fração do filme em gotas. A massa de líquido atomizada é adicionada ao núcleo. Por outro lado, as gotas transportadas pela corrente de óleo são depositadas novamente ao filme de água devido à difusão turbulenta do escoamento no núcleo. A Figura 3.2 ilustra esquematicamente um corte na seção transversal do tubo revelando o filme de água, o núcleo de óleo e as gotas em dispersão no núcleo. Ela também apresenta o processo de atomização e de deposição de gotas.

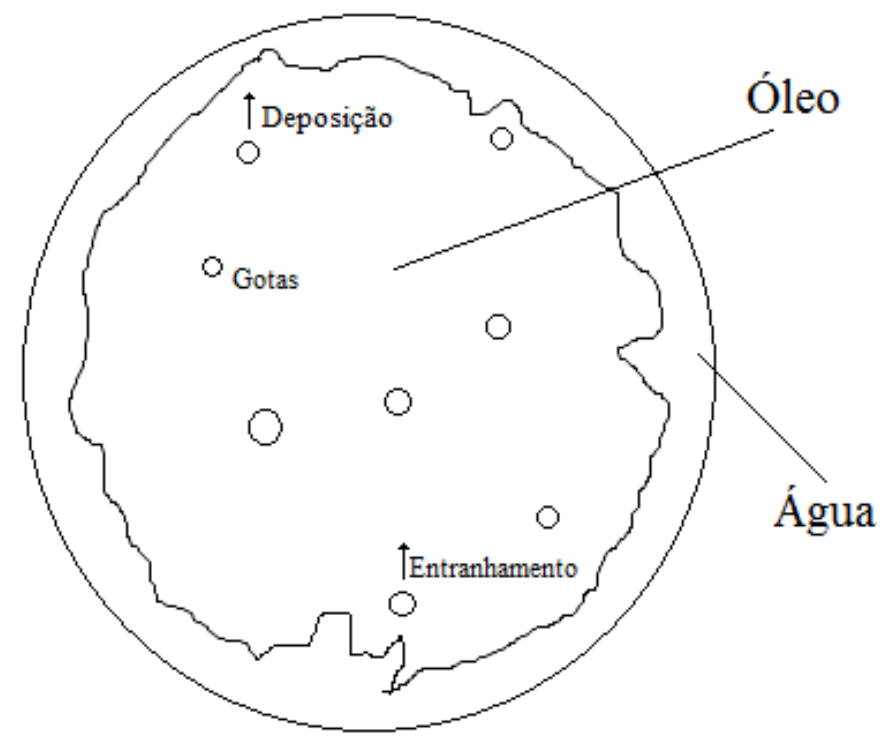

Figura 3.2 - Corte Transversal do padrão anular 
Rosa (2012) apresenta uma abordagem preliminar ao escoamento vertical anular Gás-Líquido ascendente empregando o modelo de fases separadas. A nomenclatura, está definida na Figura 3.3 , onde $\left\langle V_{L F}\right\rangle$ e $\left\langle V_{L E}\right\rangle$ são respectivamente a velocidade média do líquido no filme e no núcleo, enquanto que a velocidade do gás no núcleo é representada simplesmente por $\left\langle V_{G}\right\rangle$. $A$ área ocupada pela fase líquida é comporta por duas parcelas, uma do filme de líquido, ALF, e outra do núcleo, ALE. A área ocupada pelo gás é $A G$. A área do núcleo, $A_{C}$, é definida como sendo $A_{C}=A_{L E}+A_{G}$. $A$ partir das definições das áreas pode-se definir as frações de áreas das fases na seção transversal do tubo.

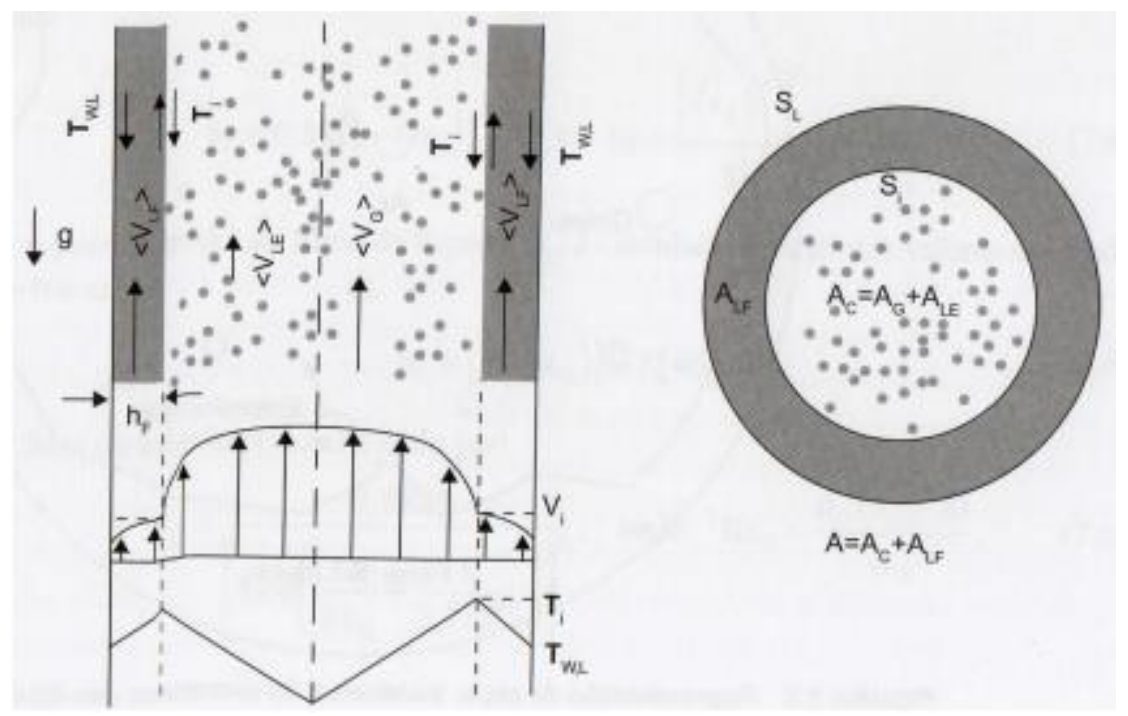

Figura 3.3 - Representação das variáveis no escoamento anular.

Considerando, por hipótese, que o filme de líquido está uniformemente distribuído, pode-se relacionar também sua espessura hь:

$$
\begin{gathered}
\alpha_{L F}=\frac{A_{F}}{A}=4\left(\frac{\mathrm{h}_{L}}{d}\right)\left(1-\frac{\mathrm{h}_{L}}{d}\right) \\
\alpha_{L C}=\frac{A_{L E}}{A} \\
\alpha_{G}=\frac{A_{G}}{A} \\
\alpha_{L F}+\alpha_{L E}+\alpha_{G}=1
\end{gathered}
$$

A fase gás no escoamento anular não molha a parede, portanto $S_{G}=0$. Desta forma, os perímetros molhados pela fase líquida e pela interface passa a ser:

$$
\begin{gathered}
S_{L}=\pi d \\
S_{i}=\pi d\left(1-2 \frac{h_{L}}{d}\right)=\pi d \sqrt{1-\alpha_{L F}}=\pi d_{C}
\end{gathered}
$$


Em que dcé o diâmetro equivalente do núcleo.

\subsubsection{Equação de transporte para o escoamento anular}

As equações de transporte para o escoamento anular 1D derivam das equações do modelo de fases separadas. Consideram-se as seguintes hipóteses simplificadoras: a) não há condensação ou evaporação entre as fases gás e líquido; b) o escoamento é axissimétrico; c) o escoamento disperso no núcleo comporta-se como uma mistura homogênea, isto é, as gotas de líquido viajam a mesma velocidade do gás e; d) o escoamento está em regime permanente. $O$ escoamento possui apenas duas fases, mas a fase líquida está presente tanto no filme quanto no núcleo. Para fins de modelagem, serão considerados fase líquida, pertencente ao filme, e uma pseudo-fase no núcleo identificada como uma mistura homogênea entre 0 gás e as gotas dispersas (Rosa, 2012).

A vazão mássica é constituída pelas massas de líquido e de gás:

$$
\dot{m}_{C}=\dot{m}_{L C}+\dot{m}_{G}=\rho_{L}\left\langle\alpha_{L C}\right\rangle\left\langle V_{L C}\right\rangle^{\alpha}+\rho_{G}\left\langle\alpha_{G}\right\rangle\left\langle V_{G}\right\rangle^{\alpha}
$$

A massa específica da mistura é definida por:

$$
\rho_{C}=\rho_{L}\left\langle\alpha_{L C}\right\rangle+\rho_{G}\left\langle\alpha_{G}\right\rangle
$$

A vazão média da mistura:

$$
\bar{V}_{C}=\frac{m_{L C}+m_{G}}{\left\langle\rho_{C}\right\rangle A_{C}}
$$

Considerando-se o escoamento no núcleo homogêneo, pode-se expressar as frações das fases das velocidades superficiais. Considerando escoamento homogêneo, encontra-se:

$$
\left\langle\alpha_{L C}\right\rangle=\frac{\frac{m_{L C}}{\rho_{L C}}}{\frac{m_{L C}}{\rho_{L C}}+\frac{m_{G}}{\rho G}} \text { e }\left\langle\alpha_{G}\right\rangle=\frac{\frac{m_{G}}{\rho G}}{\frac{m_{L C}}{\rho_{L C}}+\frac{m_{G}}{\rho G}}
$$

A determinação da Equação 3.12 requer o conhecimento das vazões mássicas de gás e líquido e no núcleo. A primeira é um dado de entrada para o modelo. A segunda, porém, é obtida por meio de um submodelo. Uma vez definidas as frações volumétricas das fases, a massa específica da mistura e a velocidade média do núcleo, Equações 3.10 e 3.11, também estão definidas.

Por hipótese, não é considerada a mudança de fase, entretanto, há uma transferência de massa do filme de líquido para o núcleo, e vice-versa, devido ao processo de atomização e deposição de líquido. Neste caso, a equação da massa, Equação 3.13, em regime permanente, passa a ter dois termos fontes: os fluxos de atomização $\left(R_{A}\right)$ e de deposição $\left(R_{D}\right)$. 


$$
\begin{aligned}
\frac{\partial}{\partial z}\left\langle\alpha_{C}\right\rangle \rho_{C}\left\langle v_{C}\right\rangle^{\alpha} & =\left(R_{A}-R_{D}\right) \frac{s_{i}}{A} \\
\frac{\partial}{\partial z}\left\langle\alpha_{L F}\right\rangle \rho_{L}\left\langle v_{L F}\right\rangle^{\alpha} & =\left(R_{A}-R_{D}\right) \frac{s_{i}}{A}
\end{aligned}
$$

$R_{A}$ e $R_{D}$, têm dimensão de massa por unidade de tempo e por unidade de área de parede lateral e expressam os fluxos mássicos de líquido transferido para o filme de líquido. A razão $\mathrm{Si} / \mathrm{A}$ é reconhecida como densidade de área interfacial. No desenvolvimento anular pode haver 2 cenários. $R_{A}>R_{D}$, onde 0 núcleo ganha massa de líquido até que o filme de líquido entra em equilíbrio $R_{A}$ $=R_{\mathrm{D}}$. No estado de equilíbrio, a massa de líquido atomizada do filme passa a ser igual a massa de líquido depositada no filme. Os mecanismos de atomização e de deposição são discutidos no próximo capitulo. Entretanto, é importante reconhecer que se tratam basicamente de um sumidouro ou uma fonte de quantidade de movimento na direção axial. Considerando que a componente axial de velocidade da gota atomizada ou depositada é $V_{A, z}$ e $V_{D, z}$, respectivamente, então a equação da conservação pode ser expressa por:

$$
\begin{aligned}
& \rho_{L} \frac{\partial v_{L F}}{\partial t}+\rho_{L}\left\langle v_{L F}\right\rangle^{\alpha} \frac{\partial\left\langle v_{L F}\right\rangle^{\alpha}}{\partial z}=-\frac{\partial P}{\partial z}-\frac{S_{L}}{A_{L F}} T_{L, W}+\frac{S_{i}}{A_{L F}} T_{i}-\rho_{L} g \\
&+\left(R_{D} V_{D, z}-R_{A} V_{A, z}\right) \frac{S i}{A}, \\
& \rho_{C} \frac{\partial v_{C}}{\partial t}+\rho_{C}\left\langle v_{C}\right\rangle^{\alpha} \frac{\partial\left\langle v_{C}\right\rangle^{\alpha}}{\partial z}=-\frac{\partial P}{\partial z}-\frac{S_{i}}{A_{C}} T_{i}-\rho_{C} g \\
&+\left(R_{A} V_{A, z}-R_{D} V_{D, z}\right) \frac{S i}{A}
\end{aligned}
$$

\subsubsection{Fator de atrito interfacial}

Uma expressão para a tensão interfacial pode ser obtida isolando $T_{i}$ da equação de quantidade de movimento da fase gás. Rosa (2012) apresentou todo o procedimento matemático feito por Fore, et al., (2000), onde é proposto um fator dependente do número de Reynolds do gás (Equação 3.17).

$$
C_{f, i}=0,005\left\{1+300\left[\left(1+\frac{17500}{R e_{G}}\right) \frac{h_{L}}{D^{\prime}}-0,0015\right]\right\}
$$

\subsection{Modelo de Mistura 1D}

O modelo de mistura 1D é empregado para simulação em regime permanente e transiente de escoamentos multifásicos em tubulações. Devido a sua capacidade de representação do processo físico, relativa facilidade de implementação e reconhecida estabilidade numérica, esse modelo e suas 
variações constituem a base dos simuladores de fluxo para tubulações aplicados nas industrias petrolífera, nuclear e química (Rosa, 2012).

A presença das paredes de uma tubulação restringe os fluxos de massa e quantidade de movimento somente para a direção axial. Esta característica permite, por meio de um processo de média na seção transversal, condensar toda informação do escoamento a um valor médio para uma dada posição axial do tubo e reduzir as equações do modelo para variações unidimensionais na direção axial e no tempo. O modelo de mistura 1D é intrinsecamente mais simples que seu análogo 3D. As velocidades se reduzem a parede do tubo, enquanto que a pressão age somente na seção transversal. Estas simplificações refletem na sua implementação numérica, tornando-a mais simples, e conferindo uma maior estabilidade numérica se comparado ao modelo de dois fluidos 1D. (Rosa, 2012)

O Modelo basicamente funciona da seguinte forma. A partir dos processos de média são definidas as densidades, a velocidade de deslizamento e o fluxo volumétrico médio na seção. Também é introduzida a relação entre o fluxo volumétrico e a velocidade de deslizamento, conhecida como relação de Zuber e Findlay (Rosa, 2012). Na sequência o processo de média é aplicado ao modelo de mistura 3D para obter equações do modelo 1D. As equações do modelo de mistura 1D, quando expressas em termos de velocidade de mistura, pressão e velocidade de deslizamento, constituem o modelo Drift Flux, apresentando por Ishii (1977). De forma alternativa, Rosa (2012) apresenta uma formulação 1D para o modelo de mistura baseada em variáveis como velocidade das fases e pressão. Esta modelagem desenvolvida por Pauchon, et al. (1993) é empregada ao modelo TACITE, que emprega diretamente a velocidade relativa entre as fases, ao invés de empregas a velocidade de deslizamento (Rosa, 2012).

\subsection{Método de Discretização}

\subsubsection{Método dos Volumes Finitos (MVF)}

O MVF tem como ponto de partida a forma integral da equação da conservação. O domínio de solução é dividido em um número finito de volumes de controle, e a equação é aplicada a cada volume. No centróide de cada volume localiza-se um nó computacional, onde as variáveis são calculadas, sendo os valores da superfície dos volumes de controle obtidos por interpolação em função dos valores dos nós (Versteeg e Malalasekera, 2007). Os integrais de volume e de superfície são aproximados usando fórmulas de quadratura apropriadas. Tendo como resultado uma equação algébrica por nó, onde aparecem os valores das variáveis do nó estudado e nós vizinhos.

O MVF se aplica a qualquer tipo de malha, sendo assim adaptado a geometrias complexas. A malha define apenas as fronteiras do volume de controle e não tem necessidade de estar relacionada com algum sistema de coordenadas.

A aproximação com o MVF é talvez a de maior compreensão, pois todos os termos que são aproximados têm significado físico, talvez por esta razão seja 
o método mais popular entre os Engenheiros. A desvantagem do MVF em relação ao MDF é o fato de métodos de ordem superior à segunda serem mais difíceis de se desenvolver em 3-D, com malhas não estruturadas (Nelson, 2007). Isto é devido ao fato da aproximação por VF requerer três níveis de aproximação: interpolação, diferenciabilidade e integração.

\subsection{Malhas}

\subsubsection{Malhas Ortogonais e Não-Ortogonais}

Dado que a geometria de problemas reais pode ser complexa e frequentemente irregular, ao se utilizar malhas ortogonais, só pode se mapear tais casos utilizando aproximações como pode ser visto no cilindro da Figura 3.4.

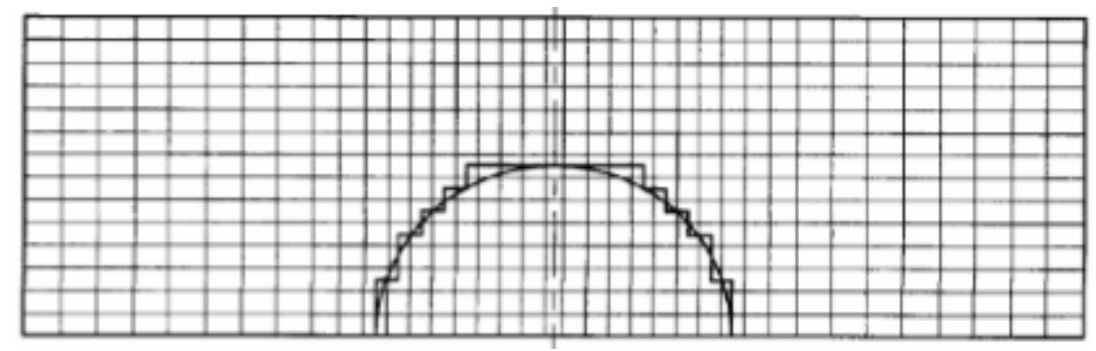

Figura 3.4 - Malha Ortogonal

A fronteira do cilindro é representada por uma aproximação e as células localizadas no interior da parte sólida não são consideradas no cálculo. Este fato apresenta desvantagens consideráveis desde as dificuldades associadas à descrição da aproximação da fronteira até à existência de erros inerentes a esta aproximação, como será o cálculo da força exercida pela parede com elevada precisão. Outra desvantagem é a desperdício de recurso de armazenamento, pois a introdução de uma malha ortogonal fina numa região de interesse particular, implica 0 desnecessário refinamento de outra região.

Os métodos de adaptação das malhas aos sólidos ou sistemas de malhas não ortogonais têm sido desenvolvidos com o objetivo de superar as limitações referidas e são cada vez mais utilizadas (Nelson, 2007). A Figura 3.5 mostra uma malha não ortogonal aplicada ao mesmo cilindro.

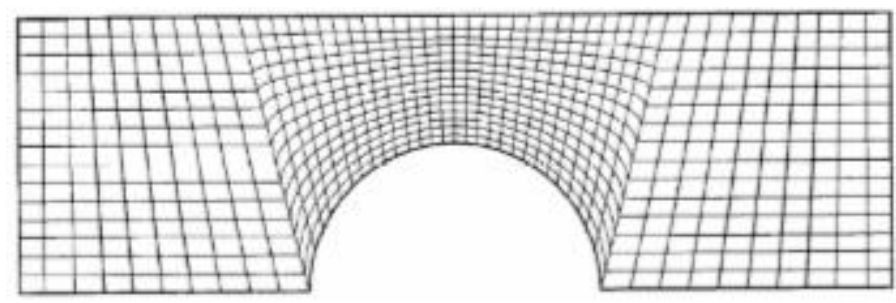

Figura 3.5 - Malha Não-Ortogonal

Um exemplo de um trocador de calor foi dado por Nelson (2007) para ilustrar o uso dos dois tipos de malha. 


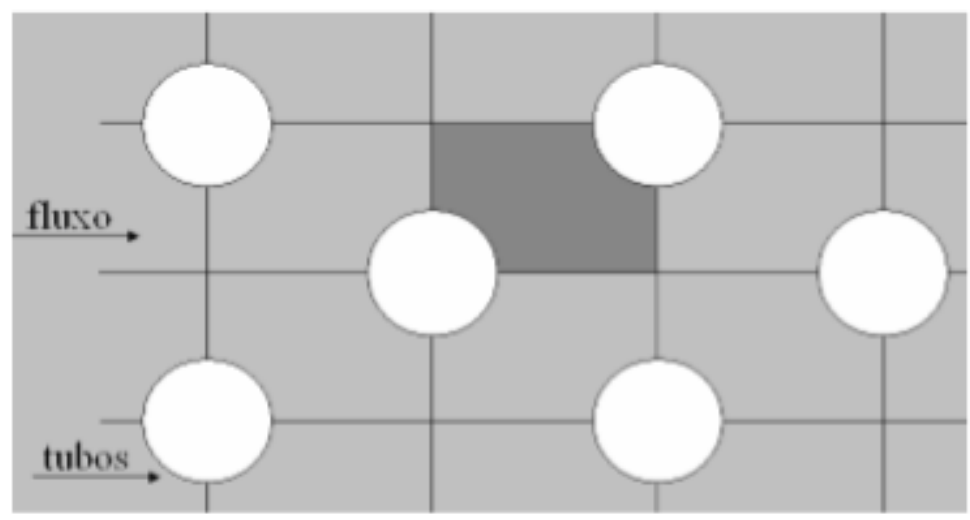

Figura 3.6 - Trocador de Calor

Para prover as características de fluxo, foi utilizado um software de CFD. A simetria foi aplicada somente na parte sombreada da Figura 3.6 A malha utilizada possui dimensão de 40×15 elementos, e pode-se observar na Figura 3.7.

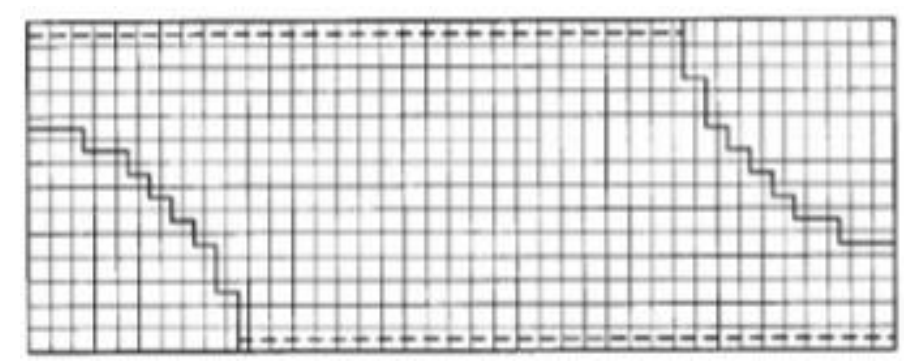

Figura 3.7 - Malha Ortogonal 40×15

Pode-se observar que $25 \%$ do espaço não é útil, uma vez que corresponde às zonas onde não passa o fluido. A Figura 3.8 apresenta uma malha não ortogonal adaptada à geometria do problema com o mesmo número de células.

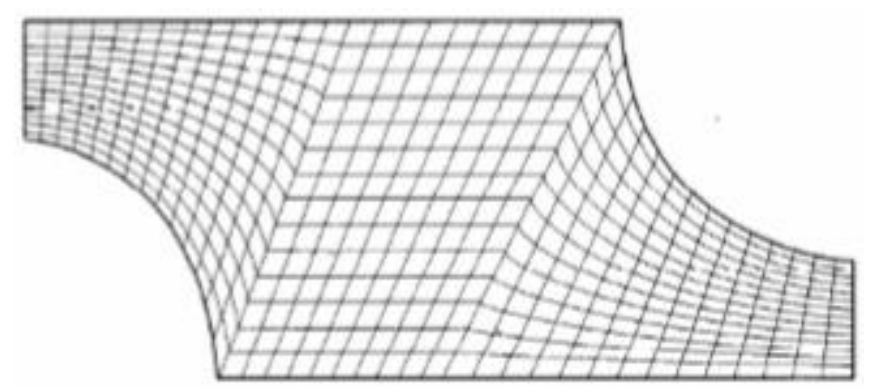

Figura 3.8 - Malha não-ortogonal 40×15

No caso, a malha ocupa toda a zona do fluido e as superfícies dos cilindros podem ser representadas com precisão. A previsão da distribuição da velocidade é apresentada nas figuras 3.9 e 3.10 , onde se pode observar um considerável aumento de detalhes e a obtenção de melhores resultados perto das regiões de entrada e de saída no caso da malha não-ortogonal. 


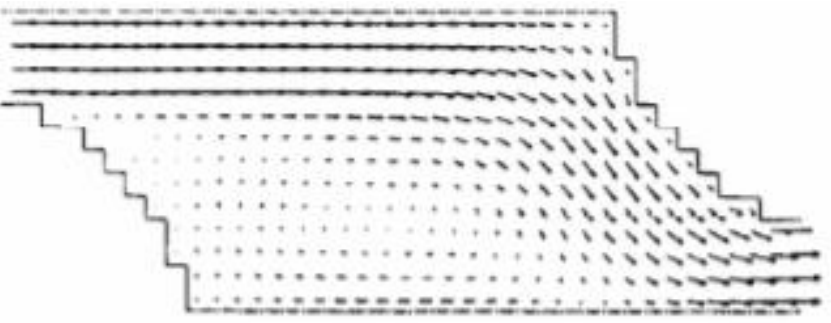

Figura 3.9 - Campo de velocidades da malha ortogonal

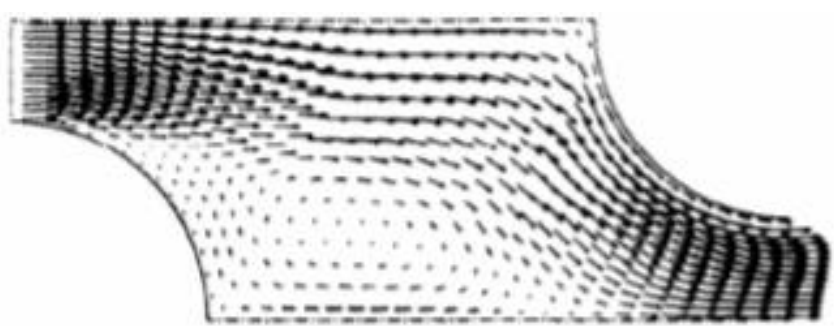

Figura 3.10 - Campo de velocidades da malha não-ortogonal

\subsubsection{Malhas Estruturadas e Não-Estruturadas}

As malhas não-ortogonais podem se dividir em dois grupos: Malhas estruturadas e Malhas não-estruturadas. São classificadas de tal forma por conta da disposição relativa dos diferentes elementos. Nas malhas estruturadas ou regulares, os elementos são dispostos em grupos de linhas, ex\m que membros de um determinado grupo não se cruzam uns com os outros e atravessam cada membro de outros grupos apenas uma vez. Isto permite que as linhas de um determinado conjunto sejam numeradas consecutivamente. A posição de qualquer ponto ou volume de controle da malha é numerada dentro do domínio, assim identificado de maneira única por um conjunto de dois ou três índices, por exemplo " $i, j, k$ ". Esta estrutura de malhas é a mais simples, uma vez que é equivalente a uma malha ortogonal. Cada ponto terá quatro vizinhos mais próximos em 2-D e seis no caso 3-D. A figura 3.11 apresenta um exemplo de estruturada.

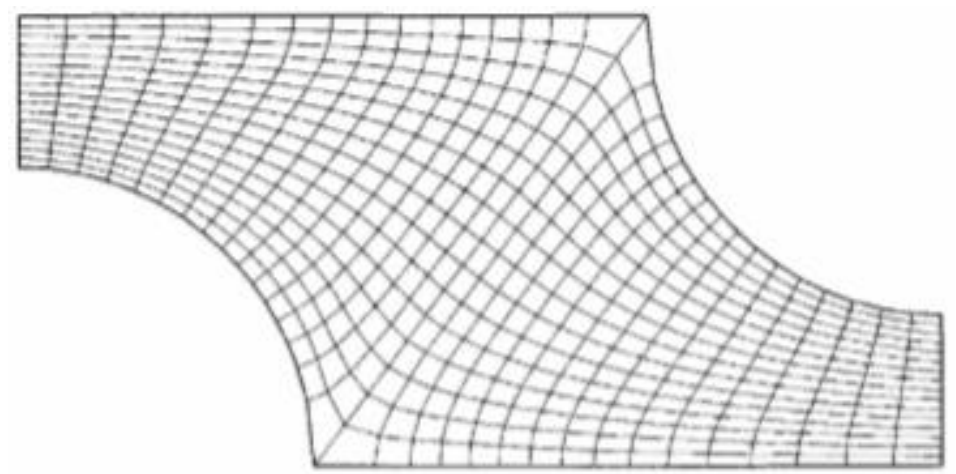

Figura 3.11 - Malha estruturada, não-ortogonal

Esta conectividade entre células vizinhas simplifica a programação e a matriz do sistema de equações algébricas apresenta uma estrutura regular, que 
tem a possibilidade de ser explorada desenvolvendo técnicas de resolução mais adequadas. A desvantagem de malhas estruturadas é que estas apenas podem ser aplicadas em domínios que têm geometrias de complexidade média e, além disso, é que pode ser difícil a distribuição dos pontos da malha; uma concentração de células numa região da malha, por razões de precisão de cálculo implica necessariamente menor espaçamento em outras regiões do domínio gerando um desperdício de recursos. Esta questão é mais grave em casos 3D.

\subsection{CFD - Computational Fluid Dynamics}

Fluidodinâmica Computacional é o conjunto de técnicas usadas para obter e interpretar soluções computacionais para as equações de conservação de grandezas físicas de interesse em um dado escoamento que tem sua origem na teoria dos fenômenos de transporte (Silva, 2009). As simulações realizadas em software de CFD são capazes de predizer com qualidade fenômenos físicos e químicos que ocorrem em escoamentos.

As vantagens de se usar tal ferramenta é a necessidade de prever com qualidade a eficiência de um novo produto, por exemplo, um reator químico, seus custos são elevados e a falha pode gerar gastos para a empresa. A única forma de se evitar esse problema é acumulando informações sobre o equipamento em diversas condições e o CFD é capaz de fornecer essas informações. O software também reproduz experimentos que são possíveis de se realizar, como explosões. Apesar das vantagens, os experimentos não podem ser desprezados, pois são a melhor forma de validar um modelo.

\subsection{Software}

O software utilizado neste trabalho foi o PHOENICS, que é um código de CFD utilizado para o estudo de fluxos, empregando coordenadas CilíndricasPolares ou Cartesianas. Ele foi lançado comercialmente em 1981 pela "Concentration, Heat and Momentum Limited in Winbledon (CHAM)". O nome PHOENICS é um acrônimo para "Parabolic, Hyperbolic or Eliptic Numerical Integration Codes Series" (Runchal, 2008).

O procedimento numérico é o método dos volumes finitos onde as equações originais diferenciais parciais são reduzidas a equações algébricas com a ajuda da discretização para os termos transientes, convectivos, difusivos e fonte. Para esta finalidade, o domínio é dividido em uma série de volumes criando uma malha. Todas as variáveis são armazenadas nos nós da malha, exceto as velocidades onde são armazenadas nas faces das células entre os nós. 


\subsection{Modelos Multifásicos no PHOENICS}

O Phoenics entende por multifásico quando em um célula estão presentes materiais distintos. Por exemplo: suspensões de óleo em água ou gotículas de combustível misturada com gases aquecidos em uma câmara de combustão.

Os métodos de simulação presentes para estes casos são o IPSA (InterPhase-SlipAlgorithm), ASLP (Algebraic SLip Mode), SEM (Scalar Equation Method), HOL (Height Of Liquid), GENTRA (GENeral TRAcking).

\subsubsection{Inter Phase-Slip Algorithm (IPSA)}

Este método resolve as equações de Navier-Stokes para cada fase. Normalmente as duas fases possuem pressões iguais, porém, podem ser diferenciadas caso exista pressão de contato entre partículas sólidas. Também é computada uma fração de volume para cada fase e ainda cada fase pode possuir, composição, tamanho de partícula e quantidade de turbulência. Porém esse modelo não consegue detectar variações muito rápidas nas interfaces das fases (Spalding, 1996).

\subsubsection{Algebraic Slip Model (ASLP)}

Este modelo disponibiliza uma alternativa ao IPSA para a modelagem, inclusive, de fluxos verdadeiramente multifásicos. Postula-se que existe um meio contínuo em que existem vários componentes da fase dispersos. Podendo estes ser gotas, bolhas ou partículas sólidas.

A mistura das fases contínuas e dispersas se comportam como um fluido único, com propriedades que podem depender ou não das dispersões.

Cada fase dispersa é representada pelas equações de concentração das espécies. A equação de transporte para cada fase dispersa possibilita 0 movimento relativo entre a fase dispersa e a fase contínua. Esse fenômeno de drift da fase dispersa é conhecido como deslizamento de fases. Considera-se que a velocidade de deslizamento pode ser calculada a partir das equações algébricas envolvendo apenas variáveis locais, ao invés de a partir das equações diferenciais parciais completas, como é o caso do IPSA. Este modelo é indicado para simulações que envolvem separação de gotas ou partículas por gravidade ou força centrifuga (Spalding, 1996).

\subsubsection{Scalar Equation Method (SEM)}

Este método envolve a interação de dois ou mais fluidos distintos separados por uma fina interface, já definida. A posição da camada livre não é conhecida a priori.

O modelo matemático irá precisar de: 
a) Localizar a camada entre os fluídos desconhecida, onde as descontinuidades existem em um ou mais fluxos;

b) Satisfazer as equações de campo que regem a conservação de massa, quantidade de movimento, energia, etc.;

c) Ser consistente com as condições de contorno.

Este método deduz a interface dos fluidos a partir da solução da equação de conservação para um escalar, uma variável de "fluid-marker".

A maior desvantagem em se usar este método é que ele apresenta problemas de difusão numérica, que exigem um alto refinamento do grid e um tratamento especial na especificação das propriedades. O SEM é aplicável em fluxos instáveis, fluxos bi ou tridimensionais, coordenadas cartesianas, polar ou curvilíneas (Spalding, 1996).

\subsubsection{Height Of Liquid (HOL)}

Assim como o modelo anterior, este método é para fluxos com superfícies livres, porém o modelo SEM precisa de técnicas especiais para tratar a difusão numérica, já o HOL não necessita de nenhum método anti dispersão e é simples, efetivo e econômico. A única restrição deste modelo é que o fluxo considerado não deve apresentar nenhum overturning da interface. Isso significa que deve haver uma direção, designada a direção up, ao longo do qual existe apenas uma intersecção da interface (Spalding, 1996)

\subsubsection{General Tracking (GENTRA)}

O GENTRA é um "add-on", ele rastreia o movimento das partículas através de um campo de fluxo, tendo em conta efeitos da velocidade do fluído, temperatura, turbulência e etc. $O$ efeito das partículas sobre a fase contínua também é considerado. Também ocorrem transferência de calor e massa nas partículas, as quais podem mudar de fase, reagir quimicamente ou até irradiar, (Spalding, 1996).

\subsection{VOF - Volume Of Fluid Method}

O VOF é um modelo simples e eficiente para rastreio e localização de superfícies livres (Ghidersa, 2004). Este tem como conceito básico a definição de uma quantidade escalar não-dimensional, que representa a fração do volume das células de malha ocupado pela fase contínua, que é, a fase líquida. Assim quando essa quantidade for igual a 1 , significa que a célula da malha está preenchida totalmente pela fase líquida, enquanto que para uma quantidade igual a 0 , a célula está preenchida com a fase dispersa (gás). Se o valor estiver entre 0 e 1 , as duas fases coexistem na mesma célula, criando uma interface (Hirt \& Nichols, 1981). Este modelo não está presente no PHOENICS, o modelo similar a este é chamado de HOL - Height of Liquid, que trata de superfície livre 


\subsection{4 - Modelos de Turbulência}

Turbulência é o estado do movimento do fluido caracterizado por aparentes vórtices caóticos tridimensionais (Wilcox, 1998). Quando a turbulência está presente no escoamento, ela aumenta a dissipação energética, a mistura, a transferência de calor, entre outros. O estudo da turbulência é necessário para melhor compreensão do escoamento, por isso diversos modelos para turbulência foram desenvolvidos, porém os mais usados são os modelos do tipo RANS de duas equações, como o K-Épsilon e o K-Ômega.

O K-Épsilon e o K-Ômega levam como fundamento a viscosidade turbulenta, proposto por Boussinesq, que foi a primeira pessoa a considerar que a transferência de quantidade de movimento molecular e turbulento são análogas.

A tensão turbulenta é relacionada ao gradiente de velocidade através da equação 3.18 e esta está relacionada às características do fluido e do escoamento, além da geometria do problema proposto.

$$
\tau_{t}=\mu_{t} \frac{d U}{d y}
$$

\subsection{1 - Modelo K-Épsilon}

Este modelo foi desenvolvido por Davidov (1961); Harlow e Nakayama (1968); Launder e Spalding (1972). Porém o desenvolvimento é creditado para Launder e Spalding (1972) por aperfeiçoar suas constantes. As duas equações que são resolvidas neste modelo são a de transporte para $k$ e a segunda equação é a de transporte para a dissipação turbulenta. A viscosidade turbulenta é calculada pela equação 3.19 .

$$
\mu_{t}=C_{\mu} \rho \frac{k^{2}}{\varepsilon}
$$

O modelo k-Épsilon possui a vantagem de ser de fácil implementação, ter boa convergência e apresentar bom funcionamento para escoamentos simples, como o escoamento em dutos ou escoamento em camada limite. Porém as desvantagens são a divergência devido à rigidez do modelo, além do fato desse modelo não conseguir integrar as equações nas regiões próximas às paredes. $O$ modelo também não funciona muito bem para escoamentos complexos, como por exemplo escoamento em degrau.

\subsection{2 - Modelo K-Ômega}

Este modelo foi desenvolvido por Wilcox (1988) e também resolve duas equações adicionais, a equação de transporte para a energia cinética turbulenta $k$, a segunda equação resolvida é a equação de transporte para a dissipação específica. A viscosidade turbulenta é calculada pela equação 3.20. 


$$
\mu_{t}=\rho \frac{k}{\omega}
$$

Como vantagem esse modelo nos oferece maior facilidade de integração na parede e assim uma maior gama de problemas são possíveis de serem solucionados. Mas o modelo apresenta a alta sensibilidade a variações das propriedades nas zonas longe da parede e a tendência a uma maior necessidade computacional. 


\section{Revisão Bibliográfica}

\subsection{Flow Structure in horizontal oil-water flow (Angeli P., Hewitt G.F.; 2000)}

Fluxos líquido-líquido são frequentes em diversos processos industriais e nas petrolíferas em particular, onde óleo e água são frequentemente produzidos e transportados juntos. Durante o fluxo concorrente em um tubo, as deformações da interface do fluido podem adquirir uma variedade de características chamadas de regimes de fluxo, cada um com suas características hidrodinâmicas. Pode ser esperado que para se obter diferentes regimes de fluxo deve-se variar as velocidades, fração volumétrica e propriedades físicas (densidade e viscosidade), das respectivas fases.

O método mais comum para identificar diferentes padrões de fluxo é observar o escoamento em uma tubulação transparente ou uma janela na parede do tubo. Além da observação visual, técnicas fotográficas também têm sido muito usadas.

Os principais regimes de fluxo, que podem ser observados em um fluxo horizontal líquido-líquido, são classificados como:

a) Fluxo Estratificado: um fluxo de dois fluídos separados pela diferença de densidade

b) Fluxo Anular: um fluido forma um filme anular na parede do tubo e o outro permanece no centro da tubulação. Esse fluxo é comum quando os fluidos possuem densidades parecidas ou um líquido tem viscosidade alta.

c) Fluxo Disperso: um fluido escoa continuamente e o outro em forma de gotas dispersas.

Foi apresentado uma tabela com os presentes estudos experimentais para escoamento em tubos horizontais de água-óleo. Os estudos tiveram como objetivo mapear os regimes de fluxo, que apresentaram diversas variações.As variáveis que apresentaram influência nos fluxos foram: velocidade superficial, diâmetro da tubulação, diferença de densidade, viscosidade do óleo e a molhabilidade, que é a habilidade que o líquido tem em manter contato com uma superfície sólida.

Angeli et al. (1998) estudaram os diferentes tipos de fluxos em duas tubulações de materiais diferentes, uma de PVC e outra de aço inoxidável, afim de observar a influência da molhabilidade.

O fluxo estratificado foi observado no duto de PVC com velocidades de mistura de $0,6 \mathrm{~m} / \mathrm{s}$, enquanto no duto de aço inoxidável a velocidade de mistura foi de $0,3 \mathrm{~m} / \mathrm{s}$. Quando a velocidade de mistura foi aumentada, gotas apareceram e o fluxo foi caracterizado como fluxo estratificado com gotas, que pode ser visto na figura 4.1 


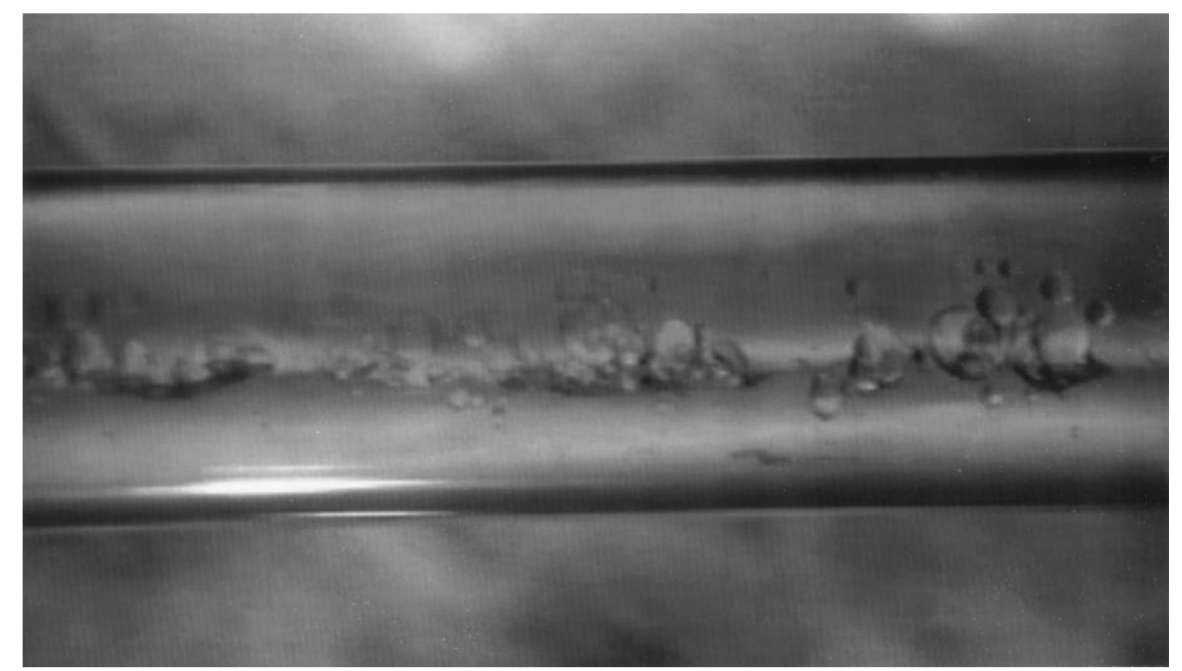

Figura 4.1 - Fluxo Estratificado com Gotas

Foi também possível observar um fluxo de 3 camadas (Figura 4.2), onde a água ficou no fundo da tubulação e óleo no topo, com uma camada de gotas das duas fases na interface. Este regime foi caracterizado em velocidades de mistura de 0.7 à $1,3 \mathrm{~m} / \mathrm{s}$ e uma fração volumétrica de água entre 0,3 à 0,5 para a tubulação de aço e no tubo de PVC velocidades de mistura de 0,9 à 1,7 m/s e frações volumétricas de 0,2 à 0,5 .

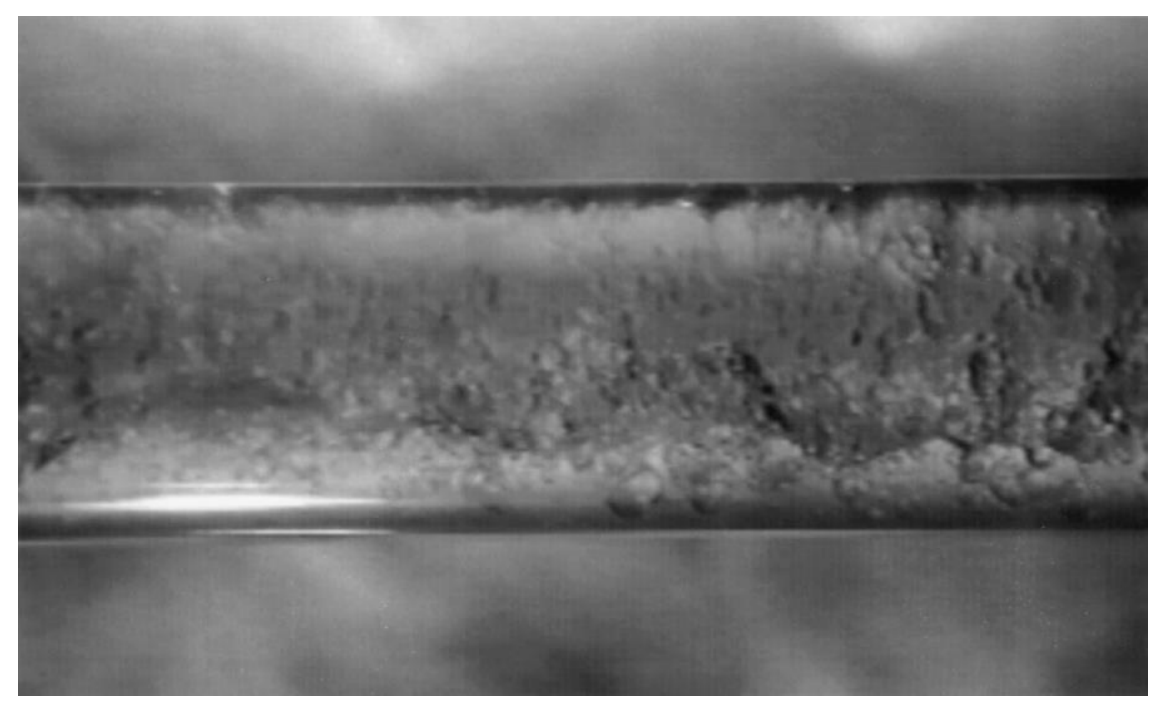

Figura 4.2 - Fluxo de 3 Camadas

Um fluxo denominado de mistura estratificada (Figura 4.3) foi observado para altas frações de água, onde uma camada de gotas de óleo são observadas no topo de uma fase contínua de água. Enquanto que para altas frações de óleo, a camada de bolhas de água foi observada no fundo da fase contínua de óleo. O fluxo mistura estratificada foi observado para velocidades similares para 0 fluxo de 3 camadas porém com frações de água abaixo de 0,3 e acima de 0,5 para ambos os tubos. 


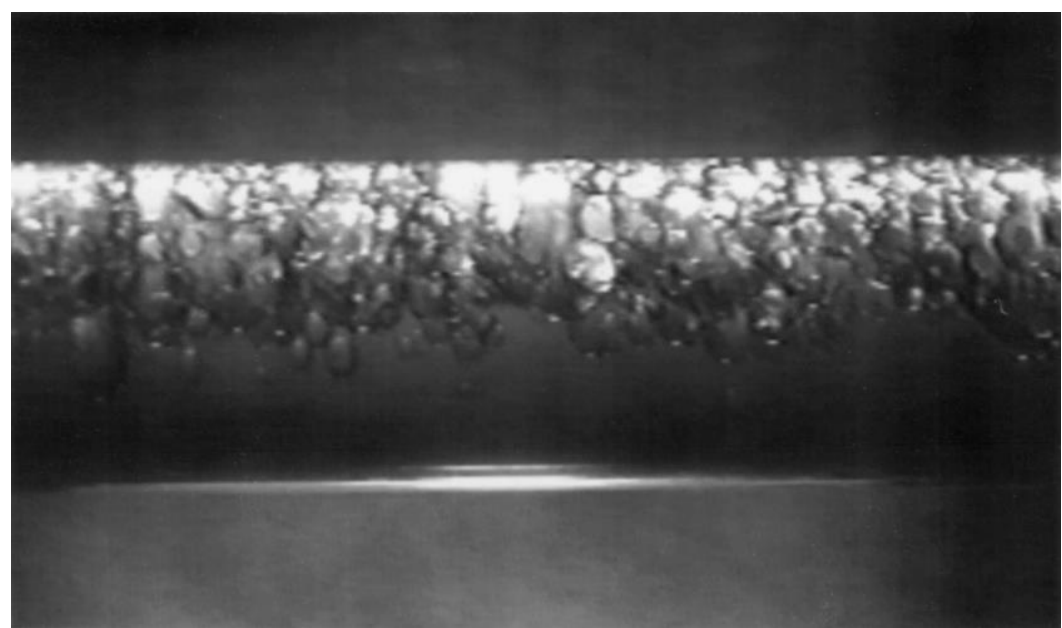

Figura 4.3 - Fluxo Mistura Estratificada

Na figura 4.4, é possível observar o fluxo caracterizado como totalmente disperso, onde uma fase está mais ou menos dispersa na outra e ocupa toda tubulação.Esse perfil foi observado para velocidade de mistura de $1,3 \mathrm{~m} / \mathrm{s}$ na tubulação de aço e de $1,7 \mathrm{~m} / \mathrm{s}$ para o PVC. Para frações baixas de água, o óleo apresentou ser a fase contínua, enquanto que para frações altas de água, a água se caracterizou como a fase contínua.

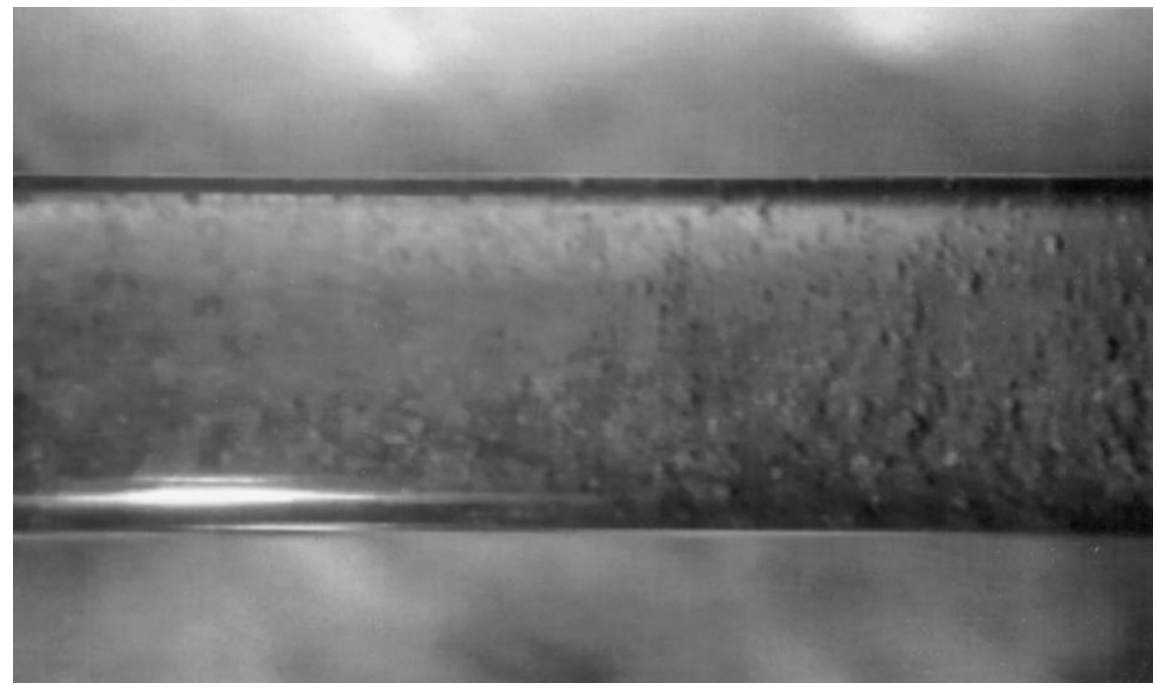

Figura 4.4 - Totalmente Disperso

Com estes dados, foi concluído que as propriedades da parede da tubulação (rugosidade e molhabilidade) podem interferir no fluxo e subsequentemente nos gradientes de pressão, que dependem do regime de fluxo. 


\subsection{Methods for multiphase computational fluid dynamics (van Wachem B.G.M., Almstedt A.E.; 2003)}

As razões para a falta de conhecimento fundamental em fluxos multifásicos são principalmente 3 .

1. Fluxos multifásicos são fenômenos físicos complexos, onde diversos tipos de escoamento podem ocorrer (gás-sólido, gás-líquido, líquidolíquido, etc.) e cada escoamento com diversas possibilidades de regimes (fluxo anular, fluxo disperso, fluxo pistonado, etc.)

2. As complexas leis da física e o tratamento matemático ocorrem na presença das duas fases (coalescência, arraste, dinâmica da interface, etc.) são ainda muito pouco desenvolvidos. Por exemplo, os modelos constitutivos propostos são empíricos mas muitas vezes há falta de validação experimental para as condições em que são aplicados.

3. Os valores numéricos para a solução das equações governantes e fechamento das leis para fluxos multifásicos são extremamente complexas. Frequentemente escoamentos multifásicos apresentam comportamento ocilatório, pedindo algoritmos de grande esforço computacional para soluções transientes.

Em uma formulação líquido-líquido, ambas as fases podem ser médias ao longo de um volume fixo. Este volume é relativamente grande ao tamanho individual das moléculas. Uma função indicadora de fase é introduzida. Mediando está função, chegamos na fração volumétrica de ambas as fases.

Sendo a fase contínua e a dispersada liquidas, elas são tratadas da mesma forma no processo. Por conta disso, o balanço de quantidade de movimento para ambas as fases são os mesmos.

Os termos de densidade e de velocidade são aproximados. O autor apresentou as equações governantes para os fluxos Líquido - Sólido e Líquido - Líquido.

\subsection{Numerical study of stratified oil-water two-phase turbulent flow in a horizontal tube (Gao et al.;2003)}

Foi considerado o fluxo bifásico estratificado em um duto horizontal como composto por fluxo de óleo no topo da tubulação e o de água na parte inferior. Com o uso do modelo VOF ("volume of fluids"), os valores para cada variável (pressão, velocidade, etc.) são definidos como uma média no elemento de volume ("volume averaged"). Sendo assim necessário conhecer a fração volumétrica de cada fase em todo domínio. O volume da fração de óleo é calculado pela equação da continuidade. A equação de movimento é dependente da fração volumétrica das duas fases. 
A viscosidade turbulenta foi calculada utilizando o modelo de turbulência para duas-camadas. O fluxo turbulento estratificado foi simulado numericamente em uma tubulação com diâmetro de $55,75 \mathrm{~mm}$ e $8 \mathrm{~m}$ de comprimento horizontal. O óleo escolhido foi petróleo destilado com densidade de $790 \mathrm{~kg} / \mathrm{m}^{3}$ e viscosidade dinâmica de $1,6 \mathrm{cP}$ na temperatura de $25^{\circ} \mathrm{C}$. Os dados de entrada da fração volumétrica de água estão no intervalo de $10-86 \%$. As velocidades das duas fases foram especificadas para a velocidade bulk de $1,05 \mathrm{~m} / \mathrm{s}$ e o número máximo de Reynolds para o óleo e a água foram de 55000 e 110000 respectivamente.

O fluxo turbulento estratificada em um tubo horizontal foi simulado numericamente usando um modelo VOF. As simulações para a perda de pressão e a taxa de deslizamento mostraram um desvio aceitável com relação aos dados experimentais apresentados. O perfil da fração local está próximo do experimental. A previsão de velocidade é bastante satisfatória. Com base nos resultados numéricos e no campo de fluxo característico são descritas correlações para a perda de pressão. O CFD demonstrou que a técnica pode ser aplicada com sucesso para fluxos de líquido-líquido turbulentos estratificada.

\subsection{Study on oil-water two-phase flow in horizontal pipelines ( $X u X$.; 2007)}

A determinação de padrões de escoamento é o principal problema na análise de fluxos bifásicos. Para o caso específico de água-óleo, as propriedades do óleo e a viscosidade da mistura podem variar muito. Do ponto de vista reológico, pode ser newtoniano como não-newtoniano, indicando dificuldades para se obter os padrões de fluxo.

Avanços significativos têm sido feitos para entender os padrões de fluxo de água-óleo. Novos e mais compreendidos padrões foram propostos como os que são apresentados na figura 4.5 .

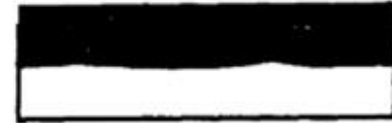

ST

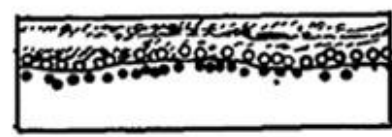

ST\&MT

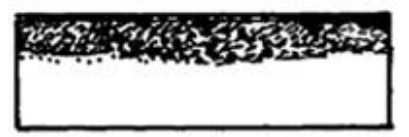

$D_{\text {ow }} \&$ W
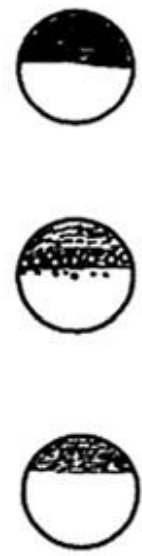

$\mathrm{D}_{\text {W/O }}$

$$
\mathrm{D}_{\text {ONW }} \& \mathrm{D}_{\text {W/O }}
$$

(t)
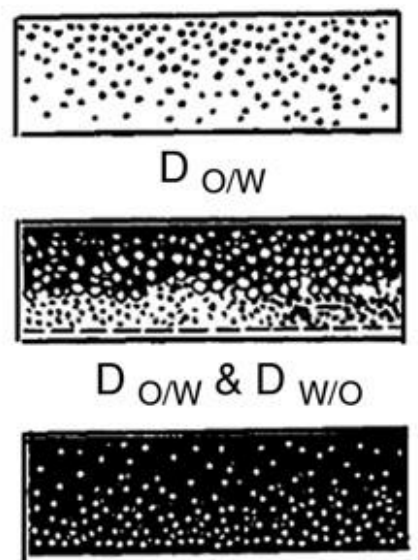

$\mathrm{D}$ om
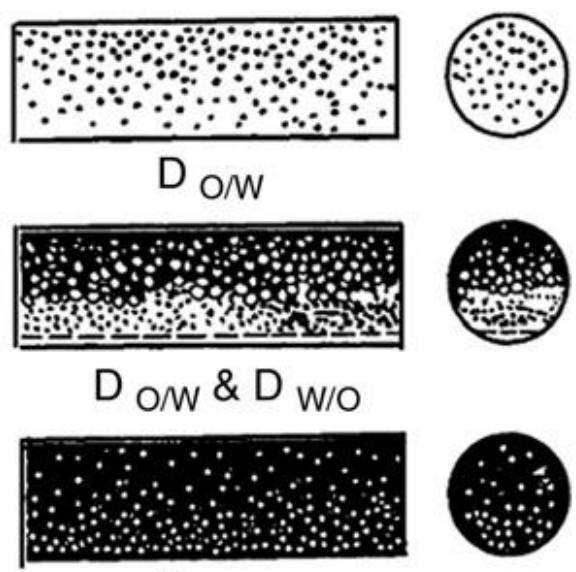

Figura 4.5 - Padrões de fluxo

A predição dos padrões de escoamento em sistemas de água -óleo são um problema complexo de hidrodinâmica. A literatura mostra que não um há um 
mapa generalizado de padrões de fluxo para escoamento horizontal ou fluxo de dois fluidos miscíveis. No entanto, para fluxos gás-líquido diversos estudos foram feitos em diversas condições e propriedades. Em alguns casos os modelos foram propostos para predizer a transição de um fluxo para outro, mas esses estudos não podem ser reproduzidos para o caso de água-óleo, portanto o conhecimento a respeito desse escoamento continua escasso.

Nos experimentos de padrões de fluxo óleo-água, diversos trabalhos utilizaram observação visual ou técnicas fotográficas (Russel, et al 1959; Arirachakarn, et al 1989). A maior parte dos trabalhos estudou os padrões de fluxo em um tubo horizontal transparente ou uma janela transparente na parede do tubo. As técnicas fotográficas têm sido usadas para fenômenos muito rápidos. Mas, no entanto, mesmo técnicas de fotografia de alta velocidade não são o suficiente para se definir com clareza um padrão, desde que complexas estruturas interfaciais resultam em diversos índices de refração que escurecem a visão, especialmente no centro da tubulação, que podem ser lidas de maneira errada, especialmente em regiões que as diferenças entre dois padrões de fluxo podem ser pequenas. A técnica mais recente é o uso de uma sonda local, um sensor de ponto cujo o tamanho e o formato é similar ao de uma agulha. A sonda emite um sinal de dois-estados capaz de identificar diferenças nas propriedades das duas fases.

A maior dificuldade na modelagem de fluxos água-óleo vem da existência de descontinuidades associadas às interfaces. Porém o seu estudo é importante pois indica a quantidade relativa de cada fase junto à parede e a porcentagem de mistura durante o escoamento. No presente momento um mapa generalizado de padrões de fluxo não é possível ser gerado, devido a fatores importantes que governam o mecanismo de transição, como velocidade superficial, viscosidade do óleo e tensão interfacial.

É necessário medir quantitativamente os parâmetros dos padrões de fluxo. A previsão de transições requer uma análise cuidadosa da estabilidade do fluxo, que institui a influência das condições hidrodinâmicas, e o efeitos das propriedades físicas do fluido, velocidade de mistura, fração de água, diâmetro do tubo e do material (molhabilidade), distribuição de tamanho de gota, a média de tamanho de gota, etc. No entanto, esses efeitos fundamentais ainda não são bem compreendidos.

É evidente que, sob certas condições, os modelos podem proporcionar certa explicação racional ao fenômeno experimental. No entanto, desde que as condições experimentais são diferentes, a previsão por modelos têm certa limitations.

\subsection{Modelling of stratified gas-liquid two-phase flow in horizontal circular pipes (Sampaio P. A. B., et al.; 2008)}

Neste trabalho um fluxo estratificado gás-líquido totalmente desenvolvimento em escoamento bifásico em um duto circular horizontal foi avaliado. Tento em vista a simetria do fluxo com respeito ao plano vertical, 
apenas a seção transversal foi considerada no presente modelo. Na figura 4.6 é possível ver o esquema com os domínios ocupados pelas fases gasosa e liquida denominadas por $\Omega_{\mathrm{g}}$ e $\Omega_{\mathrm{f}}$ respectivamente. Considerou-se que o fluxo volumétrico das fases são conhecidos. A interface entre as fases é adotada como horizontal, no entanto, sua posição é desconhecida e será função das vazões, diâmetro da tubulação e propriedades físicas dos fluidos.

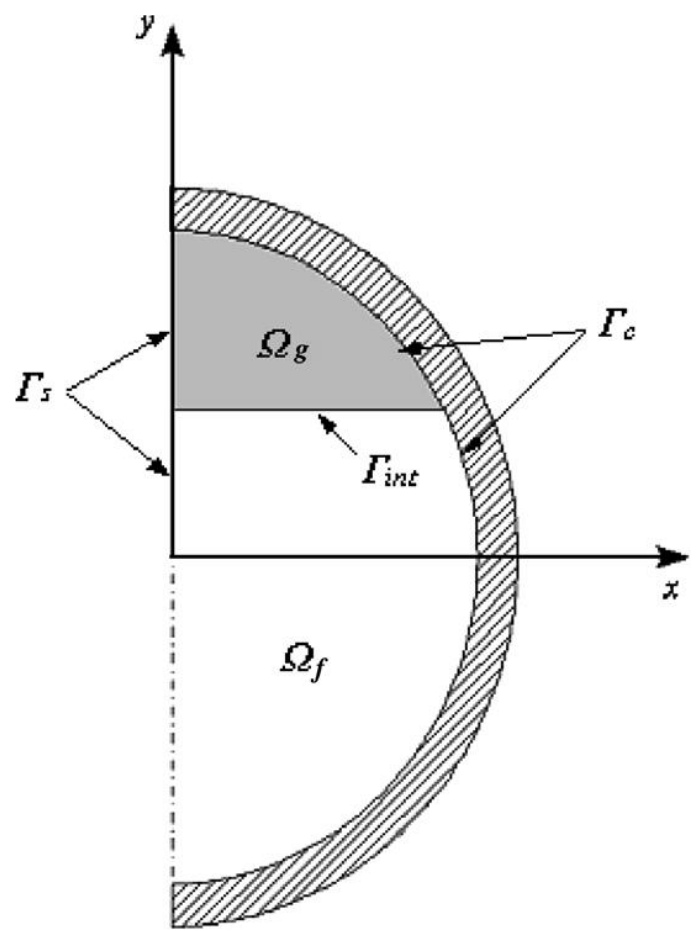

Figura 4.6 - Fluxo Estratificado

O modelo RANS é adotado para descrever o fluxo turbulento em ambas as fases.

A solução do sistema é obtido pelo uso de um processo interativo que combina duas técnicas numéricas. A primeira é o método Newton-Raphson que é usado para solucionar um sistema não linear de equações e o segundo é chamado de solução de fluxo que "roda" internamente e envolve a solução do elemento do volume finito.

Utilizando esse método foi possível a modelagem numérica do sistema bifásico. Os resultados indicaram que o modelo $k-\omega$ é bom para esse tipo de fluxo. No entanto, um melhor entendimento de como impor valores de para $\mathrm{k} \mathrm{e}$ $\omega$ é necessário para se obter um resultado mais próximo de dados experimentais.

\subsection{Numerical study of dispersed oil-water turbulent flow in horizontal} tube (Walvekar R.G., et al.; 2009)

Aqui um fluxo tridimensional de óleo e agua com uma velocidade uniforme escoa através de um tubo horizontal de $9,7 \mathrm{~m}$ de comprimento com diâmetro interno de $0,024 \mathrm{~m}$, exemplificado na figura 4.7 . 


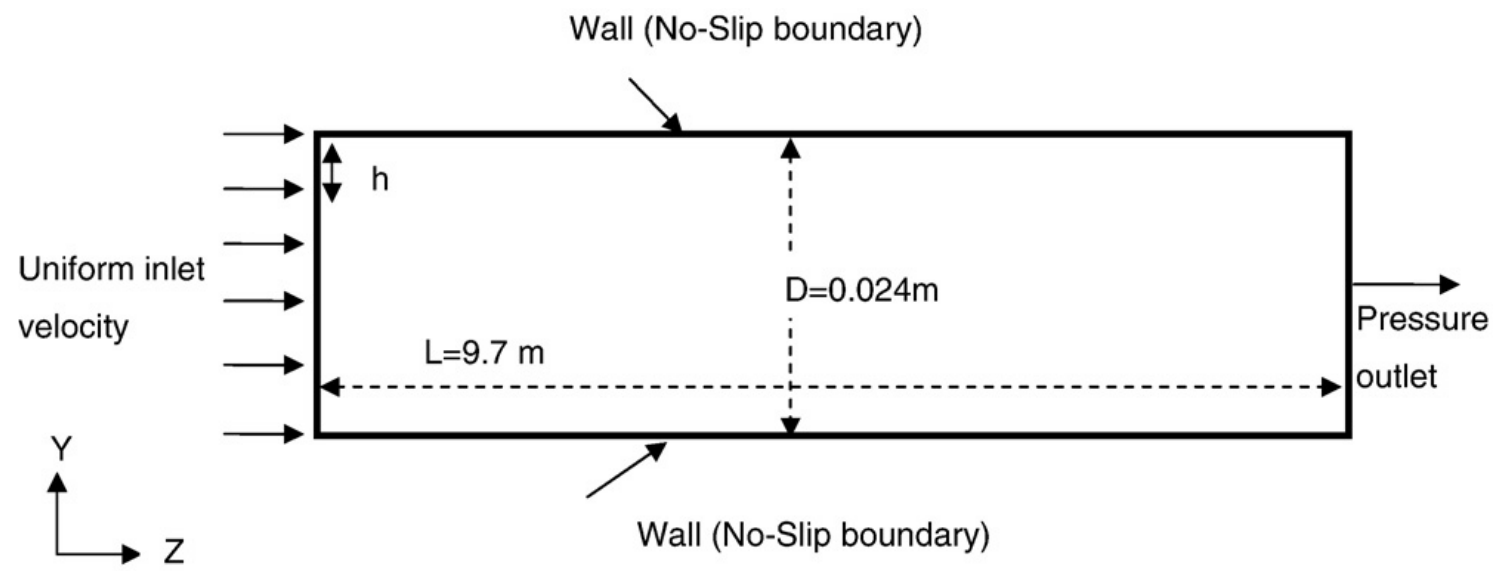

Figura 4.7 - Escoamento

Uma abordagem Euleriana-Euleriana modela o fluxo de todas as fases em um quadro baseado na suposição do contínuo interpenetrante. Aqui, todas as fases dividem o domínio e interpenetram quando escoam. Cada fase é caracterizada pela distinção da velocidade e fração volumétrica. Para lidar com o acoplamento entre as fases, diversas forças interfaciais são levadas em conta, como por exemplo, o arraste e a dispersão turbulenta.

Considerou-se que as fases dividem o espaço em proporção as suas frações volumétricas. Todo domínio foi dividido em regiões afetadas pela viscosidade e totalmente turbulentas baseado no número turbulento de Reynolds

Os modelos k- $\varepsilon$ são semi empíricos. A velocidade turbulenta e a escala de comprimento são determinados independentemente usando duas equações de transporte separadas (energia cinética turbulenta k, e taxa de dissipação, $\varepsilon$ ).

A turbulência na fase contínua é calculada da mesma forma que um fluxo simples usando as equações de transporte para $k$ e $\varepsilon$.

$\mathrm{Na}$ parede foram utilizadas condições de não deslizamento, igualando todas as velocidades a zero.

A simetria utilizada pode ser vista na figura 4.8, sendo esta visando o melhor resultado com o menor tempo operacional possível.

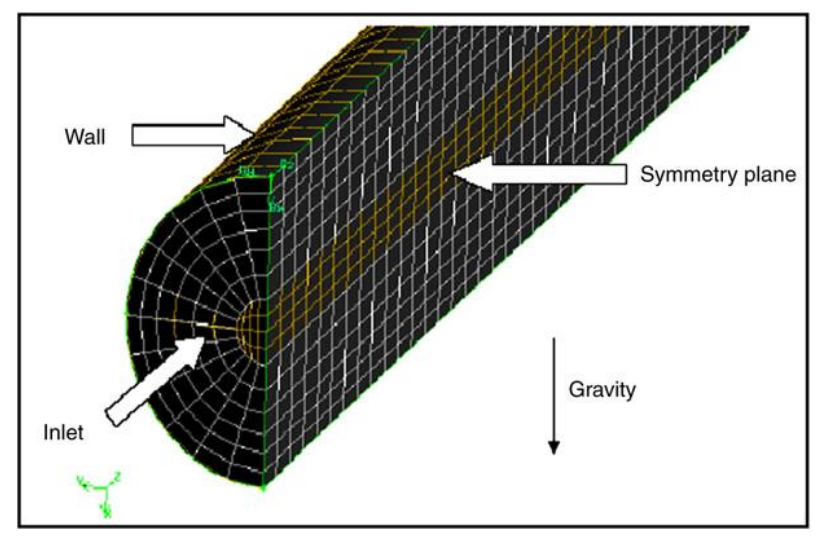

Figura 4.8 - Simetria 
A partir dessas condições, o estudo foi desenvolvido através do software Fluent 6.2. As células quadrilaterais não uniformes foram geradas utilizando 0 software comercial GAMBIT. O critério de convergência relativa usado foi de 10${ }^{4}$ e foi aceito convergência quando todos os resíduos atingiram o critério específico. A malha com 1.160 .000 células.

Com os resultados obtidos foi possível prever os valores de pressão, fração de água e óleo e velocidade com valores similares à literatura. Assim é possível concluir que a ferramenta CFD pode ser aplicada para a simulação numérica de escoamentos líquido-líquido.

\subsection{Study on oil-water two-phase upflow in vertical pipes (Mydlarz- Gabryk K., et al. 2014)}

Um escoamento vertical que consiste em dois líquidos imiscíveis foi estudado. O sistema não estacionário em certas condições, apresenta instabilidade, seja no formato do escoamento ou nas frações das fases.

Apesar da familiaridade com os fluxos de gás-líquido, o interesse em escoamentos de líquidos imiscíveis tem se tornado o foco de estudos em diversos centros de pesquisa, pois é um fenômeno que é encontrado em diversos equipamentos industriais, como em colunas de extração, reatores tubulares, tubulações usadas para transporte de petróleo bruto, entre outros.

A literatura nesse campo, cujo em sua maioria é experimental, oferece uma compreensão limitada do fenômeno, levando assim os autores do presente artigo a estudar a complexidade da hidrodinâmica do escoamento de forma mais detalhada.

O equipamento utilizado no artigo está apresentado na Figura 4.9. 


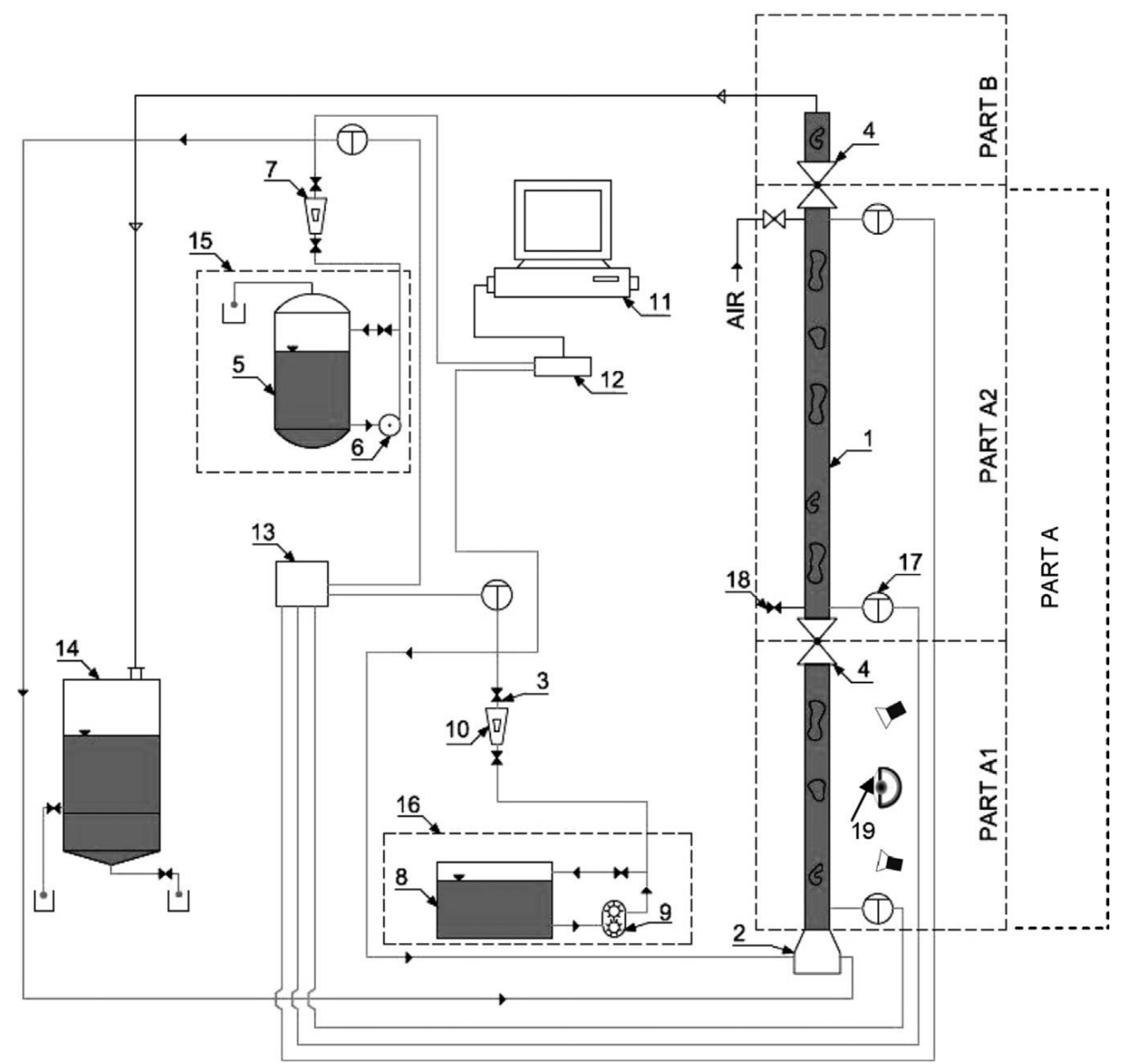

Figura 4.9 - Diagrama do equipamento: (1) canal de observação; (2) câmara de Mistura; (3) válvula de regulagem; (4) válvula do tipo membrana; (5) tanque de água; (6) bomba; (7) sistema de regulagem de água; (8) tanque de óleo; (9) bomba 2; (10) sistema de regulagem de água; (11)sistema computacional para capitação de dados experimentais (12) modulo; (13) placa captura; (14) separador; (15) suprimento de água; (16) suprimento de óleo; (17) termômetro; (18) válvula de drenagem; (19) câmera digital.

Durante os ensaios foi possível observar que havia velocidades superficiais baixas de água e velocidades superficiais altas de óleo. A água escoou em forma de gotas de diversos tamanhos e formas, enquanto que o óleo predominava na tubulação. Com o aumento da velocidade superficial da água, houve coalescência das gotículas de água, resultando em um fluxo transitório. $O$ aumento da velocidade superficial da água levou a formação de um fluxo empistonado de óleo, antes das fases se inverterem, ou seja, haver gotas de óleo na tubulação que agora predomina água. A figura 4.16, demonstra os padrões de fluxo. 


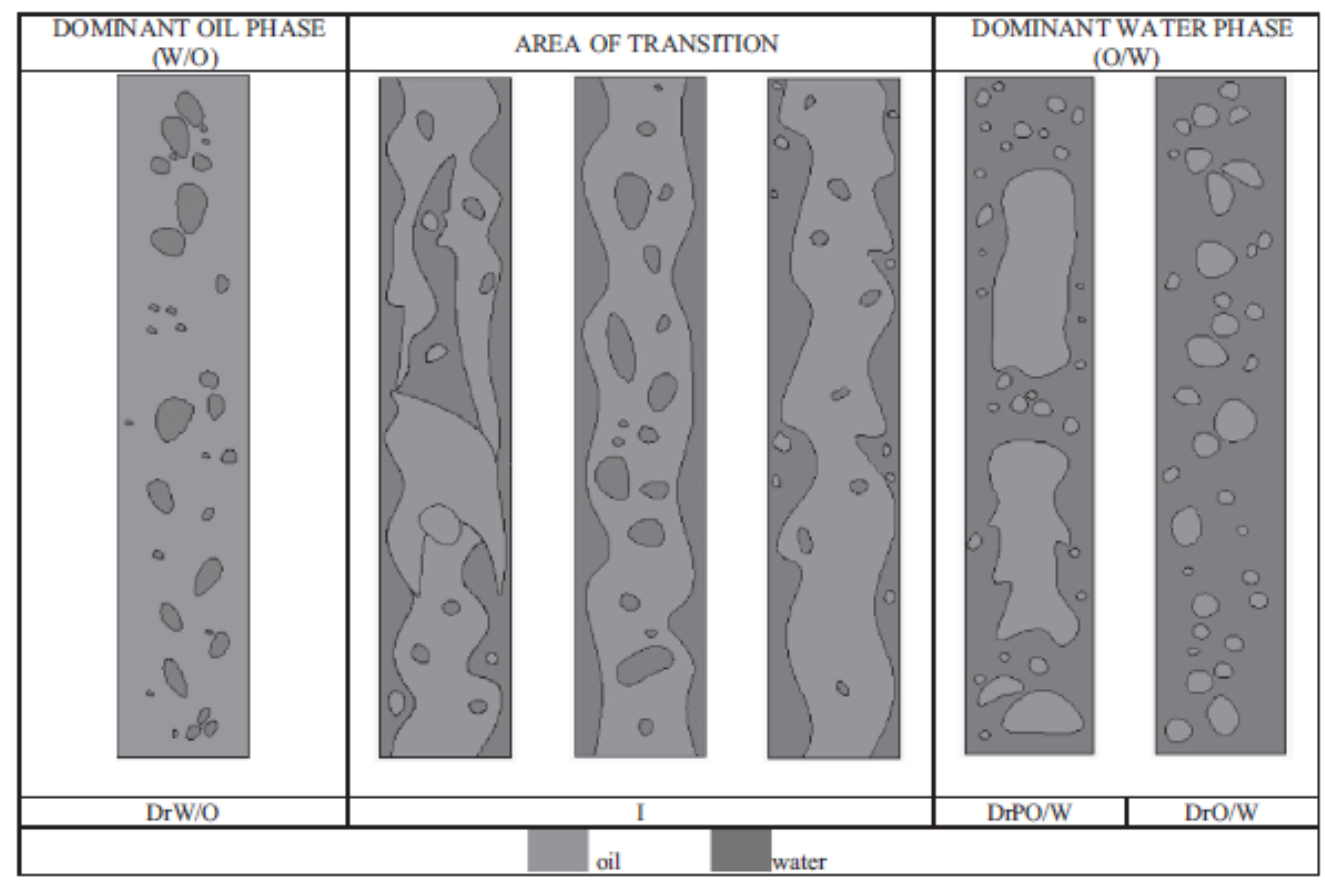

Figura 4.10 - Padrões de fluxo

\subsection{A Fourier analysis of the IPSA/PEA algorithms applied to multiphase flows with mass transfer (Miller T.F, Miller D.J. 2003)}

O método Interphase-Slip Algorithm (IPSA) é um dos mais usados para simulações de fluxos multifásicos. Assim como a maioria dos métodos pressurebased, uma iteração pelo método IPSA é feita por dois estágios (Spalding, 1996).

A formulação do IPSA é demonstrada por Miller et al., (2003). Primeiro, uma solução é obtida através de uma aproximação algébrica das equações diferenciais de quantidade de movimento resolvendo a velocidade, mas usando o campo de pressão da iteração anterior. O campo de velocidade não irá satisfazer a conservação de massa local até que a solução esteja totalmente convergida.

No segundo estágio, uma equação implícita para a correção da pressão é resolvida. Esse campo de pressão corrigido é usado para corrigir as velocidades para satisfazer os requerimentos da conservação de massa local. A equação de correção da pressão não é análoga à equação de transporte diferencial. Em vez disso, ela é obtida substituindo as equações de correção da velocidade em uma aproximação algébrica da equação da continuidade. Os valores de velocidade e pressão obtidos são usados para calcular coeficientes e termos fontes para as equações do volume finito. Os estágios 1 e 2 são repetidos até atingir a convergência.

Equacionamento:

A formulação da equação de quantidade de movimento é,

$$
\left(a_{P}^{i}+\sum_{j \neq i} D_{P}{ }^{i j}\right) u_{P}^{i}=\sum_{P} a^{i}{ }_{K} u^{i}{ }_{K}-\propto^{i}\left(\frac{p_{E}-p_{W}}{2 h}\right)+S^{i}+\sum_{j \neq i} D_{P}{ }^{i j} u^{j}{ }_{P}
$$


Aqui, $a^{i}$ representa o coeficiente do volume finito obtido através das equações diferencias de momento, e $a^{i}{ }_{P}$ é a soma de todos os $a^{i}{ }_{K}$ associados ao nó $P$.

Assim,

$$
D_{P}^{i j}=k^{i j}+\dot{m}^{i j}{ }_{p} \mathrm{e} D_{P}^{j i}=k^{i j}+\dot{m}^{j i}{ }_{p}
$$

Note que $k^{i j}=k^{j i}, \dot{m}^{i j}{ }_{p} \neq \dot{m}^{j i}{ }_{p}$ e consequentemente $D_{P}{ }^{i j} \neq D_{P}{ }^{j i}$.

Os símbolos definidos a seguir serão usados para a análise do primeiro estágio:

$$
A_{P}^{i}=a_{P}^{i}+\sum_{j \neq i} D_{P}^{i j}
$$

Também definindo,

$$
\begin{aligned}
& \Pi^{i}=A_{P}^{i}-\omega^{i}\left(a_{E}^{i} e^{i \theta}+a^{i}{ }_{w} e^{-i \theta}\right) \\
& R^{i}=\left(1-\omega^{i}\right) A_{P}^{i}+\omega^{i}\left(a_{E}^{i} e^{i \theta}+a^{i}{ }_{w} e^{-i \theta}\right)
\end{aligned}
$$

Sendo $(i)^{2}=-1$.

Durante o segundo estágio, as equações de correção de pressão tem a forma:

$$
a_{p}^{p} p_{p}^{\prime}=a_{E}^{p} p_{E}^{\prime}+a^{p}{ }_{w} p^{\prime}{ }_{w}+S_{p}^{p}
$$

Onde os coeficientes são definidos de maneiras ligeiramente diferentes dependendo do método colocado para as velocidades convectivas (Miller, 2003).

As definições a seguir se aplicam ao segundo estágio

$$
\begin{gathered}
\Pi^{P}=\left(a^{p}{ }_{E} e^{i \theta}+a^{p}{ }_{w} e^{-i \theta}\right)-d^{p}{ }_{P} \\
\Delta^{i}{ }_{u}=\alpha^{i}{ }_{e}\left(\frac{e^{i \theta}+1}{2}\right)-\alpha^{i}{ }_{w}\left(\frac{1+e^{-i \theta}}{2}\right) \\
\Delta^{i}{ }_{p}=\frac{\alpha^{i} e}{2}\left\{C^{i}{ }_{E}\left(\frac{e^{i 2 \theta}-1}{2 h}\right)+C^{i}{ }_{P}\left(\frac{e^{i \theta}-e^{-i \theta}}{2 h}\right)-\left(C^{i}{ }_{E}+C^{i}{ }_{P}\right)\left(\frac{e^{i \theta}-1}{h}\right)^{i}\right\}- \\
\frac{\alpha^{i}{ }_{w}}{2}\left\{C^{i}{ }_{P}\left(\frac{e^{i \theta}-e^{-i \theta}}{2 h}\right)+C^{i}{ }_{w}\left(\frac{1-e^{i 2 \theta}}{2 h}\right)-\left(C^{i}{ }_{P}+C^{i}{ }_{w}\right)\left(\frac{1-e^{i \theta}}{h}\right)\right\}
\end{gathered}
$$

Letras maiúsculas representam erros e suas decomposições de Fourier como:

$$
\left[\begin{array}{c}
\left\{u_{P}^{i}\right\}_{\text {current }}-\left\{u_{P}^{i}\right\}_{\text {fully converged }} \\
\left\{p_{P}\right\}_{\text {current }}-\left\{p_{P}\right\}_{\text {fully converged }}
\end{array}\right]=\left(\begin{array}{c}
U^{i} \\
P
\end{array}\right)_{P}=\sum_{\theta}\left(\begin{array}{c}
\beta_{u^{i}} \\
\beta_{p}
\end{array}\right) \exp \left\{\frac{i \theta x}{h}\right\}
$$


As matrizes de amplificação são configuradas para multiplicar os vetores coeficientes de Fourier como:

$$
\overline{A_{1}}\left(\begin{array}{c}
\beta_{u^{i}} \\
\beta_{p}
\end{array}\right)=\left(\begin{array}{c}
\hat{\beta}_{u^{i}} \\
\hat{\beta}_{p}
\end{array}\right) \quad \text { e } \overline{A_{2}}\left(\begin{array}{c}
\hat{\beta}_{u^{i}} \\
\hat{\beta}_{p}
\end{array}\right)=\left(\begin{array}{c}
\hat{\hat{\beta}}_{u^{i}} \\
\hat{\beta}_{p}
\end{array}\right)
$$

Os acentos circunflexos acima de algumas variáveis representam o primeiro ou segundo estágio da operação do algoritmo.

\section{Estágio Um:}

O desenvolvimento começa com a discretização das equações de quantidade de movimento; totalmente implícita em termos de velocidade, mas utilizando o campo de pressão da iteração anterior.

$$
A_{P}^{i} u_{P}^{i}=\sum_{P} a_{k}^{i} u_{k}^{i}-\alpha_{P}^{i}\left(\frac{p_{E}-p_{W}}{2 h}\right)+S_{P}^{i}+\sum_{j \neq i} D_{P}{ }^{j i} u_{P}^{j}
$$

Substituindo as equações implícitas para $u_{P}^{j}$ na equação anterior:

$$
\begin{array}{r}
{\left[A^{i}{ }_{P} \sum_{j \neq i} \frac{D_{P}{ }^{i j} D_{P}{ }^{j i}}{A_{P}}\right]=\sum_{P} a^{i}{ }_{k} u^{i}{ }_{k}-\left(\alpha^{i}{ }_{P}+\sum_{j \neq i} \frac{D_{P}{ }^{i j} D_{P}{ }^{j i}}{A^{j} j_{P}}\right)\left(\frac{p_{E}-p_{W}}{2 h}\right)+} \\
\left(S_{P}^{i}+\sum_{j \neq i} \frac{D_{P}{ }^{i j} D_{P}{ }^{j i}}{A^{j} P_{P}}\right)+\sum_{j \neq i} \frac{D_{P}{ }^{j i}}{A_{P}^{j}}\left(\sum_{h \neq j, i} D_{P}{ }^{h j} u_{P}^{h}+\sum_{P} a^{j}{ }_{k} u^{j}{ }_{k}\right)
\end{array}
$$

A expressão para o componente de erro de Fourier é:

$$
\begin{aligned}
& \left(\Pi-\sum_{j \neq i} \frac{D_{P}^{i j} D_{P}^{j i}}{A_{P}^{j}}\right) \hat{\beta}_{u^{i}}=(1-\omega)\left(A_{P}^{i}-\sum_{j \neq i} \frac{D_{P}^{i j} D_{P}^{j i}}{A^{j} P}\right) \hat{\beta}_{u^{i}}+\omega \sum_{j \neq i}\left[\frac { D _ { P } ^ { i j } } { A _ { P } ^ { j } } \left(a_{E}^{j} e^{i \theta}+\right.\right. \\
& \left.\left.a^{j}{ }_{w} e^{-i \theta}\right)+\sum_{j \neq i} \frac{D_{P}{ }^{h i} D_{P}^{j g}}{A^{h}}\right] \hat{\beta}_{u^{j}}-\left(\sum_{j \neq i} \frac{D_{P}{ }^{h i}}{A_{P}^{j}} \alpha_{P}^{j}+\alpha_{P}^{i}\right)\left(\frac{i \omega \sin \theta}{h}\right) \beta_{P}
\end{aligned}
$$

Onde $\mathrm{g} \neq \mathrm{i}, \mathrm{j}$, h. Os passos intermediários são demonstrados por Miller (2003). A matriz erro para o estágio um é:

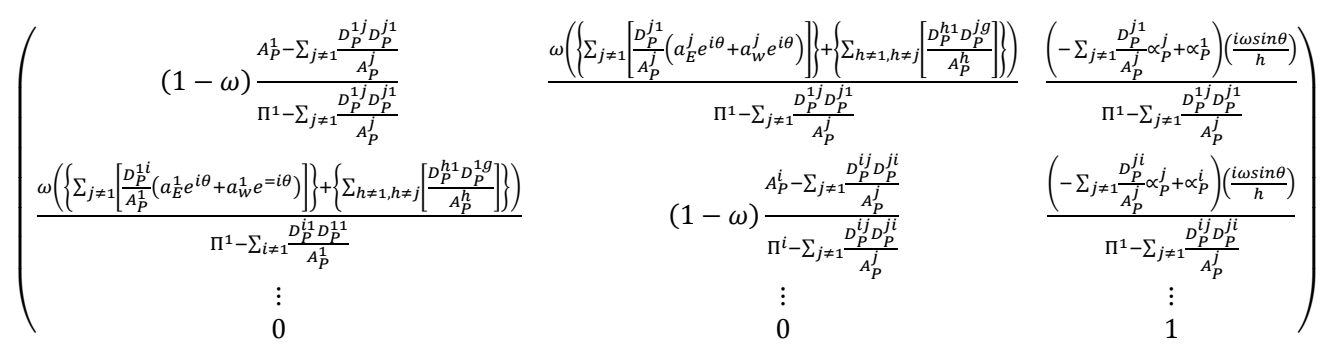

Estágio dois:

Continuidade Global:

Para a fase $i$ a equação da continuidade é 


$$
\begin{aligned}
& \frac{\partial\left(\alpha^{i} \rho^{i} u_{k}^{i}\right)}{\partial x_{k}}=\sum_{j \neq i}\left(\dot{m}^{j i}-\dot{m}^{i j}\right) \\
& \frac{\alpha^{i} \rho^{i} u^{i}\left|e^{-} \alpha^{i} \rho^{i} u^{i}\right|_{w}}{h}=\sum_{j \neq i}\left(\dot{m}^{j i}-\dot{m}^{i j}\right) \\
& \sum_{\text {alli }} \frac{\alpha^{i} u^{i}-\alpha^{i} u^{i}}{h}=\sum_{\text {all } i}\left[\sum_{j \neq i}\left(\frac{\dot{m}^{j i}-\dot{m}^{i j}}{\rho^{i}}\right)\right]
\end{aligned}
$$

Em que $\dot{m}$ representa a taxa de transferência de massa volumétrica, o sobrescrito $i j$ indica transferência de massa positiva da fase $i$ para a fase $j$. A determinação das velocidades depende da malha utilizada, assim como a pressão e a correção da velocidade.

Determinação das velocidades ( $P$ WI Method)

A velocidade da fase é calculada através do método pressure-weitghted interpolation ou PWIM (Miller et al., 1988).

Presumindo inicialmente uma malha uniforme:

$$
\begin{aligned}
& \hat{u}_{e}^{i}=\frac{\hat{u}_{E}^{i} \widehat{u}_{P}^{i}}{2}+(1-\omega)\left[\hat{u}_{e}^{i}-\left(\frac{u_{E}^{i}-u_{P}^{i}}{2}\right)\right]-\frac{\omega}{A_{e}^{i}}\left\{\sum_{e} a_{k}^{i} \widehat{u}_{k}^{i}-\left.\alpha_{e}^{i} \frac{d p}{d x}\right|_{e}+S_{e}^{i}+\sum_{j \neq i} D_{e}^{j i} \hat{u}_{e}^{i}\right\}- \\
& \frac{\omega}{2}\left\{\frac{\sum_{E} a_{k}^{i} \widehat{u}_{k}^{i}-\left.\alpha_{E}^{i} \frac{d p}{d x}\right|_{E}+S_{E}^{i}+\sum_{j \neq i} D_{E}^{j i} \widehat{u}_{E}^{i}}{A_{e}^{i}}+\frac{\sum_{P} a_{k}^{i} \widehat{u}_{k}^{i}-\left.\alpha_{P}^{i} \frac{d p}{d x}\right|_{P}+S_{P}^{i}+\sum_{j \neq i} D_{P}^{j i} \hat{u}_{P}^{i}}{A_{P}^{i}}\right\} \\
& \frac{\sum_{e} a_{k}^{i} \widehat{u}_{k}^{i}+\sum_{j \neq i} D_{e}^{j i} \hat{u}_{e}^{i}}{A_{e}^{i}}=\frac{1}{2}\left\{\frac{\sum_{E} a_{k}^{i} \hat{u}_{k}^{i}+\sum_{j \neq i} D_{E}^{j i} \widehat{u}_{E}^{i}}{A_{e}^{i}}+\frac{\sum_{P} a_{k}^{i} \widehat{u}_{k}^{i}+\sum_{j \neq i} D_{P}^{j i} \hat{u}_{P}^{i}}{A_{P}^{i}}\right\} \\
& \frac{\alpha_{e}^{i}}{A_{e}^{i}}=\frac{1}{2}\left(\frac{\alpha_{E}^{i}}{A_{E}^{i}}+\frac{\alpha_{P}^{i}}{A_{P}^{i}}\right)
\end{aligned}
$$

É possível simplificar a equação 23 para:

$$
\begin{aligned}
& \hat{u}_{e}^{i}=\frac{\widehat{u}_{E}^{i}+\widehat{u}_{P}^{i}}{2}+(1-\omega)\left[u_{e}^{i}-\left(\frac{u_{E}^{i}+u_{P}^{i}}{2}\right)\right]-\left.\frac{\omega}{2}\left\{C_{E}^{i}+C_{P}^{i}\right\} \frac{d p}{d x}\right|_{e}+ \\
& \frac{\omega}{2}\left\{\left.C_{E}^{i} \frac{d p}{d x}\right|_{E}+\left.C_{P}^{i} \frac{d p}{d x}\right|_{P}\right\}
\end{aligned}
$$

Sendo

$$
C_{P}^{i}=\frac{\alpha_{P}^{i}}{A_{P}^{i}} \quad \text { e } \quad C_{E}^{i}=\frac{\alpha_{E}^{i}}{A_{E}^{i}}
$$

Correção da Velocidade e da Pressão

A correção da velocidade e da pressão segue os passos abaixo:

$$
\hat{\hat{u}}_{P}^{i}=\hat{u}_{P}^{i}+\omega C_{P}^{i}\left(\frac{p^{\prime} E^{-}{ }^{\prime} W}{2 h}\right)
$$


Onde

$$
\begin{aligned}
& \widehat{\hat{\varphi}}-\hat{\varphi}=\varphi^{\prime} \\
& \hat{u}_{e}^{i}=\frac{\widehat{u}_{E}^{\prime i}+\widehat{u}_{P}^{\prime i}}{2}-\left.\frac{\omega}{2}\left(C_{E}^{i}+C_{P}^{i}\right) \frac{d p^{\prime}}{d x}\right|_{e}+\frac{\omega}{2}\left(\left.C_{E}^{i} \frac{d p^{\prime}}{d x}\right|_{E}+\left.C_{P}^{i} \frac{d p^{\prime}}{d x}\right|_{P}\right) \\
& \hat{u}_{e}^{i}=\hat{u}_{e}^{i}-\frac{\omega}{2}\left\{C_{E}^{i}+C_{P}^{i}\right\}\left(\frac{p^{\prime}{ }_{E}-p^{\prime} P}{h}\right)
\end{aligned}
$$

Substituindo a equação acima na equação da continuidade global, se tem:

$a_{P}^{p} p_{P}^{\prime}=a_{E}^{p} p_{E}^{\prime}+a_{W}^{p} p_{W}^{\prime}+S_{P}^{p}$

Onde:

$$
\begin{aligned}
& a_{E}^{p}=\frac{\omega}{2(h)^{2}} \sum_{A l l i} \alpha_{e}^{i}\left(C_{E}^{i}+C_{P}^{i}\right) \\
& a_{w}^{p}=\frac{\omega}{2(h)^{2}} \sum_{A l l i} \alpha_{w}^{i}\left(C_{P}^{i}+C_{W}^{i}\right) \\
& a_{P}^{P}=a_{E}^{P}+a_{w}^{P} \\
& S_{P}^{p}=\sum_{A l l i}\left\{\frac{\sum_{j \neq i}\left(\dot{m}^{j i}-\dot{m}^{i j}\right)}{\rho^{i}}-\left(\frac{\alpha_{e}^{i} \widehat{u}_{e}^{i}-\alpha_{w}^{i} \widehat{u}_{w}^{i}}{h}\right)\right\}
\end{aligned}
$$

Após a solução da equação a pressão é corrigida utilizando:

$\hat{\hat{p}}=\hat{p}+\omega_{P} p^{\prime}$

Para a correção da velocidade é usada a equação 40

$$
\begin{gathered}
A_{P}^{i} u_{P}^{\prime i}=\omega\left\{\sum_{P} a_{k}^{i} u_{k}^{\prime i}+\sum_{j \neq i} D_{p}^{j i} u_{P}^{\prime j}-\left.\alpha_{P}^{i} \frac{d p^{\prime}}{d x}\right|_{P}\right\} \\
{\left[A_{P}^{i}-\omega\left(\sum_{P} a_{k}^{i}+\sum_{j \neq i} D_{P}^{j i}\right)\right] u_{P}^{\prime i}=\omega\left\{\sum_{P} a_{k}^{i}\left(u_{k}^{\prime i}-u_{P}^{\prime i}\right)+\right.} \\
\left.\sum_{j \neq i} D_{p}^{j i}\left(u_{P}^{\prime j}-u_{P}^{\prime i}\right)-\left.\alpha_{P}^{i} \frac{d p^{\prime}}{d x}\right|_{P}\right\} \\
u_{P}^{\prime i}=\frac{-\left.\omega \alpha_{P}^{i} \frac{d p}{d x}\right|_{P}}{A_{P}^{i}-\omega\left(\sum_{P} a_{k}^{i}+\sum_{j \neq i} D_{P}^{j i}\right)}
\end{gathered}
$$

Sendo assim a correção da velocidade é 


$$
\widehat{\hat{u}}_{P}^{i}=\widehat{u}_{P}^{i}-\left(\frac{\omega}{1-\omega}\right) C_{P}^{i}\left(\frac{p_{E}^{\prime}-p_{w}^{\prime}}{2 h}\right)
$$

Matriz erro do estágio 2

$$
\overline{A_{2}}=\left[\begin{array}{ccccc}
1-\frac{i \omega \prime \sin \theta C_{p}^{i} \Delta_{u}^{i}}{\Pi^{P}(h)^{2}} & \ldots & -\frac{i \omega \prime \sin \theta C_{p}^{i} \sum_{i \neq j} \Delta_{u}^{j}}{\Pi^{P}(h)^{2}} & \ldots & -\frac{i \omega \prime \sin \theta C_{p}^{i}\left(\sum_{\text {All } i} \Delta_{P}^{i}\right)}{\Pi^{P}(h)^{2}} \\
-\frac{i \omega \prime \sin \theta C_{p}^{j} \sum_{i \neq j} \Delta_{u}^{i}}{\Pi^{P}(h)^{2}} & \ldots & 1-\frac{i \omega \prime \sin \theta C_{p}^{j} \Delta_{u}^{j}}{\Pi^{P}(h)^{2}} & \ldots & -\frac{i \omega \prime \sin \theta C_{p}^{j}\left(\sum_{A l l i} \Delta_{P}^{i}\right)}{\Pi^{P}(h)^{2}} \\
\frac{\omega_{P} \Delta_{u}^{i}}{\Pi^{P} h} & \ldots & \frac{\omega_{P} \Delta_{u}^{j}}{\Pi^{P} h} & \ldots & 1+\frac{\omega_{P} \sum_{A l l i} \Delta_{P}^{i}}{\Pi^{P} h}
\end{array}\right]
$$

\subsection{Algebraic Slip model in Phoenics (Spalding, 1992)}

O modelo Algebraic Slip fornece uma alternativa ao IPSA para a modelagem de fluxos multifásicos.

Em misturas, as fases se comportam como um único fluido, podendo suas propriedades depender, ou não, da fase dispersa. As variáveis da mistura, serão expostas no PHOENICS como densidade de mistura e viscosidade de mistura.

No caso de várias fases dispersas, cada fase será representada por uma equação de concentração de espécies. A equação de transporte para cada fase dispersa permite o movimento relativo entre as fases. Este movimento entre as fases é chamado de phase slip ou deslizamento entre fases.

Também é suposto que a velocidade de deslizamento pode ser calculada a partir de equações algébricas que envolvem apenas as variáveis locais, em vez de a partir das equações diferenciais parciais, como é o caso do IPSA.

\subsubsection{Princípios básicos do modelo}

As equações de movimento para cada componente, que é tratado como uma fase distinta, são dependentes dos seguintes termos: variação do tempo, convecção, difusão, gradiente de pressão, força de campo, atrito entre os fluidos. Sendo que o modelo assume que os 3 últimos termos citados são dominantes.

A não importância das derivadas em relação ao tempo e a distância, significa que a velocidade relativa é função apenas das variáveis locais. Sendo assim, a velocidade relativa, pode ser calculada a partir de equações algébricas em vez de equações diferenciais parciais.

\subsubsection{Cálculo da velocidade de deslizamento}

O Arraste é dado por:

$$
F_{d}=C_{d} \cdot A_{p} \cdot 0,5 \cdot \rho \cdot\left(V_{s}\right)^{2}
$$

Sendo, 
$\mathrm{Ou}$,

$$
C_{d}=\frac{24}{R e} \quad \text { Baixo Número de Reynolds }
$$

$$
\left.C_{d}=0,42 \quad\right\} \text { Alto Número de Reynolds }
$$

O modelo também apresenta outros valores para $\mathrm{C}_{\mathrm{d}}$ em sua biblioteca, em casos onde há dois regimes diferentes de escoamento. Como é o caso do padrão anular, que se pode obter um núcleo turbulento enquanto que o fluido da parede escoa no regime laminar.

A força de deslizamento das partículas é dada por:

$$
F_{S}=B \cdot V_{p} \cdot \Delta \rho
$$

\subsubsection{Implementação no PHOENICS}

As soluções para todos volumes de controle são obtidas simultaneamente, devida as fortes ligações entre as equações. É considerado uma iteração na célula quando as seguintes etapas são realizadas: (1) Velocidades de deslizamento são calculadas em cada face da célula; (2) A velocidade da fase tida como contínua em cada uma das células é calculada; (3) Desequilíbrio nos volumes são calculados para cada componente; (4) Frações de volume são ajustadas.

\subsubsection{Formulas auxiliar ao modelo}

Densidade e Viscosidade da mistura:

$$
\begin{aligned}
& \langle\rho\rangle=\left(1-\sum(P T)\right) \rho+\sum(P T . \rho) \\
& \langle V\rangle=\left(1-\sum(P T)\right) v+\sum(P T . v)
\end{aligned}
$$

4.9 The Volume of Fluid (VOF) Method (Hird C. W., Nichols B. D. 1981)

Existem várias formas de se representar a superfície livre em escoamentos de fluidos. No método Volume of Fluid (VOF), primeiramente introduzido por Hirt e Nichols (Hirt and Nichols, 1981), são utilizadas funções marcadoras para reconstrução da superfície livre, que assumem valores entre 0 e 1, dependendo da quantidade de fluido em cada célula. A cada passo no tempo, a superfície livre é reconstruída a partir das funções marcadoras. Esta 
superfície livre é então movida com a velocidade normal, para a atualização das funções marcadoras (Estacio et al., 2006)

A Equação Governante para a função marcadora $F$ é:

$$
\frac{\partial F}{\partial t}+u \frac{\partial F}{\partial x}+v \frac{\partial F}{\partial y}=0
$$

A Equação 49 determina que $F$ se move com o fluido. Em uma malha Lagrangeana a Equação 49 é reduzida para o conceito que $F$ se mantem constante em cada célula. Nesse caso, a função F serve somente para indicar as células que contém fluido. Em uma malha Lagrangeana-Euleriana, o fluxo de $\mathrm{F}$ movendo-se com o fluido através da célula precisa ser computado.

Em resumo, o método VOF oferece um esquema de rastreamento das regiões com os mínimos requisitos de armazenamento. Além disso, dado que se segue regiões, em vez de superfícies, todos os problemas lógicos associados com intersecção de superfícies devem ser evitados de se utilizar VOF. 


\section{Materiais e Métodos}

\subsection{Introdução}

O foco do presente trabalho foi representar computacionalmente os perfis de fluxo obtidos anteriormente por Farias (2013), em uma unidade experimental de escoamento multifásico, capaz de reproduzir o perfil de fluxo Core - Flow, esta unidade será apresentada em detalhes no capítulo a seguir. As simulações foram divididas em 6 Fases, onde a complexidade do problema é aumentada gradativamente.

Fase 1: Esboço Inicial de um trecho reto com fluxo de água e inserção das propriedades dos fluídos a serem estudados

Fase 2: Inserção de fluxo multifásico Água/Óleo no trecho reto

Fase 3: Estudo do perfil core - flow no trecho reto

Fase 4: Inserção de fluxo multifásico Água/Óleo em trecho com curva

Fase 5: Estudo do perfil core - flow em trecho com curva

Fase 5: Inserção do trecho completo com fluxo multifásico Água/Óleo

Fase 6: Estudo do perfil Core - Flow no trecho completo

\subsection{Unidade Experimental}

A unidade experimental foi montada na Universidade Santa Cecilia, Santos/SP, é composta por um motor WEG 22 Plus de $2 \mathrm{hp} \mathrm{com} \mathrm{rotação} \mathrm{nominal}$ de $3385 \mathrm{rpm}$, ligado à bomba regenerativa Ferrari modelo IDB de $1 \mathrm{CV}$, com rotação de $3500 \mathrm{rpm}$. O motor está conectado a um inversor de frequência da WEG, modelo CFW 08. Estes equipamentos têm a função de succionar o óleo através de uma tubulação de $1 \frac{1 / 2}{2}$ de PVC com diâmetro interno de $40 \mathrm{~mm}$, do tanque de óleo $(39,5 \times 62 \times 31 \mathrm{~cm})$ e transportá-lo por uma tubulação de PVC transparente de uma polegada de diâmetro nominal (diâmetro interno de 27,19 $\mathrm{mm}$ ), até o injetor. No percurso entre a bomba regenerativa Ferrari e o injetor havia duas válvulas de gaveta. A primeira foi utilizada para executar as medidas de vazão do sistema e a segunda, para fechar o sistema e abrir o sistema de reciclo. O fluido usado foi composto por água/óleo para estudo do escoamento bifásico. 




Figura 5.1 - Planta em escala de laboratório do sistema multifásico. Legenda: 1 - Motor WEG PLUS de 2HP, 2 - Bomba Regenerativa FERRARI IDB, 3 - Tanque de óleo, 4 - Tanque água/óleo, 5 - Injetor, 6 - Bomba KSB Hydrobloc P-500, 7 - Motor WEG 22 PLUS de 1HP, 8 Tanque de água, $\mathbf{9}$ - Inversor de frequência para os motores.

\subsection{Simulações}

As simulações foram feitas para um fluxo multifásico em um sistema de tubulações similar ao do equipamento presente na figura 5.1. Foi adotado que a água possui densidade de $0,988 \mathrm{~kg} / \mathrm{L}$ e o óleo densidade de $0,917 \mathrm{~kg} / \mathrm{L}$, iguais aos valores utilizados nos ensaios experimentais. A primeira geometria estudada envolvia apenas o trecho inferior do equipamento, e a segunda o equipamento completo. Dois modelos multifásicos foram estudados e validados. Os modelos de turbulência K- $\omega$ e K- $\varepsilon$ também foram avaliados.

\subsubsection{Geometria}

A geometria do presente estudo visou representar o trecho do equipamento em que é feita a visualização do fenômeno. Para isso as medidas de diâmetro, comprimento e curvas foram adotadas iguais a unidade experimental apresentada no tópico 5.2. As simulações iniciais envolveram apenas o trecho inferior da tubulação, para uma imersão facilitada ao ambiente do software. Nas figuras 5.2 e 5.3 é possível ver o equipamento e a geometria da simulação respectivamente. 


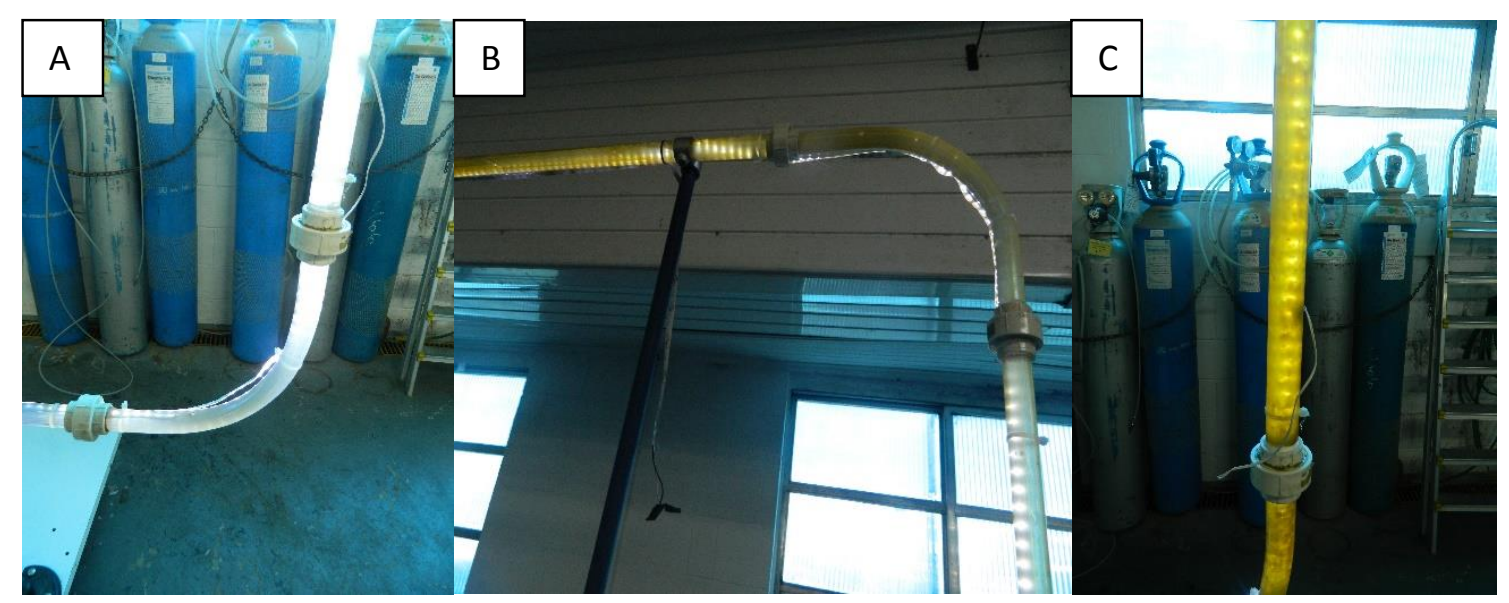

Figura 5.2 - (A) Trecho Inferior; (B) Trecho Superior; (C) Trecho Vertical.

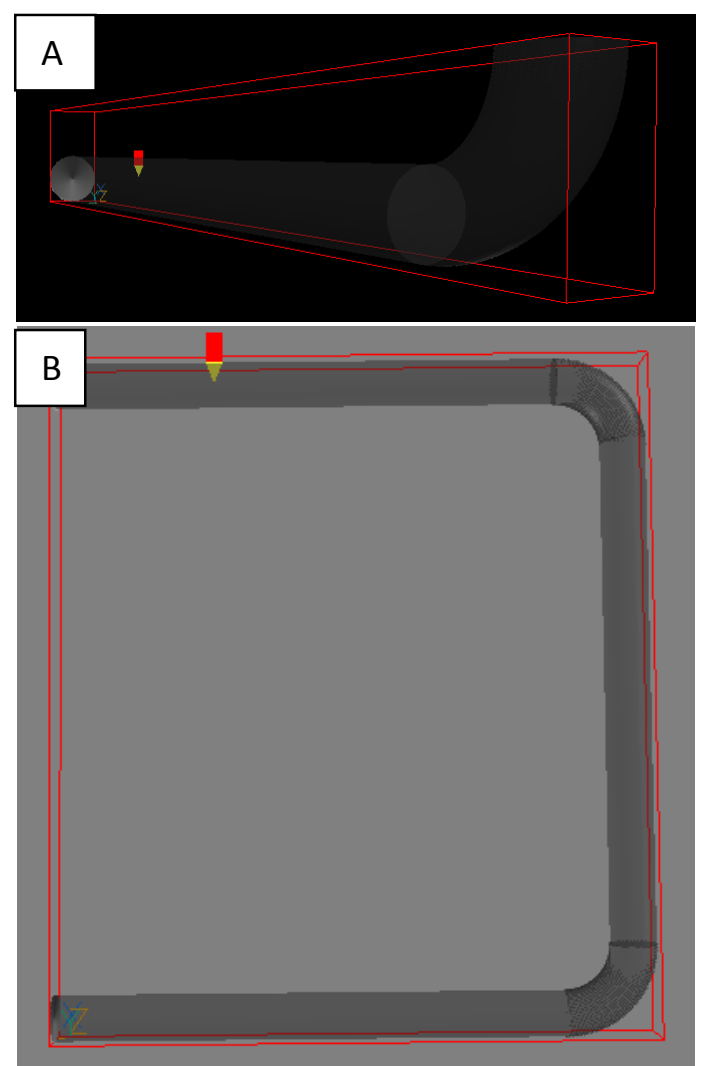

Figura 5.3 - (A) Trecho Inferior; (B) Geometria Completa

\subsubsection{Malha}

A malha utilizada nas simulações foi gerada pelo próprio software de CFD. Foi escolhida a malha ortogonal (Figura 5.4), pois quando gerado a malha Body Fitted (malha que envolve todo corpo da geometria) havia algumas aproximações incorretas nas curvas. Por conta disso, uma malha ortogonal com grande densidade de células, afim de encontrar a interface de contato dos líquidos e o processo de atomização e deposição de gotas, apresentou melhores resultados na geometria adotada, apesar de requerer um tempo de computação maior. A geometria inicial (tubo reto mais uma curva) tinha 3.182.278 células enquanto que a geometria final que envolve a parte visual do equipamento 
possui 54.479 .837 células. O grande número de células para o segundo caso, foi devido a configuração do equipamento, as células que envolveram a tubulação foi aproximadamente igual a 9.564.834. Foram fixados esses valores após os resultados não apresentarem mudança significativa das variáveis (convergência de malha), buscando assim um menor tempo computacional.

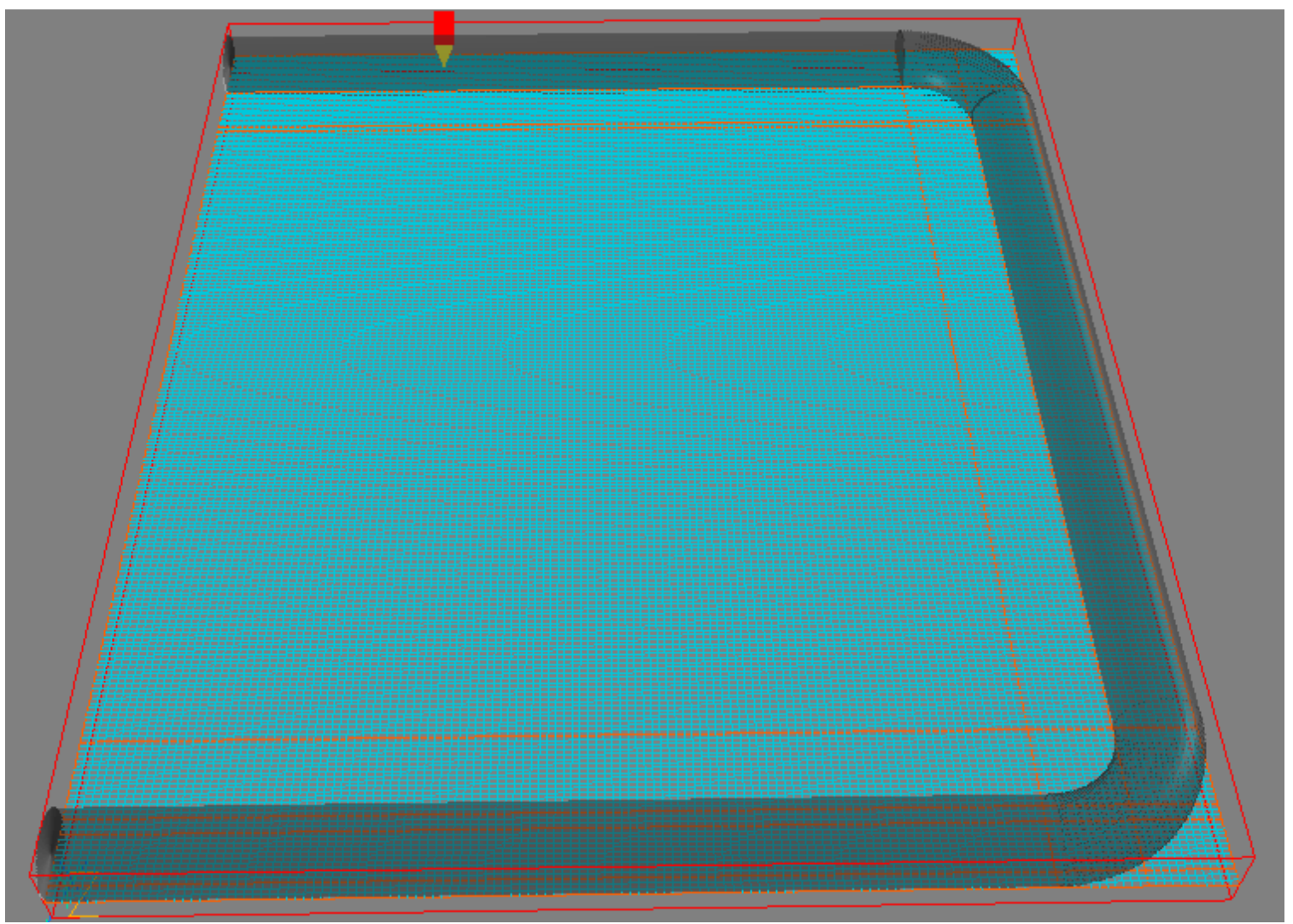

Figura 5.4 - Malha Ortogonal

\subsubsection{Modelos}

Os modelos estudados foram o ONE PHASE, para o fluxo monofásico e os IPSA - Interphase Slip Algorithm e Algebraic Slip para o fluxo multifásico.

\subsubsection{1 - ONE PHASE}

Esse é um modelo simples que é utilizado para a resolução das equações de transporte quando estão presentes diversos materiais que não podem ser distintos e se comportam como um só (Spalding, 1996)

\subsubsection{2 - IPSA- Interphase Slip Algorithm}

O método Interphase Slip Algorithm (IPSA) é um dos mais usados para simulações de fluxos multifásicos. Assim como a maioria dos métodos pressure based, uma iteração pelo método IPSA é feita por dois estágios primários (Spalding, 1996).

A formulação do IPSA é demonstrado por Miller, et al., (2003). Primeiramente, uma solução é obtida através de uma aproximação algébrica das equações diferenciais de quantidade de movimento em termos de velocidade, 
mas usando o campo de pressão da iteração anterior. O campo de velocidade não irá satisfazer a conservação de massa local até que a solução esteja totalmente convergida.

No segundo estágio uma equação implícita para a correção da pressão é resolvida. Esse campo de pressão corrigido é usado para corrigir as velocidades para satisfazer os requerimentos da conservação de massa local. A equação de correção da pressão não é análoga a equação de transporte diferencial. Em vez disso, ela é obtida substituindo as equações de correção da velocidade em uma aproximação algébrica da equação da continuidade. Os valores de velocidade e pressão obtidos são usados para calcular coeficientes e termos fontes para as equações do volume finito. Os estágios 1 e 2 são repetidos até atingir a convergência.

\subsubsection{3 - Algebraic Slip}

Spalding (1996) apresenta a formulação do modelo e diz que é uma alternativa ao IPSA, onde se assume que há uma fase dominante no sistema e uma fase secundária dispersa. A fase dispersa é representada por equações de concentração de espécies. As equações permitem um movimento entre a fase dispersa e a fase contínua e ainda a possibilidade de interação das partículas da fase dispersa. Também se assume que a velocidade de deslizamento pode ser calculada por equações algébricas envolvendo apenas variáveis locais, em vez de a partir das equações parciais completas, como é no caso do IPSA.

É possível observar deduções matemáticas do modelo nos artigos de Shang Z. et al., 2013, e Bravo H.R., 2007.

\subsection{Convergência}

De acordo com Rosa (2010), a convergência é atingida no PHOENICS quando os valores das variáveis se mantém constantes, com um resíduo baixo e a relação da somatória do resíduo sobre o resíduo de referência for próximo ou igual a 1. O trabalho seguiu esses parâmetros para se considerar que a convergência foi atingida.

\subsubsection{Resíduo e Relaxação}

A técnica mais conhecida para melhor atingir a convergência numérica é o uso de relaxações. Elas retardam as mudanças feitas às variáveis passo a passo, melhorando assim o residual. O resíduo de uma forma geral é a diferença no valor de uma dada variável entre duas iterações, ou seja, quanto menor o resíduo, menor será a mudança do valor da variável caso se continue a iteragir.

É importante saber que as relaxações não alteram a solução final, apenas o caminho que ela é atingida. Dois tipos de relaxações estão disponíveis no software: Linear e False Time step.

As soluções das equações de volume finito geram um campo de valores de $f\left(f_{\text {new }}\right)$. As relaxações do tipo Linear substituem esse por: 


$$
f^{*}{ }_{\text {new }}=f_{\text {old }}+L\left(f_{\text {new }}-f_{\text {old }}\right)
$$

Onde fold é o valor do passo anterior; $L$ é o coeficiente de relaxação que varia entre 0 à 1 . $O$ valor de 1 indica sem relaxação e de 0 previne qualquer mudança do passo anterior.

Relaxações do tipo False Time step modificam as equações do volume finito, adicionando um tempo pseudotransiente.

$$
\text { (massa na célula) } x \frac{\left(f_{\text {old }}-f_{\text {new }}\right)}{d t_{f}}
$$

Em que $\mathrm{dt}_{\mathrm{f}}$ é o False Time step. Grande valores de $\mathrm{dt}_{\mathrm{f}}$ fazem o termo adicional ter proporções pequenas caracterizando relaxações leves. Pequenos valores de $\mathrm{dt}_{\mathrm{f}}$ fazem o termo adicional ter grandes proporções caracterizando relaxações pesadas.

As relaxações adotadas nesse trabalho visaram em cima desses conhecimentos buscar o melhor valor residual para a simulação. 


\section{Resultados e discussões}

\subsection{Trecho reto mais uma curva}

\subsection{1 - Resultados das Simulações}

Nesta etapa das simulações foi utilizado o modelo IPSA. De acordo com a Figura 6.1 é possível observar que os Spot Values, que são os valores de cada variável ao longo do cálculo em um determinado ponto, se mantém constantes. E que a porcentagem de erro vai diminuindo ao longo da simulação até que permanece constante. Estas são as primeiras características da convergência do sistema.

Spot Values at $(13,4,13)$

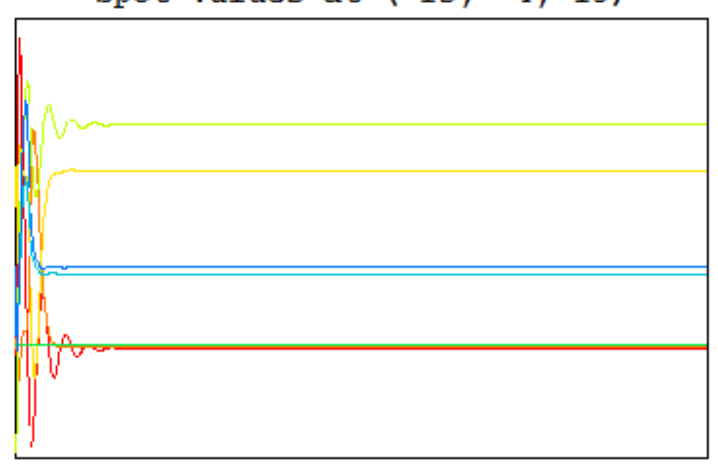

* Error - Cut ott 1.000E-01 \%

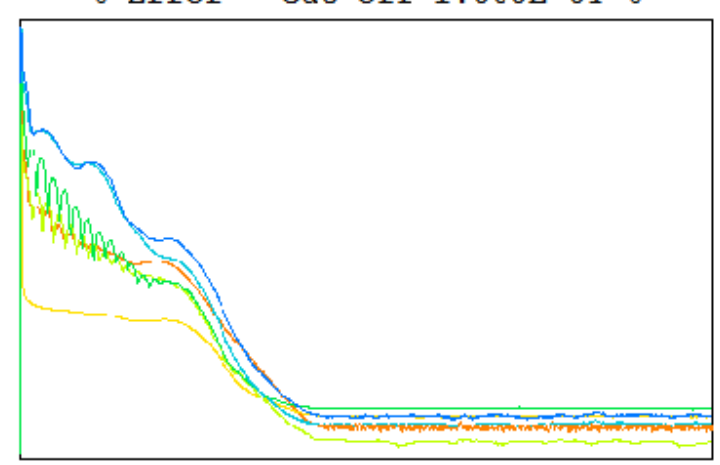

Figura 6.1 - Gráficos de acompanhamento da simulação

Porém, para se ter certeza que o sistema realmente convergiu numericamente, é necessário analisar os resíduos para cada modelo de turbulência utilizado. Estes estão presentes na Tabela 1.

Tabela 1 - Resíduos da simulação usando os modelos k- $\varepsilon$ e k- $\omega$

\begin{tabular}{|c|c|c|c|c|c|c|c|}
\hline & P1 & U1 & V1 & W1 & R2 & K & Ép. - Om \\
\hline k- $\omega$ & $2,710^{-3}$ & $1,410^{-3}$ & $1,910^{-3}$ & $2,410^{-3}$ & $2,710^{-3}$ & $9,910^{-3}$ & $5,110^{-1}$ \\
\hline $\mathrm{k}-\varepsilon$ & $6,810^{-4}$ & $1,110^{-3}$ & $1,010^{-4}$ & $2,310^{-3}$ & $6,910^{-4}$ & $3,210^{-5}$ & $5,510^{-4}$ \\
\hline
\end{tabular}

O modelo K- $\omega$ apresentou um valor residual maior em relação ao K- $\varepsilon$ para todas as variáveis. Isso pode ser devido à alta sensibilidade do modelo K- $\omega$ nas zonas distantes da parede.

Para as simulações utilizando o modelo de turbulência $k-\varepsilon$, os perfis de velocidade e pressão podem ser vistos nas Figuras 6.2C e D.

O perfil de velocidades no centro do tubo e ao longo da posição axial, do ponto $0 \mathrm{~m}$ até $2,1 \mathrm{~m}$, que corresponde ao meio da curva, esta na Figura 6.3. Observa-se que a velocidade máxima atingida pelo sistema é de aproximadamente $4 \mathrm{~m} / \mathrm{s}$, sem diferenças significativas para os dois perfis.

A curvatura da tubulação resulta em modificações tanto no perfil de velocidade quanto na pressão. No raio interno da curva, as pressões são menores do que no raio externo. Observa-se uma região de maior velocidade junto ao raio interno (regiões vermelhas nas Figuras 6.2A e C. As velocidades 
foram reduzidas junto à parede, provavelmente devido à condição de contorno de não deslizamento.

O perfil de densidades para as simulações com $k-\varepsilon$ e $k-\omega$ foram muito similares. As Figuras 6.4A e 6.5A apresentam os resultados das simulações, onde o óleo (azul) está no centro da tubulação e a água (vermelho) ao seu redor, lubrificando o fluxo. As Figura 6.4B e 6.5B são fotos do equipamento real para comparação.

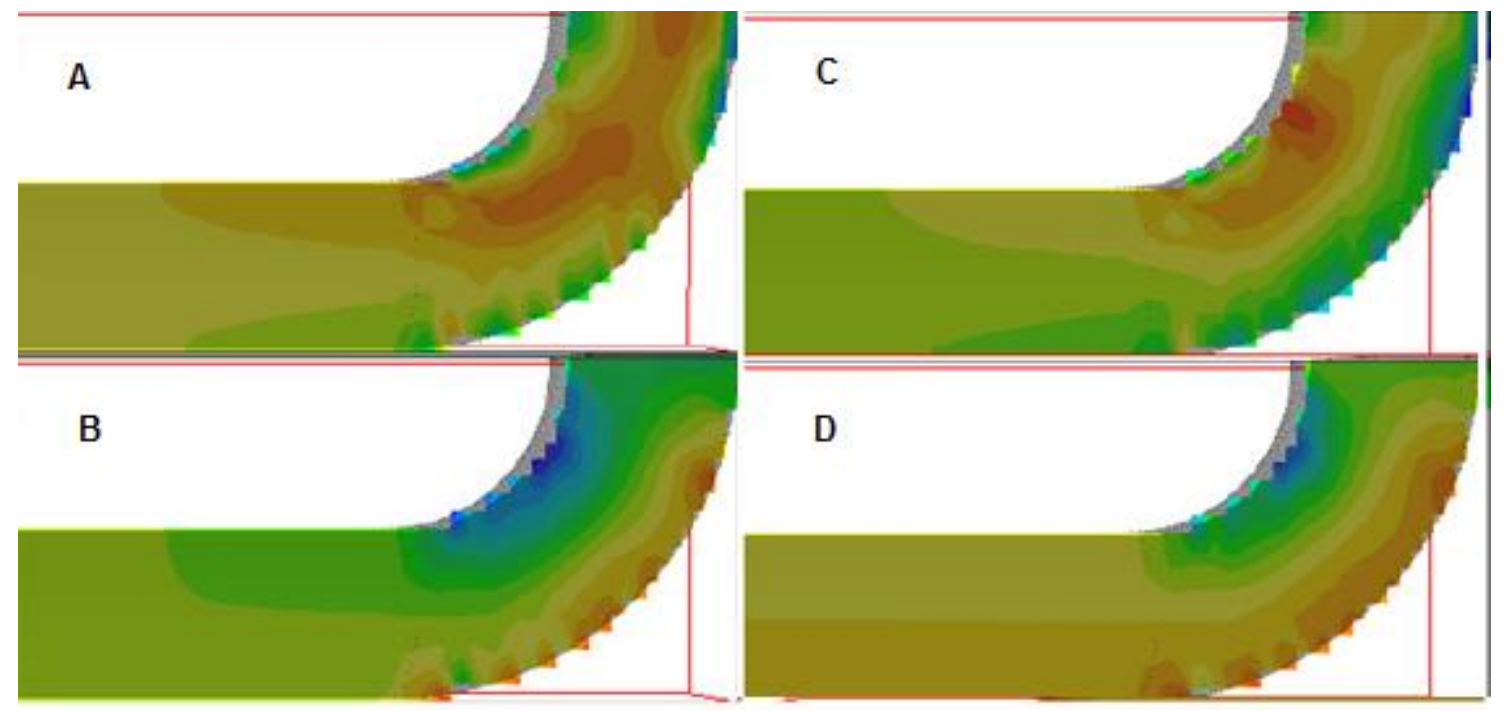

Figura 6.2 - (A) Isosuperfíces de velocidades para o modelo $k-\varepsilon$; (B) Isosuperfíces de pressões para o modelo $k-\varepsilon ;(C)$ Isosuperfíces de velocidades para o modelo $k-\omega ;(D)$ Isosuperfíces de pressões para o modelo $k-\omega$.

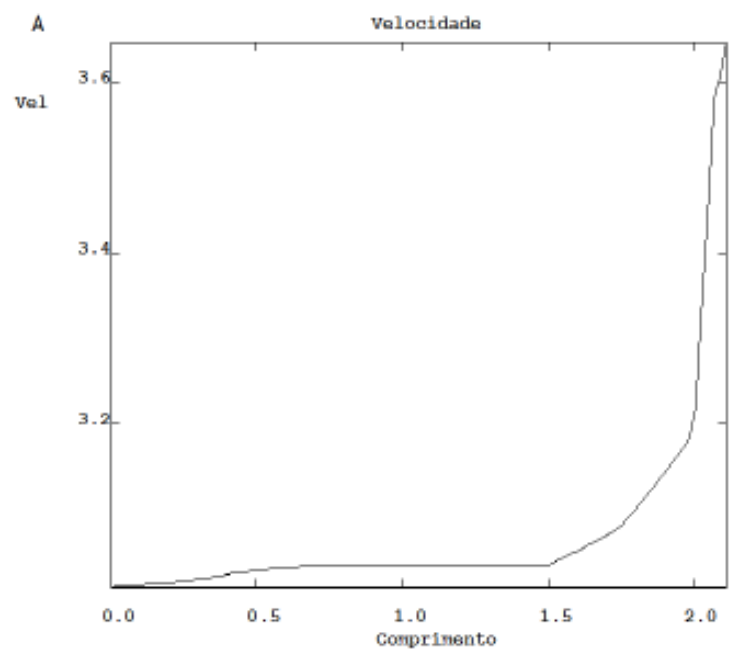

Figura 6.3 - A) Plotagem das Velocidades do modelo k- $\varepsilon$; B) Plotagem das Velocidades k- $\omega$.

\subsection{2 - Validação Experimental}

Foi feita uma validação simples comparando-se as simulações obtidas aqui e fotos da unidade experimental (Figuras 6.4 e 6.5). Tanto a simulação como as imagens reais da operação do equipamento monstram o fluxo de óleo sendo 
lubrificado pela água. No trecho horizontal o óleo se mantém próximo a parede superior da tubulação devido a sua densidade. Na curva o fluxo de óleo é empurrado para próximo a parede. Pode-se afirmar que houve uma concordância satisfatória tanto para o trecho reto quanto para o trecho curvo.
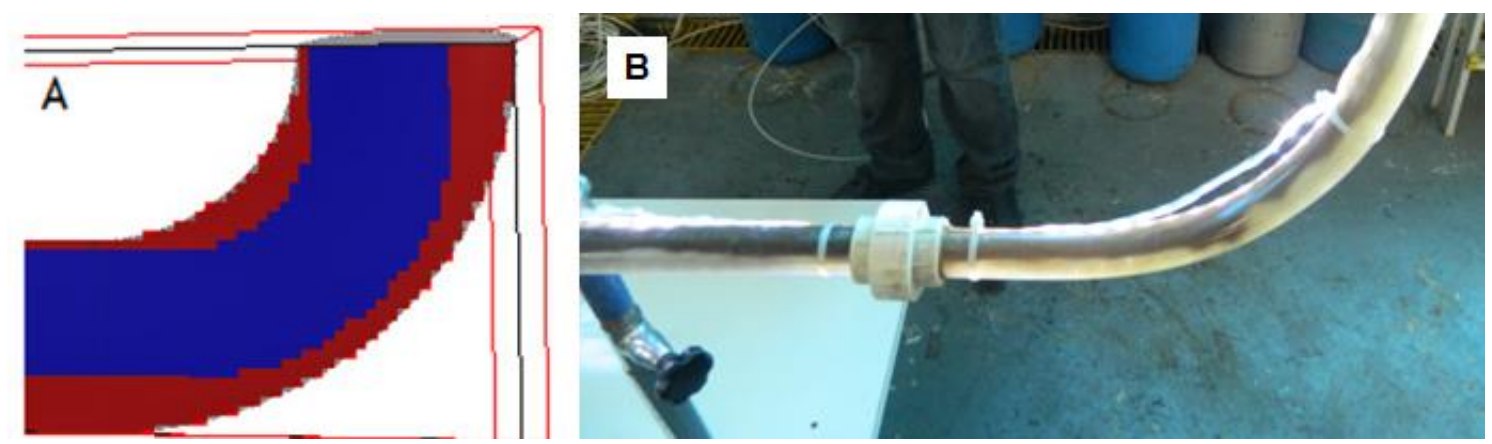

Figura 6.4 - (A) Simulação das densidades na curva; (B) Foto do Trecho Curvo do Equipamento.

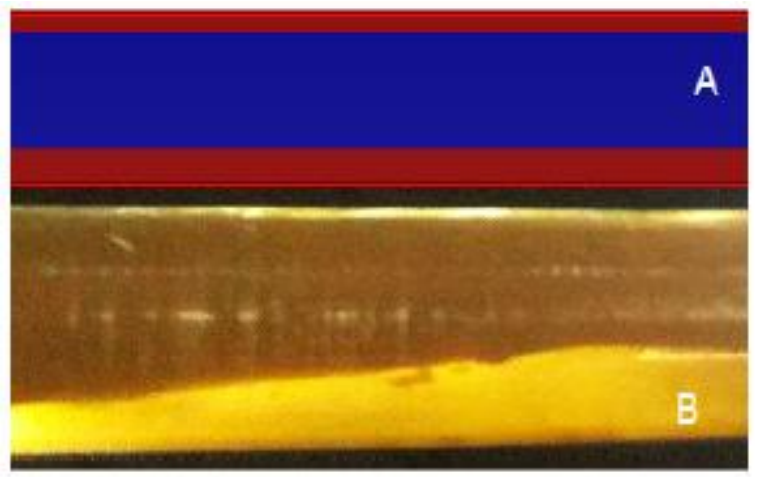

Figura 6.5 - (A) Simulação das densidades no trecho reto; (B) Foto do Escoamento no trecho reto.

\subsection{Simulação do Trecho Completo}

Nesta etapa das simulações foi utilizado o modelo IPSA e Algebraic Slip para a resolução das equações de transporte. Também foram estudados os modelos $\mathrm{K}-\varepsilon$ e $\mathrm{K}-\omega$ para a turbulência.

\subsection{1 - Resultados da simulação para o modelo IPSA}

A Figura 6.6 mostra que foi atingida a convergência na simulação, com os Spot Values constantes e os resíduos diminuindo ao longo do tempo. 


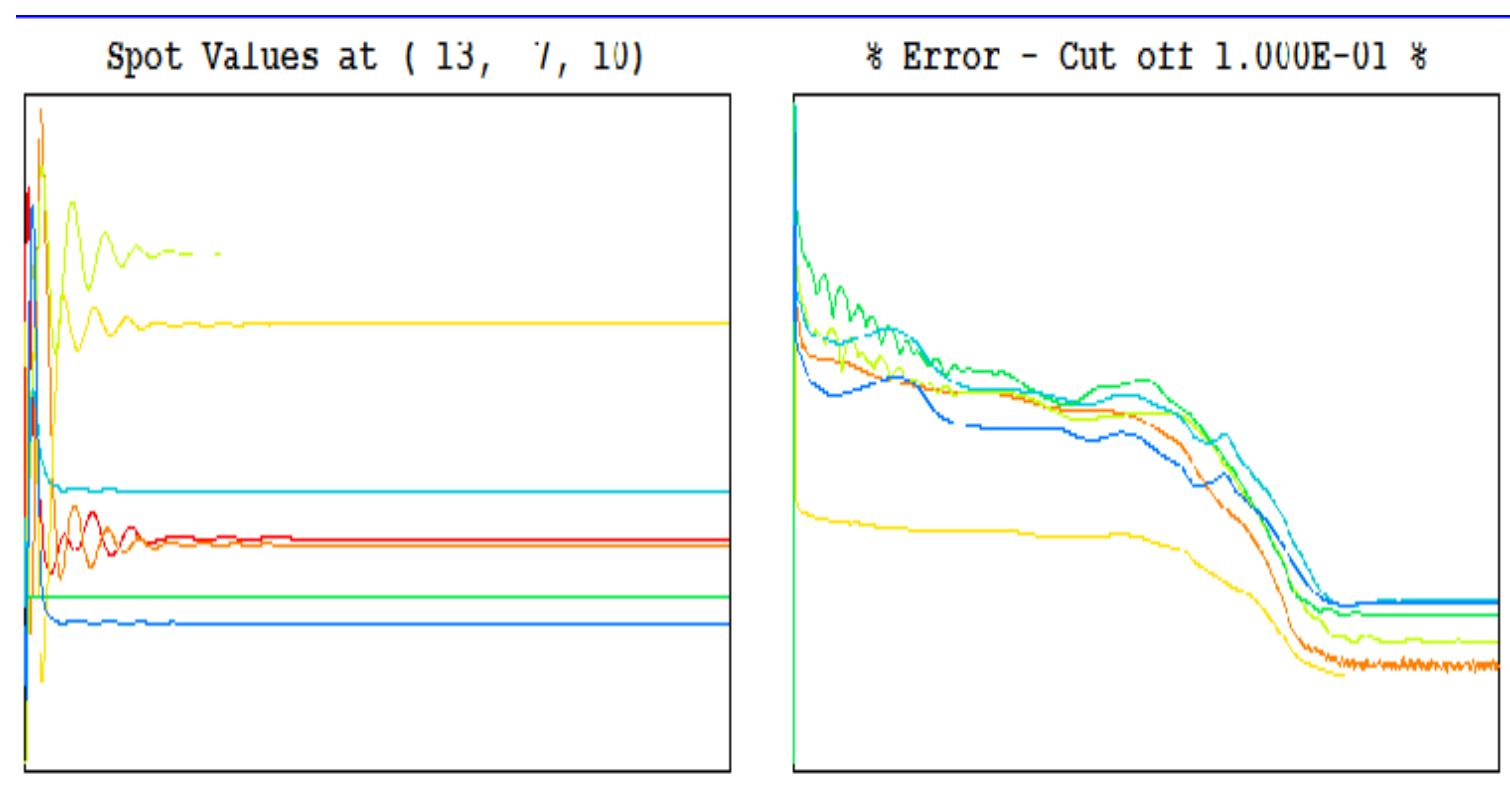

Figura 6.6 - Gráficos de monitoramento da simulação

Os perfis de pressão, velocidade e densidade estão expostos nas figura 6.7, 6.8 e 6.9, respectivamente, mas o modelo não conseguiu prever a deposição e a atomização de gotas como também o movimento da interface. De acordo com Spalding (1996), isso é devido a variações muito rápidas e frequentes que o modelo não é capaz de processar.

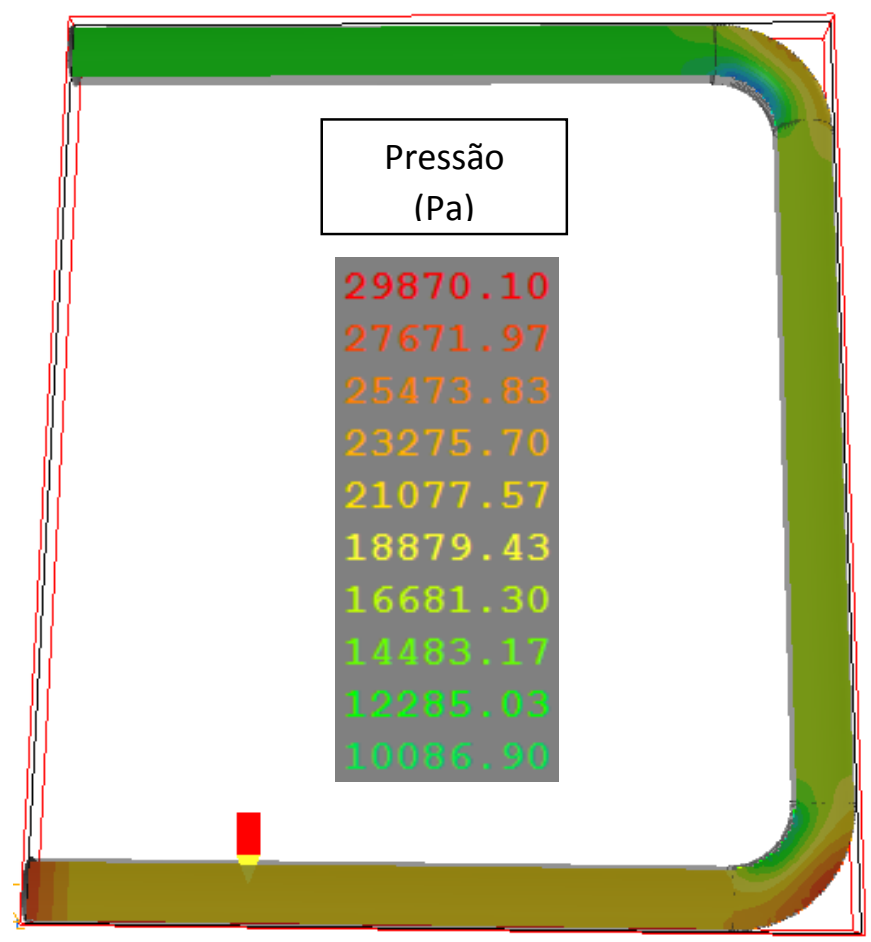

Figura 6.7 - Isosuperfíce de Pressão

É possível observar na Figura 6.7 uma zona de maior pressão nas curvas externas, enquanto há uma zona de menor pressão nas curvas internas. Que são os trechos com maior variação de pressão. 


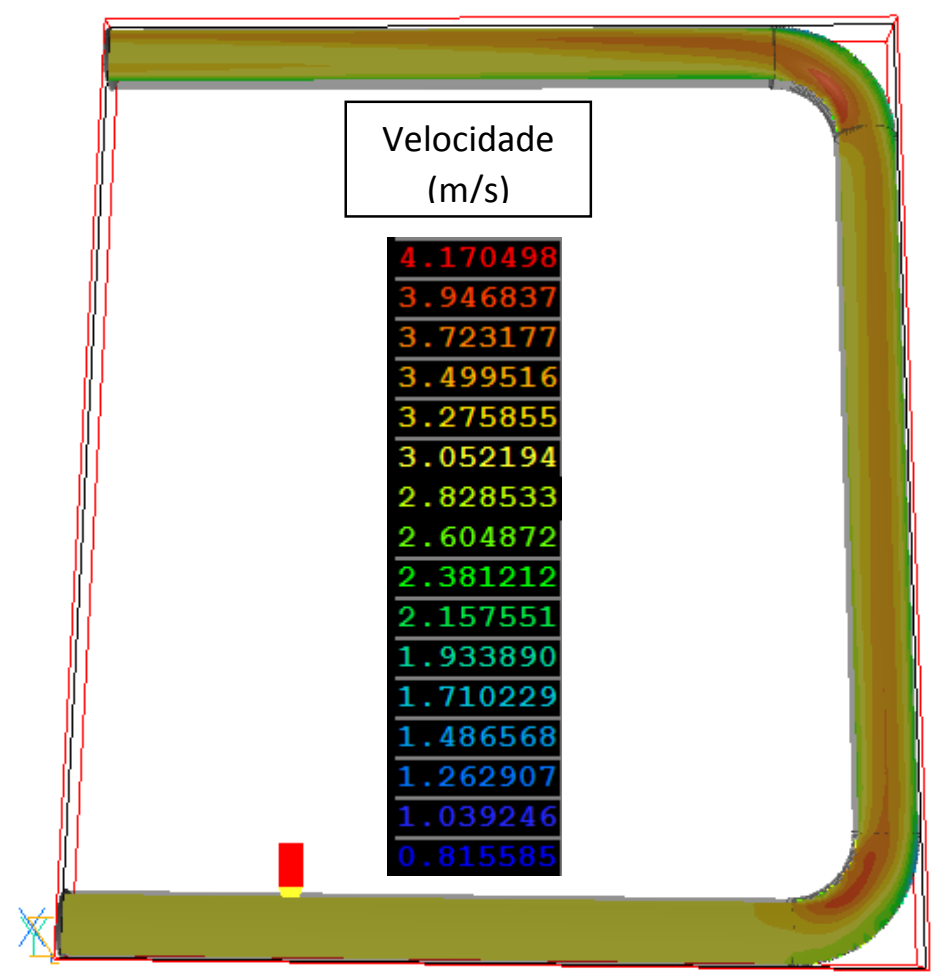

Figura 6.8 - Isosuperfíce de Velocidade

$\mathrm{Na}$ figura 6.8, percebe-se que a velocidade se mantem constante no primeiro trecho horizontal, porém na primeira curva há aumento do seu valor no centro da tubulação, que se mantém constante até o final do escoamento.

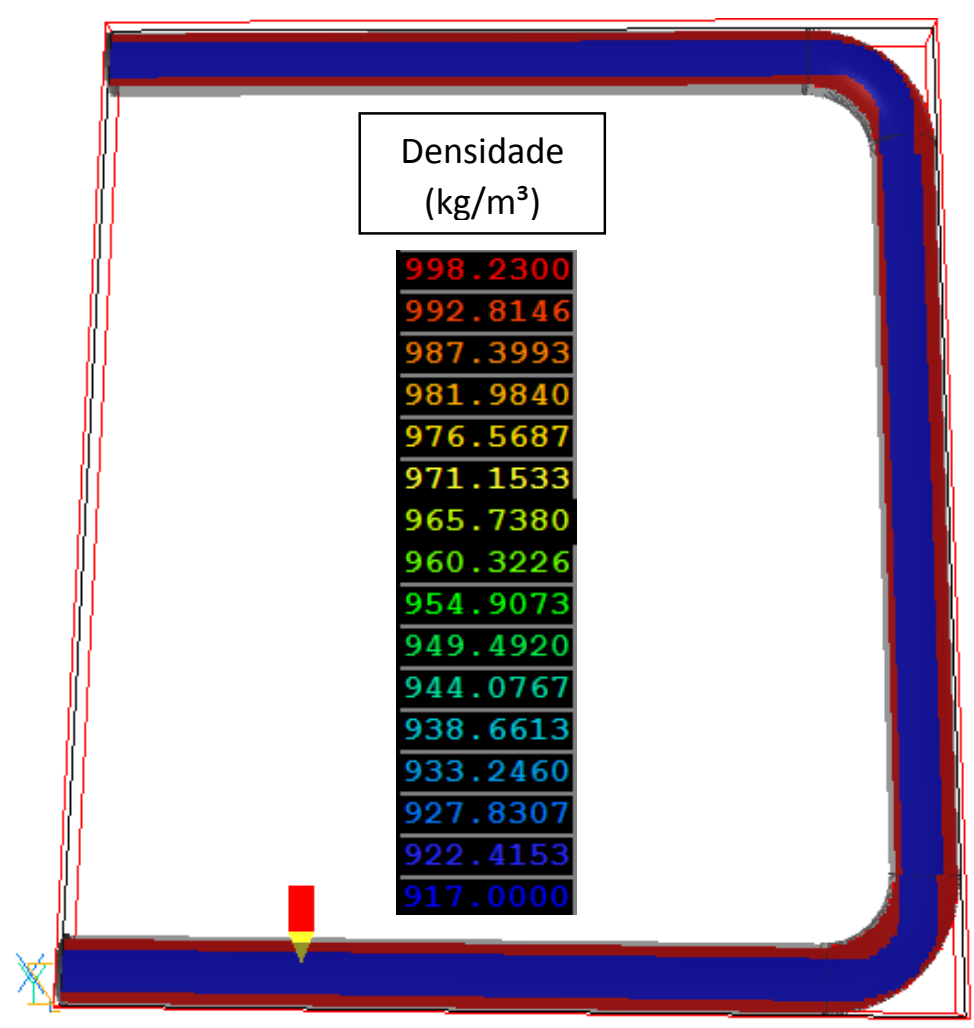

Figura 6.9 - Isosuperfíce de Densidade 
Na figura 6.9 é possível notar a presença de água envolvendo o fluxo de óleo que se mantem no centro da tubulação. Caracterizando o padrão de fluxo anular.

\subsubsection{Resultados da simulação para o modelo Algebraic Slip}

De acordo com a Figura 6.10 é possível observar que os Spot Values tendem a permanecer constantes e que a porcentagem de erro diminui ao longo do tempo, assim como nas simulações anteriores, a simulação atingiu convergência com número de iterações (steps) superior a 1000.
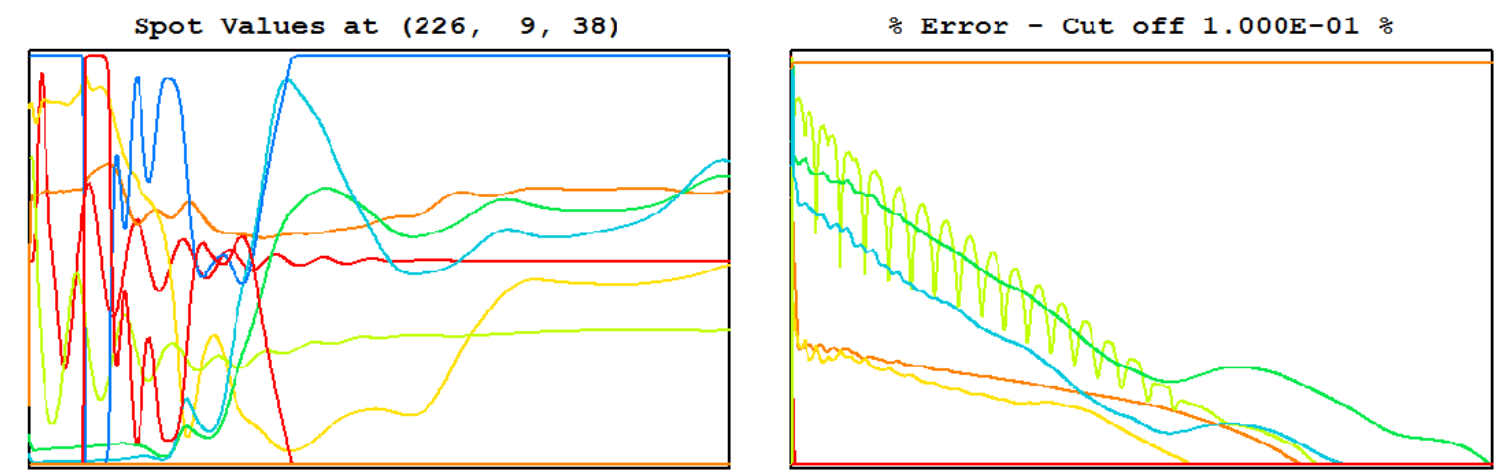

Figura 6.10 - Gráficos de acompanhamento da simulação após 1000 Steps.

Analisando os resíduos do final da simulação, presentes na Tabela 2, considera-se que a convergência foi atingida. Foram estudados os modelos de turbulência $k-\varepsilon$ e $k-\omega$, porém o sistema não atingiu a convergência para 0 segundo modelo, que manteve um residual na ordem de $10^{+1}$ para as velocidades.

Tabela 2 - Resíduos da simulação usando os modelos k- $\varepsilon$ e k- $\omega$

\begin{tabular}{|c|c|c|c|c|c|c|c|}
\hline & P1 & U1 & V1 & W1 & VFOL & K & EP e OM \\
\hline k- $\varepsilon$ & $1,310^{-4}$ & $3,110^{-3}$ & $2,210^{-4}$ & $1,210^{-3}$ & $1,110^{-6}$ & $3,310^{-4}$ & $1,210^{-5}$ \\
\hline k- $\omega$ & $1,310^{-4}$ & $5,610^{+0}$ & $2,310^{+1}$ & $2,610^{+1}$ & $1,110^{-8}$ & $5,810^{-2}$ & $1,610^{+0}$ \\
\hline
\end{tabular}

Analisando o perfil de pressão, presente na Figura 6.11, é possível observar uma grande queda de pressão ao longo da coluna de líquido vertical, enquanto que quase não há variação de pressão ao longo dos tubos horizontais. Quando o fluxo encontra as curvas, há uma redução significativa da pressão.

O perfil no trecho horizontal com curva estudado nas simulações anteriores também foi reproduzido pelas simulações atuais, com resultados semelhantes. 


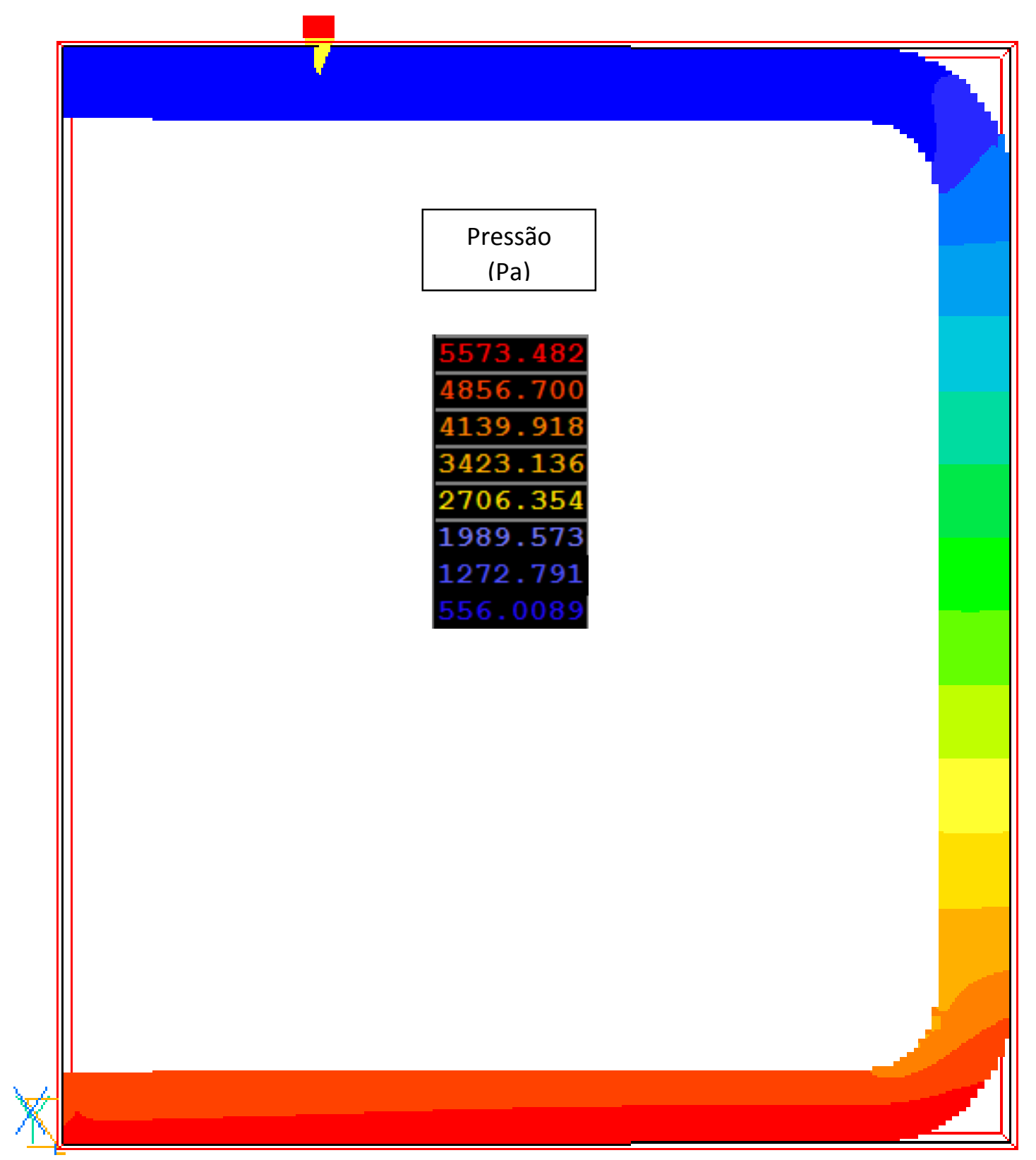

Figura 6.11 - Isosuperfíce de Pressão

No perfil de velocidades, exibido na Figura 6.12, tem-se que a velocidade de entrada é de aproximadamente $2,8 \mathrm{~m} / \mathrm{s}$ para o óleo. Este valor vai sendo reduzido até permanecer praticamente constante em $2,0 \mathrm{~m} / \mathrm{s}$ no centro da tubulação até a segunda curva, onde o intervalo de maior velocidade está na parte superior do duto com aproximadamente $2,5 \mathrm{~m} / \mathrm{s}$ e a de menor velocidade na parte inferior, com $1,8 \mathrm{~m} / \mathrm{s}$. 


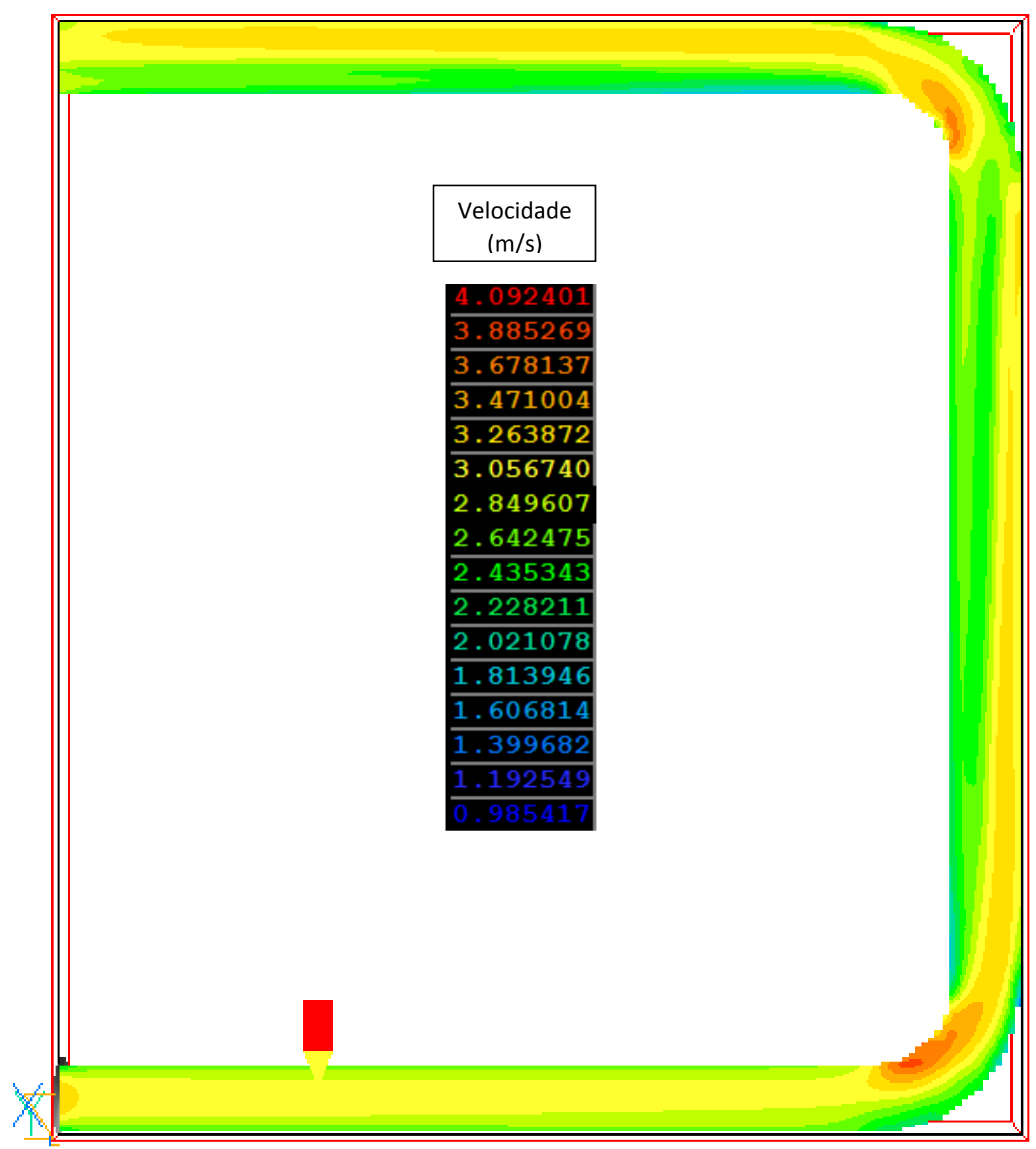

Figura 6.12 - Isosuperfíce de Velocidades

Os gráficos $6.13,6.14,6.15 \mathrm{~A}$ e B onde estão expostas as velocidades em função da distância da origem, para o trecho horizontal de entrada, o trecho vertical e o trecho horizontal de saída (parte superior e inferior), respectivamente, apresentam tais afirmações mais claramente. 


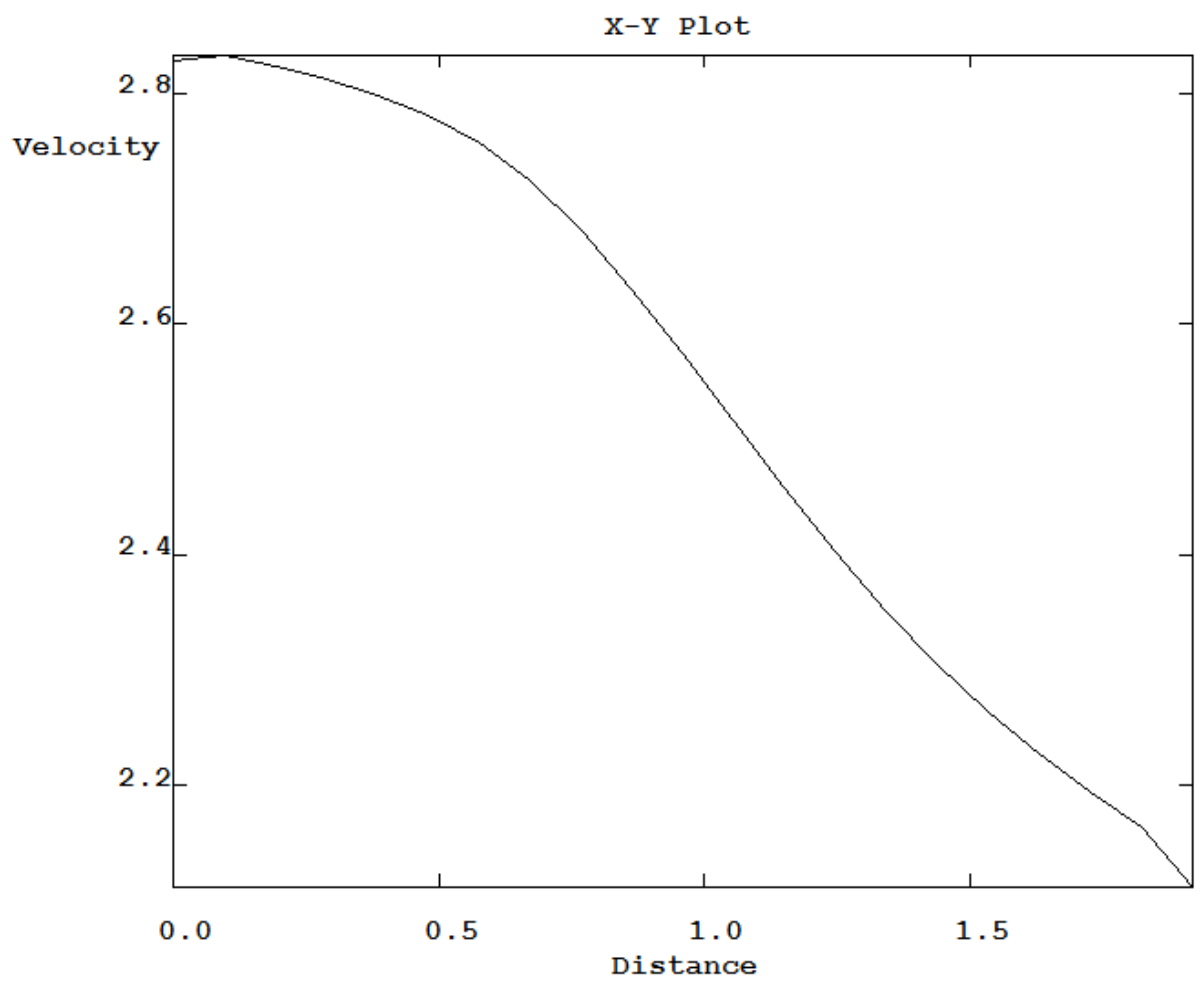

Figura 6.13 - Primeiro Trecho Horizontal

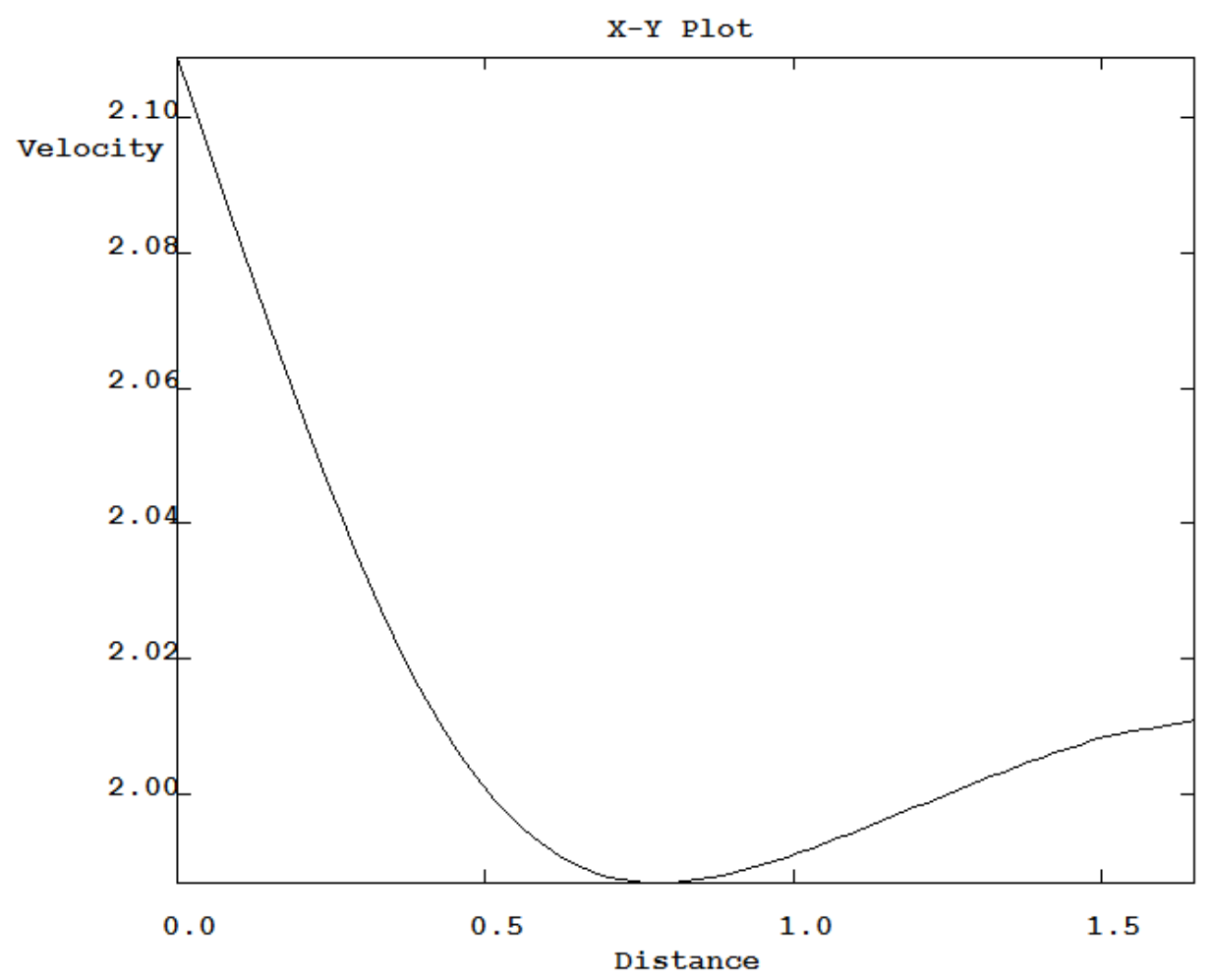

Figura 6.14 - Trecho Vertical 

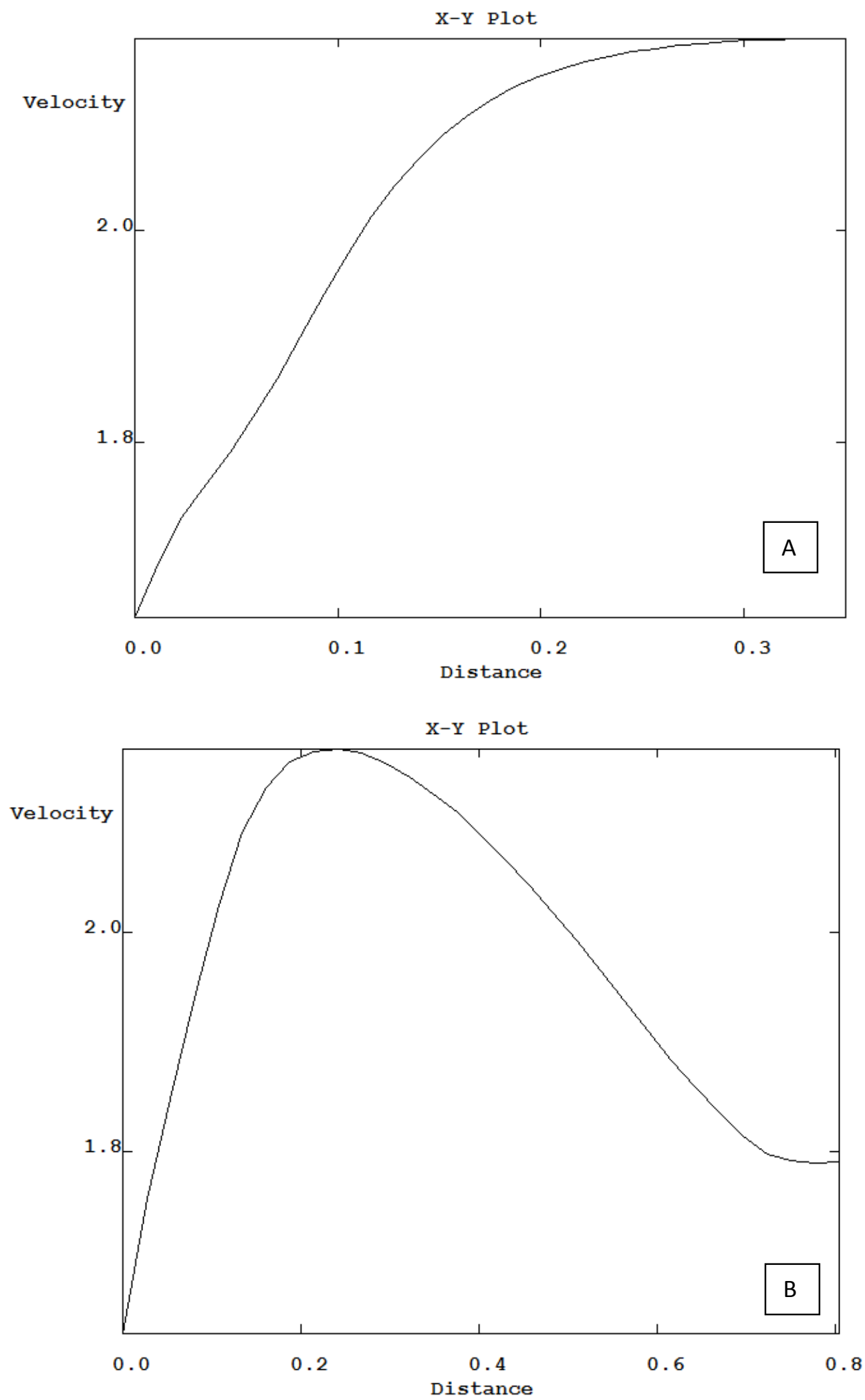

Figura 6.15 - (A) Trecho Horizontal Superior; (B) - Trecho Horizontal Inferior

Do perfil de densidades (Figura 6.16) é possível observar que o óleo (coloração vermelha) tende se concentrar no centro da tubulação vertical e a 
água ao seu redor (coloração azul), enquanto que para os trechos horizontais ele possui um perfil estratificado, com o óleo na parte superior.

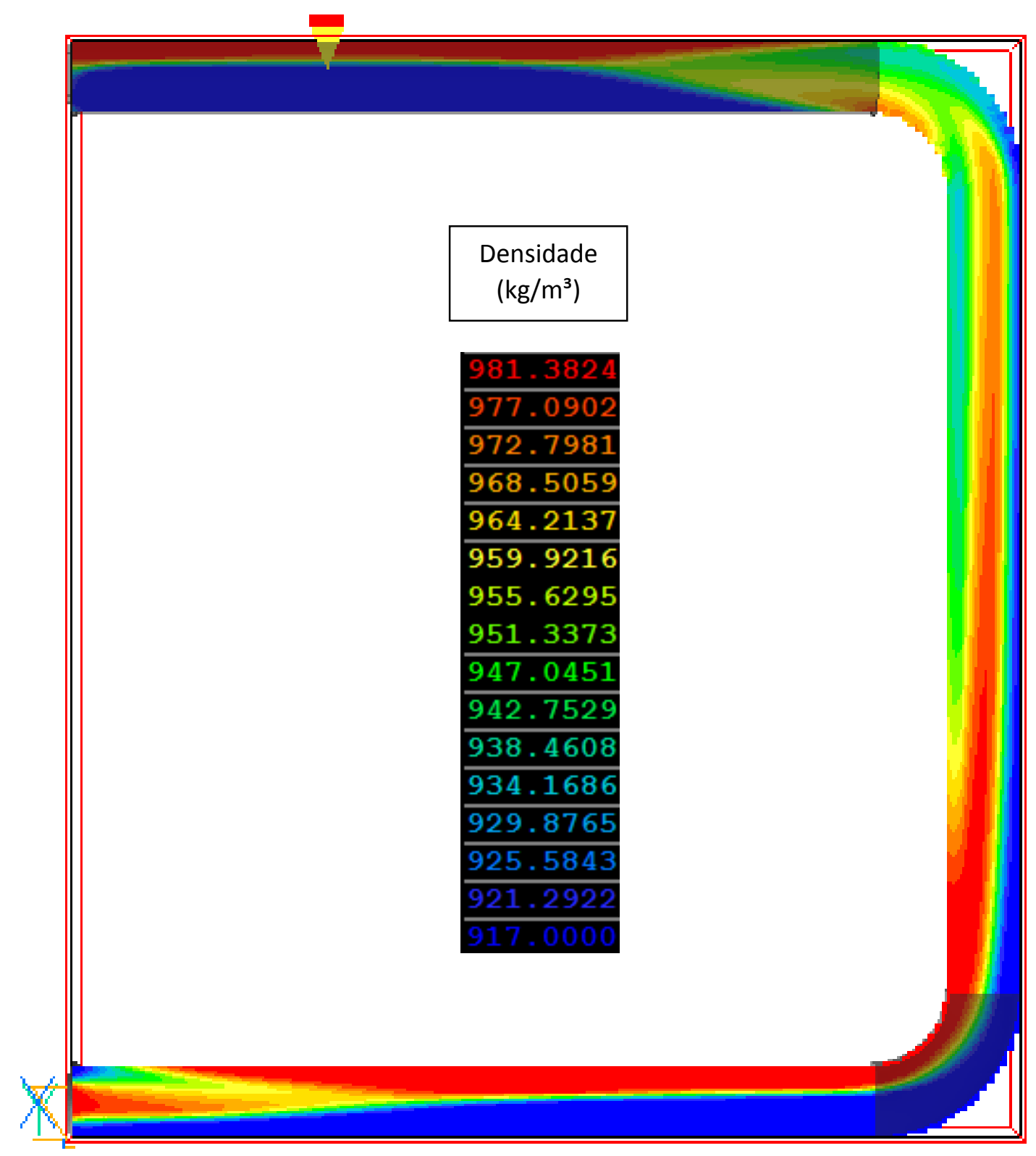

Figura 6.16 - Isosuperfíce de densidade

Estudando o sistema transiente com um tempo inicial em 12 s e tempo final em 20s (Figura 6.17), é possível observar o desprendimento do óleo na parede a partir de 14 segundos, onde vai se deformando até $18 \mathrm{~s}$, onde mantém o perfil praticamente constante. Também, de acordo com a Figura 6.17 é possível observar que a velocidade mais alta do sistema se encontra na entrada de óleo e na curva, onde começa a ocorrer o desprendimento e a redução da velocidade. 


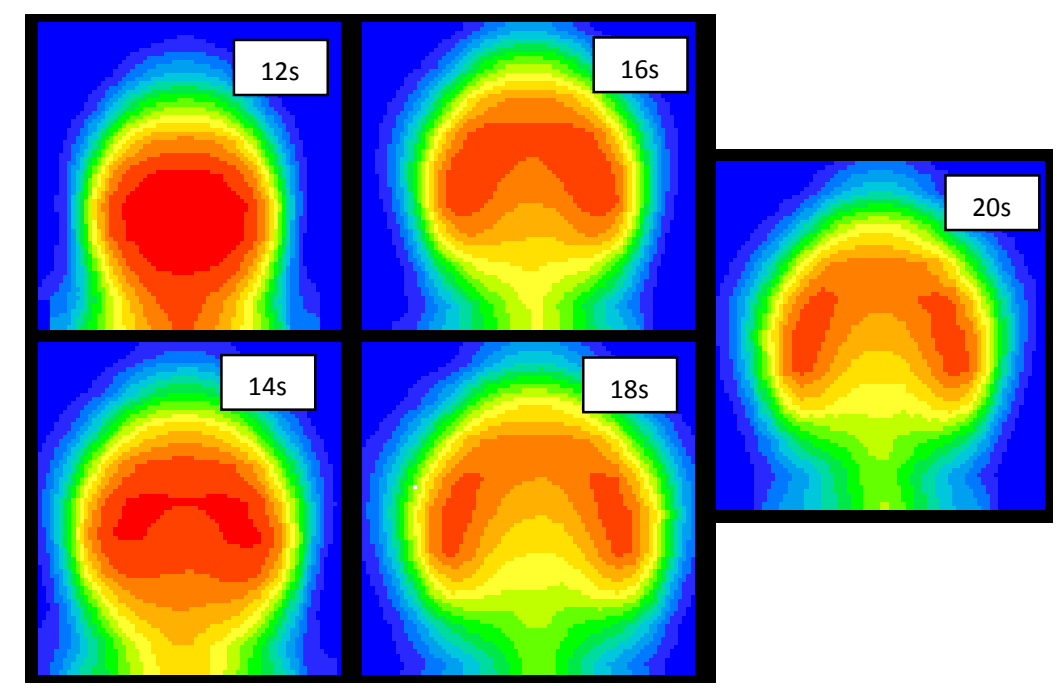

Figura 6.17 - Vista do eixo $X$ do tubo vertical em diferente instantes

Com o corte no eixo X da Figura 6.17, é possível observar que o fluxo de óleo não é puro, há a entrada de partículas de água no seu interior, devido ao processo de atomização e deposição de gotas, apresentado por Rosa (2012).

Observando o perfil de velocidade (Figura 6.18) para o modelo de turbulência K- $\omega$, é possível observar alguma semelhança no primeiro trecho da simulação, porém as imagens diferem para a segunda curva.

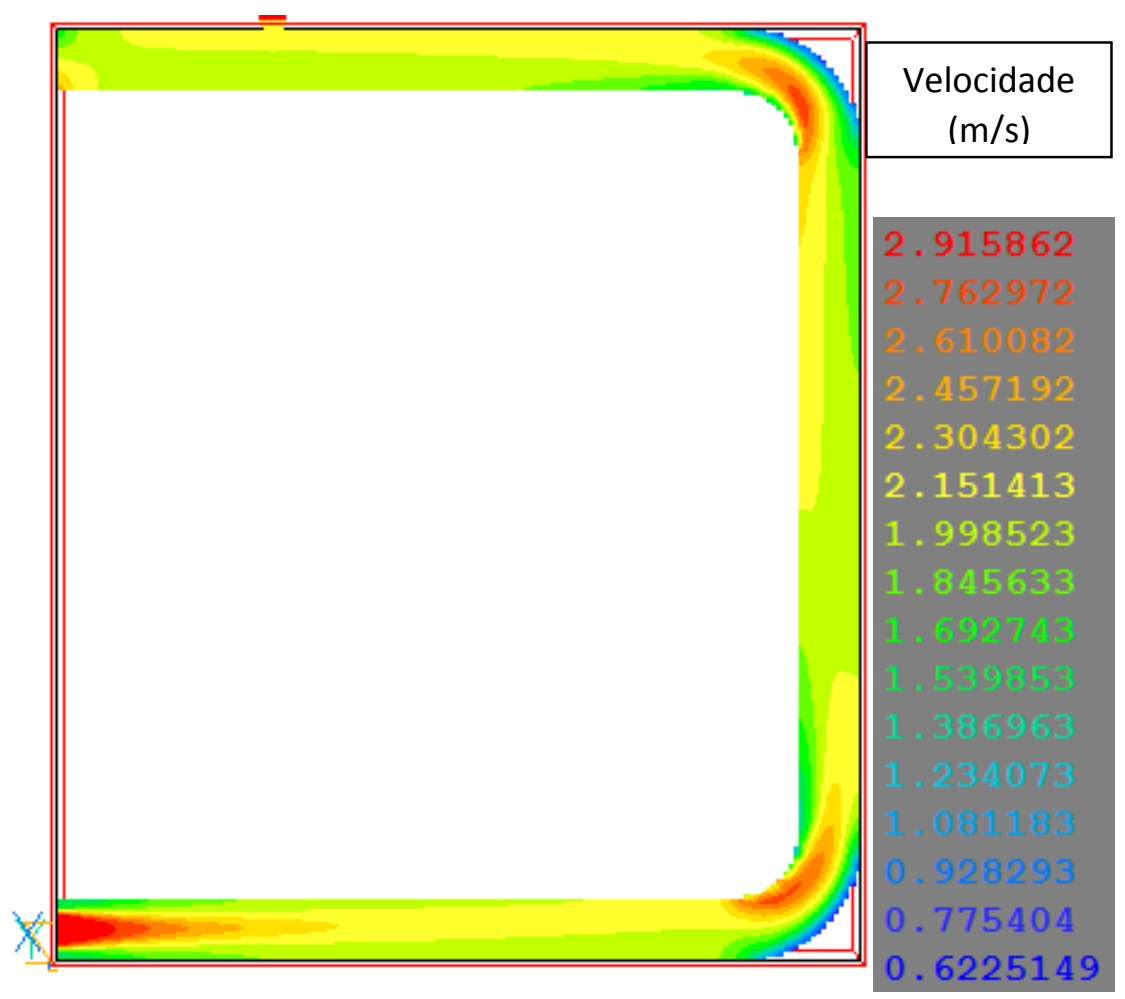

Figura 6.18 - Isosuperfíce de velocidades

O campo de pressão (Figura 6.19) aparenta estar consistente com a realidade, onde o fluido escoa no sentindo da zona de menor pressão, e também mostrando uma queda de pressão com variação constante ao longo da coluna vertical de líquido. 


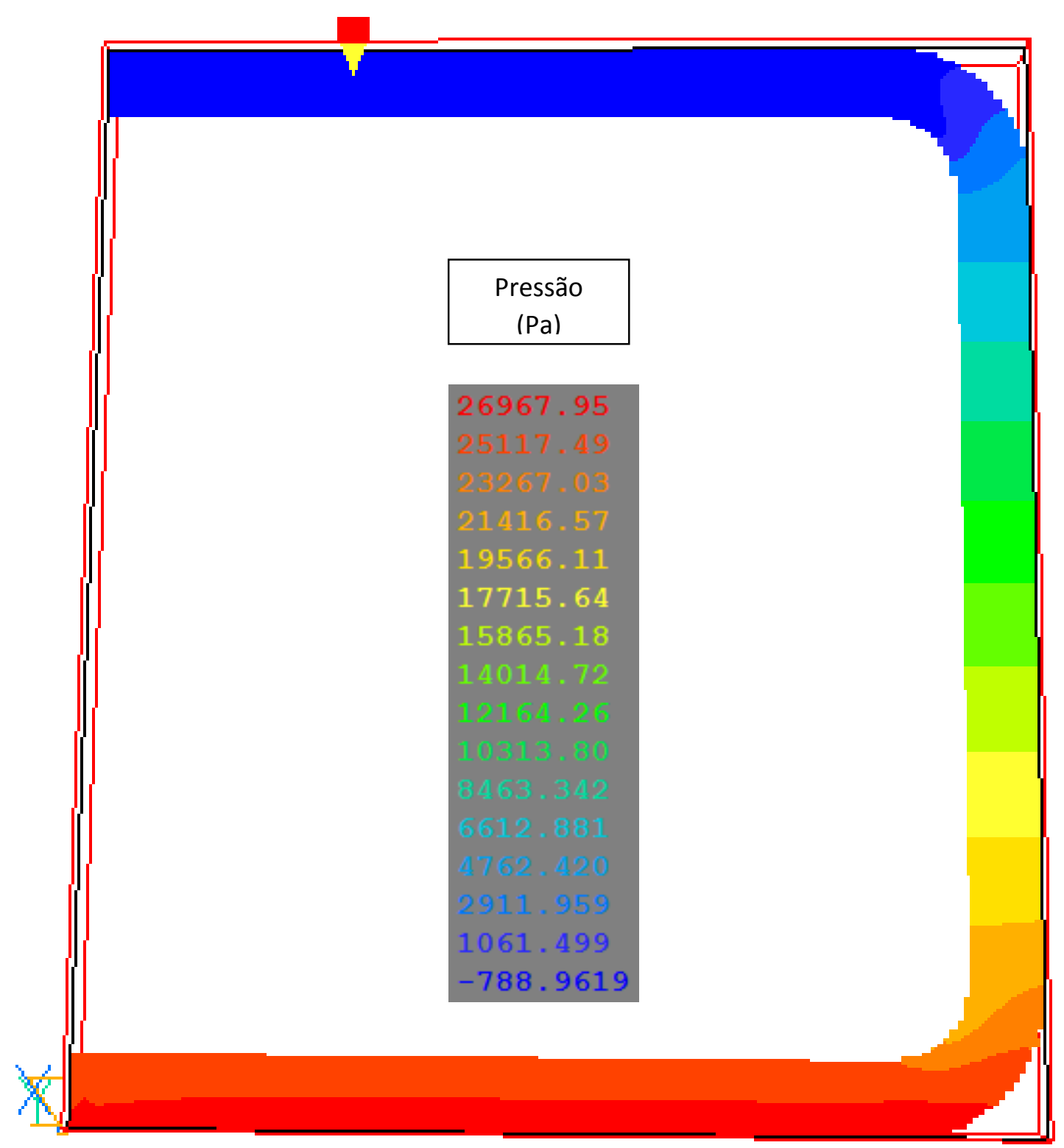

Figura 6.19 - Isosuperfíce de pressão

No perfil de densidade (Figura 6.20) o óleo manteve-se estratificado até o final do escoamento. Portanto, as condições operacionais analisadas mantém a forma estratificada, que favorece a redução de perda de carga. 


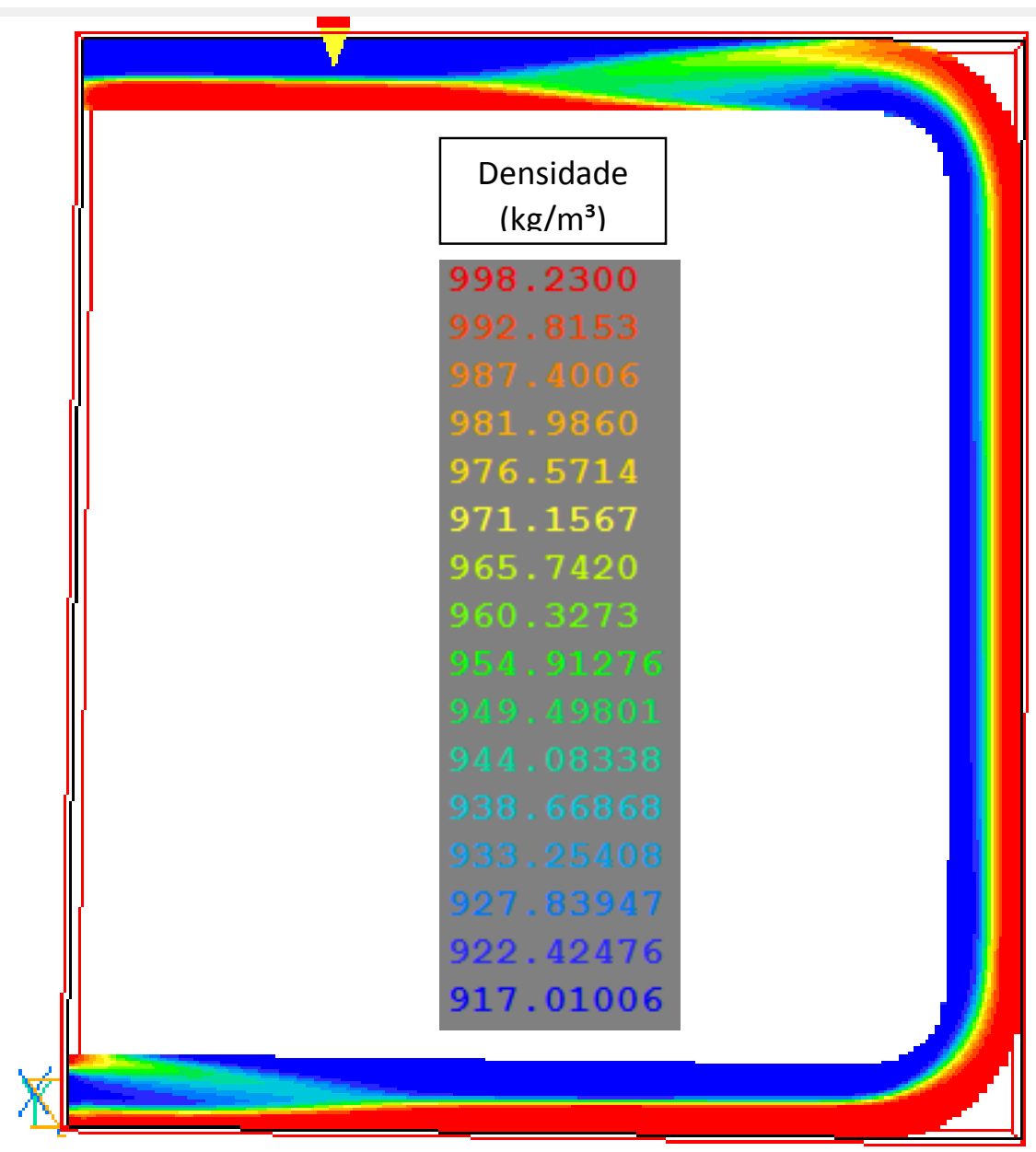

Figura 6.20 - Isosuperfíce de densidade

Devido a grande diferença entre os perfis de ambos os modelos, é necessário um estudo em cima da unidade piloto, para observar qual melhor representa o fenômeno.

\subsubsection{Estudo da perda de carga}

Estudos como o de Farias (2013) e o de Prada (1999) mostram que a técnica de escoar água pela parede e óleo no centro da tubulação leva a redução significativa da perda de carga em comparação com o escoamento monofásico de óleo. Com o objetivo de observar esse fenômeno, as simulações acima foram comparadas com simulações monofásicas que estão expostas abaixo.

As simulações para o fluxo monofásico de óleo utilizaram o modelo ONEPHASE e apresentaram um campo residual com ordens inferiores a $10^{-3}$ como pode ser visto na Tabela 3 para o modelo de turbulência $\mathrm{K}-\varepsilon$.

Tabela 3 - Resíduos da simulação usando o modelo K- $\varepsilon$

\begin{tabular}{|c|c|c|c|c|c|c|}
\hline & $\mathrm{P} 1$ & $\mathrm{U} 1$ & $\mathrm{~V} 1$ & $\mathrm{~W} 1$ & $\mathrm{~K}$ & $\mathrm{EP}$ \\
\hline $\mathrm{k}-\varepsilon$ & $7,510^{-3}$ & $3,110^{-3}$ & $3,710^{-3}$ & $3,210^{-3}$ & $1,410^{-6}$ & $1,110^{-5}$ \\
\hline
\end{tabular}


O campo de velocidade (Figura 6.21) se mantém praticamente constante em $1 \mathrm{~m} / \mathrm{s}$, com pequenas variações nas curvas onde é reduzido para $0,8 \mathrm{~m} / \mathrm{s}$.

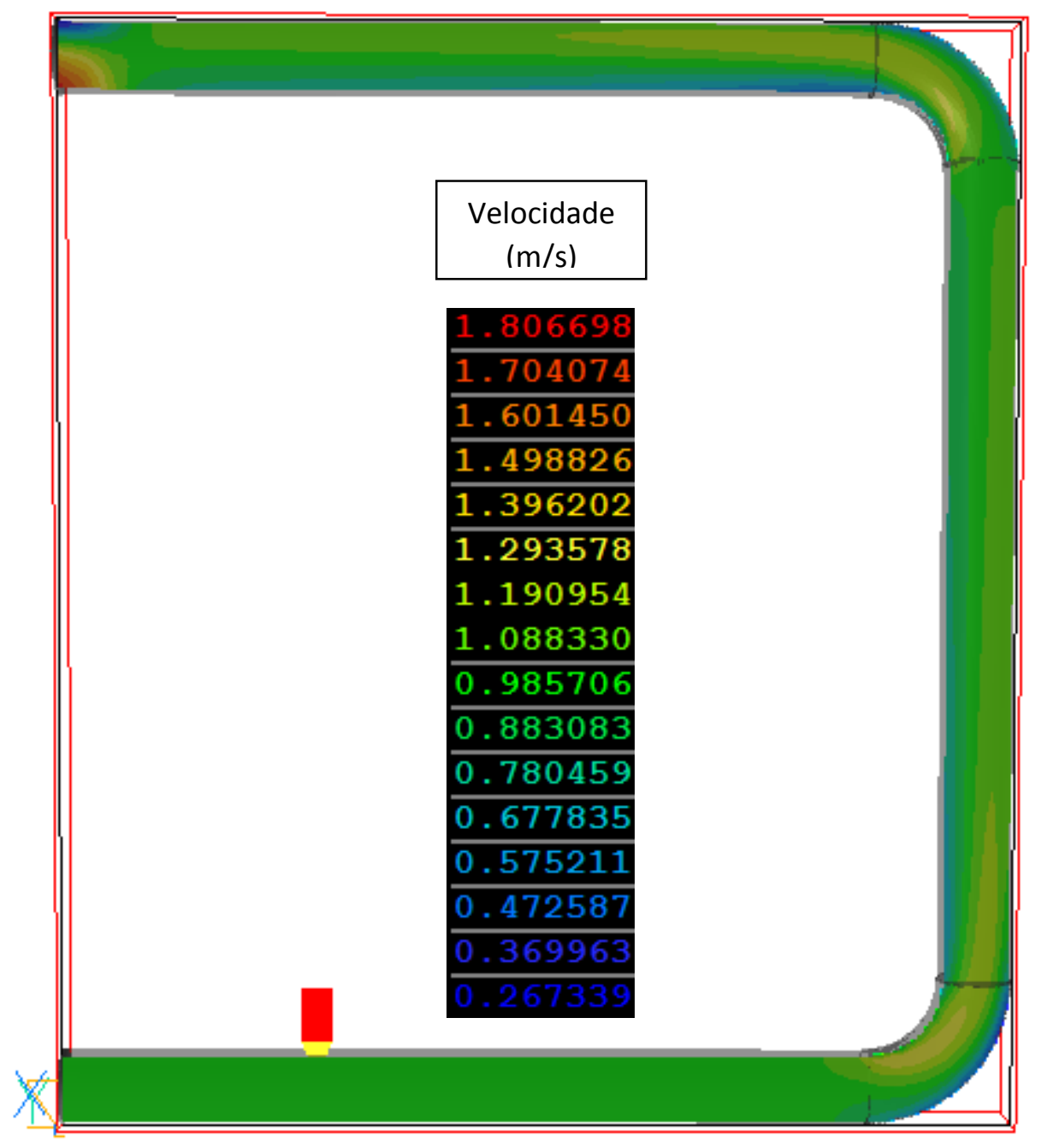

Figura 6.21 - Isosuperfíce de Velocidade

Estudando o campo de pressão de uma forma mais detalhada, é possível observar na Figura 6.20 que se tem uma pressão na saída de $1.317 \mathrm{~Pa}$ e na entrada de $25.011 \mathrm{~Pa}$, resultando em uma queda de pressão de $23694 \mathrm{~Pa}$. A maior região de variação está na coluna de líquido, assim como nas simulações monofásicas. Comparando a Figura $6.22 \mathrm{com}$ um perfil de pressão mais detalhado da simulação multifásica, utilizando o modelo Algebraic Slip e o modelo $k-\varepsilon$ para a turbulência (Figura 6.23), é possível observar que a queda de pressão para esse caso é de $5017 \mathrm{~Pa}$. Sendo assim, realmente a perda de carga foi reduzida significativamente como citado no começo deste capítulo. 


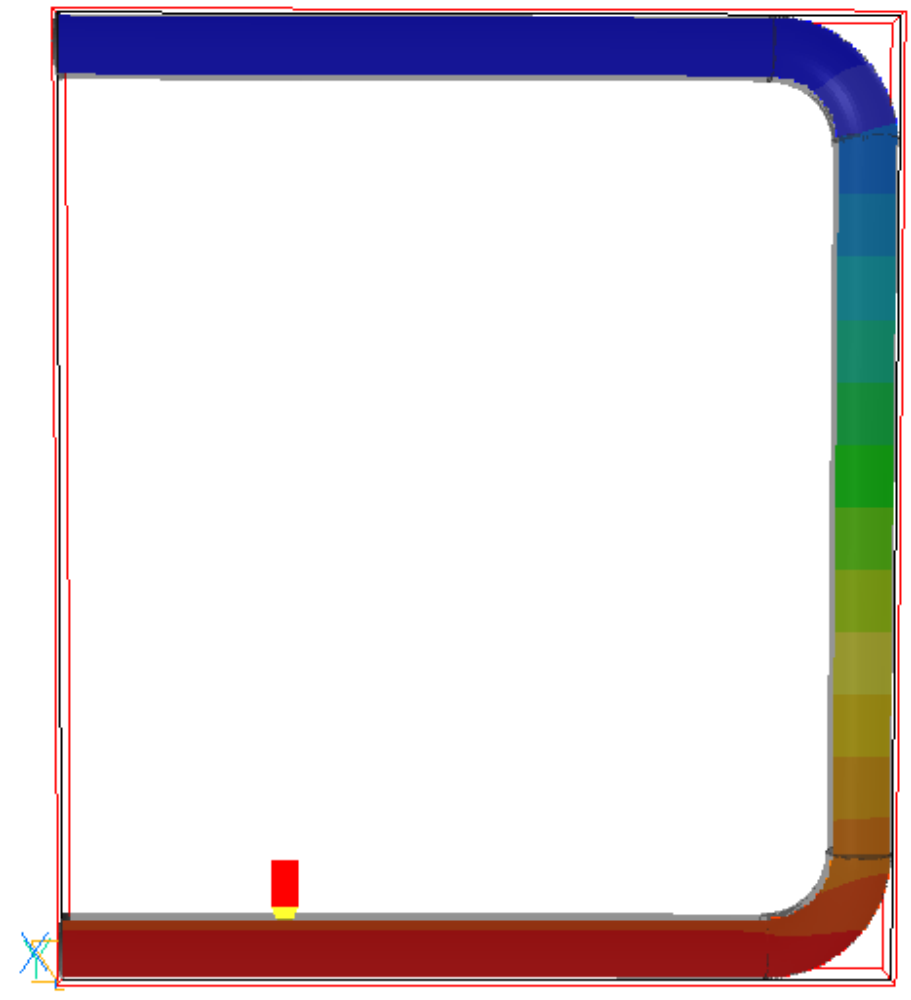

Pressure, $\mathrm{Pa}$

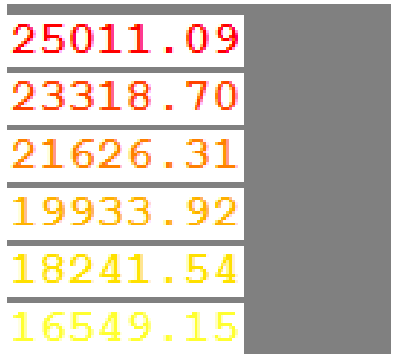

14856.76

\begin{tabular}{l}
$\frac{13164.37}{11471.98}$ \\
\hline 9779.591 \\
\hline 8087.202 \\
\hline 6394.813 \\
\hline 4702.425 \\
\hline 3010.036 \\
\hline$\frac{1317.647}{-374.7415}$
\end{tabular}

Figura 6.22 - Queda de pressão com valores para fluxo de óleo

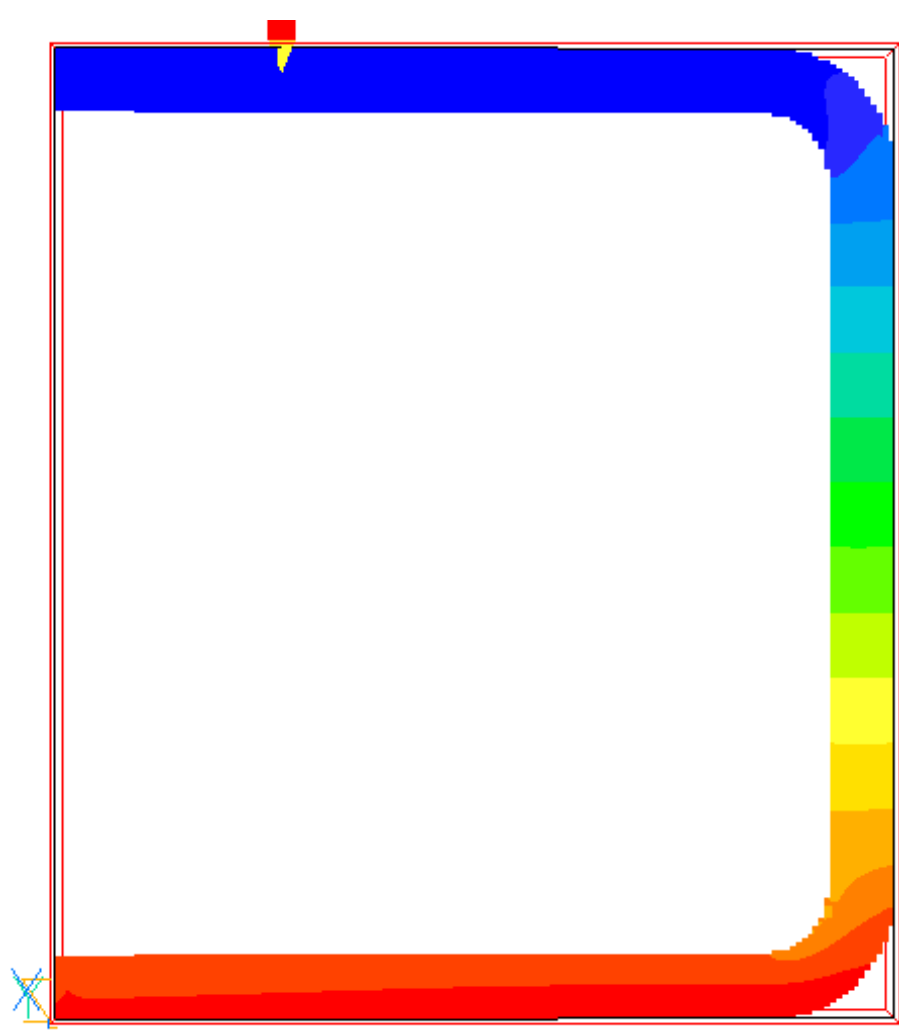

Figura 6.23 - Queda de pressão modelo multifásico 


\subsubsection{Validação Experimental}

A validação experimental foi feita comparando os perfis de densidade com as fotos do equipamento em operação, e é possível observar a semelhança entre ambos. O perfil estratificado está presente nos dutos de entrada e saída (Figura 6.24 e 6.25) e um perfil próximo do Core Annular Flow, porém oscilante, no trecho vertical (Figura 6.28), reproduzindo o que é observado na simulação exposta nas Figuras 6.26 e 6.27 em diferentes ângulos e instantes. Também é conclusivo que o modelo de turbulência $\mathrm{K}-\omega$ não conseguiu prever o perfil de escoamento, talvez devido a sua alta sensibilidade as variações em regiões longe da parede.

A figura 6.27, de forma mais detalhada, prevê o padrão de escoamento transiente em um corte transversal da tubulação vertical ao longo do eixo $X$. $O$ óleo (coloração vermelha), parte em contato com a tubulação, quando a partir de 14 segundos de operação, ele se desprende da parede e começa a se deformar. Atingindo 20 segundos de operação, o óleo começa a retornar ao estado apresentado em $16 \mathrm{~s}$, esse processo é repetido durante todo o escoamento no trecho vertical com pequenas variações. A observação do mesmo trecho, através da unidade experimental (figura 6.28), apresenta que o escoamento se deforma ao longo da tubulação no mesmo padrão previsto pela simulação.

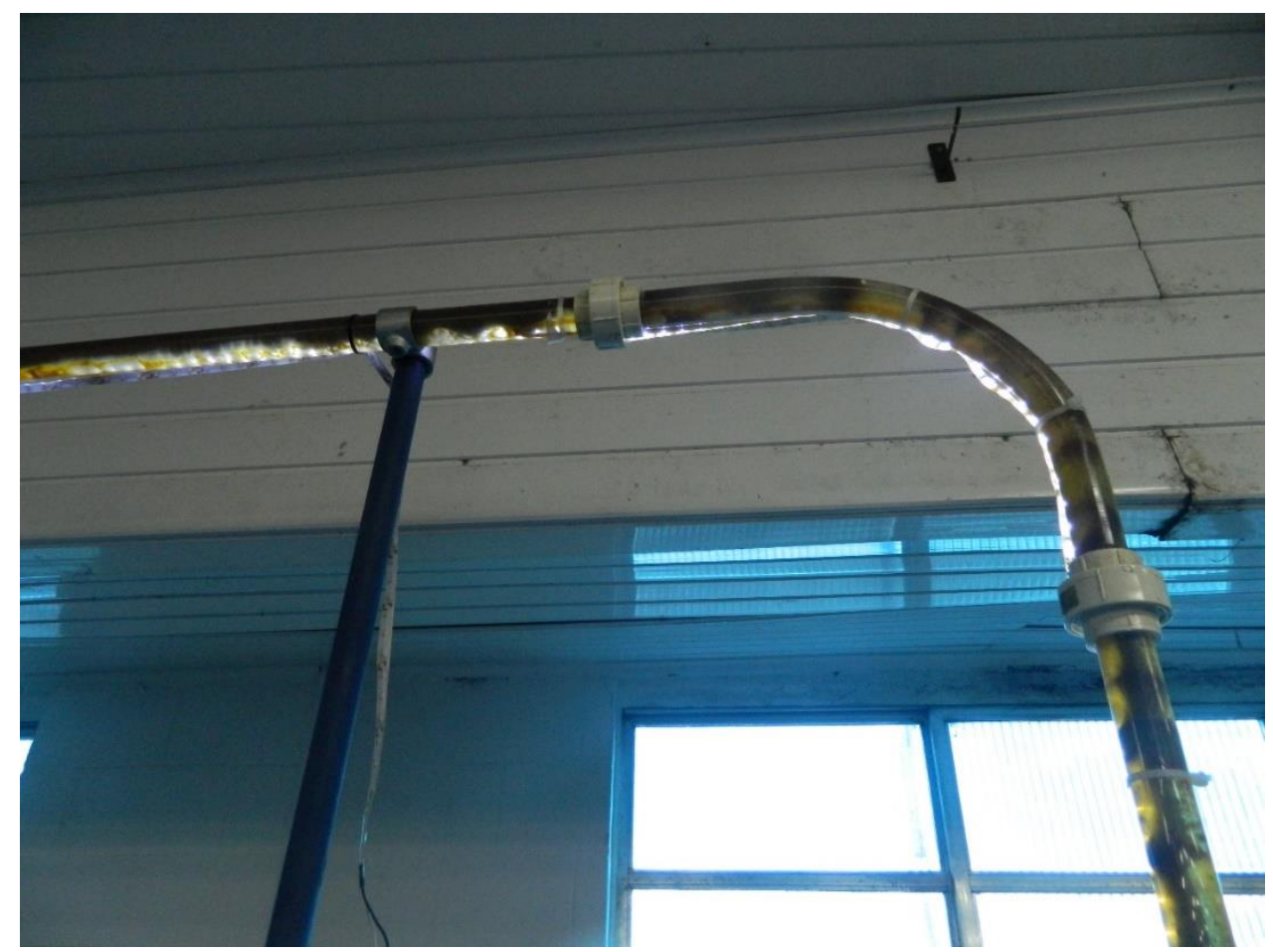

Figura 6.24 - Curva e trecho horizontal superior 


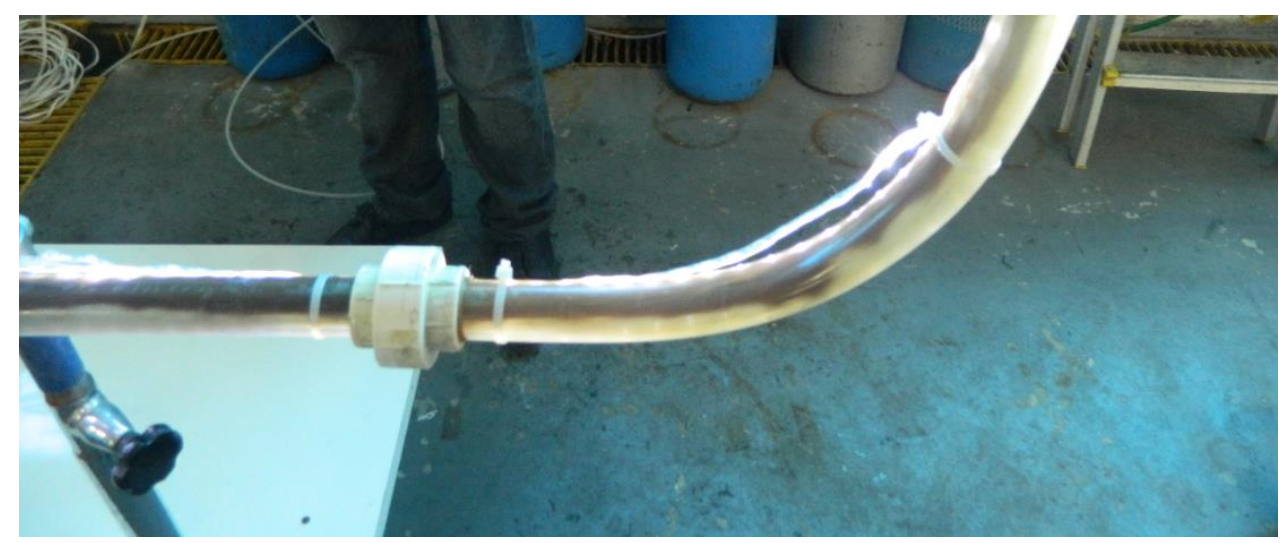

Figura 6.25 - Curva Inferior

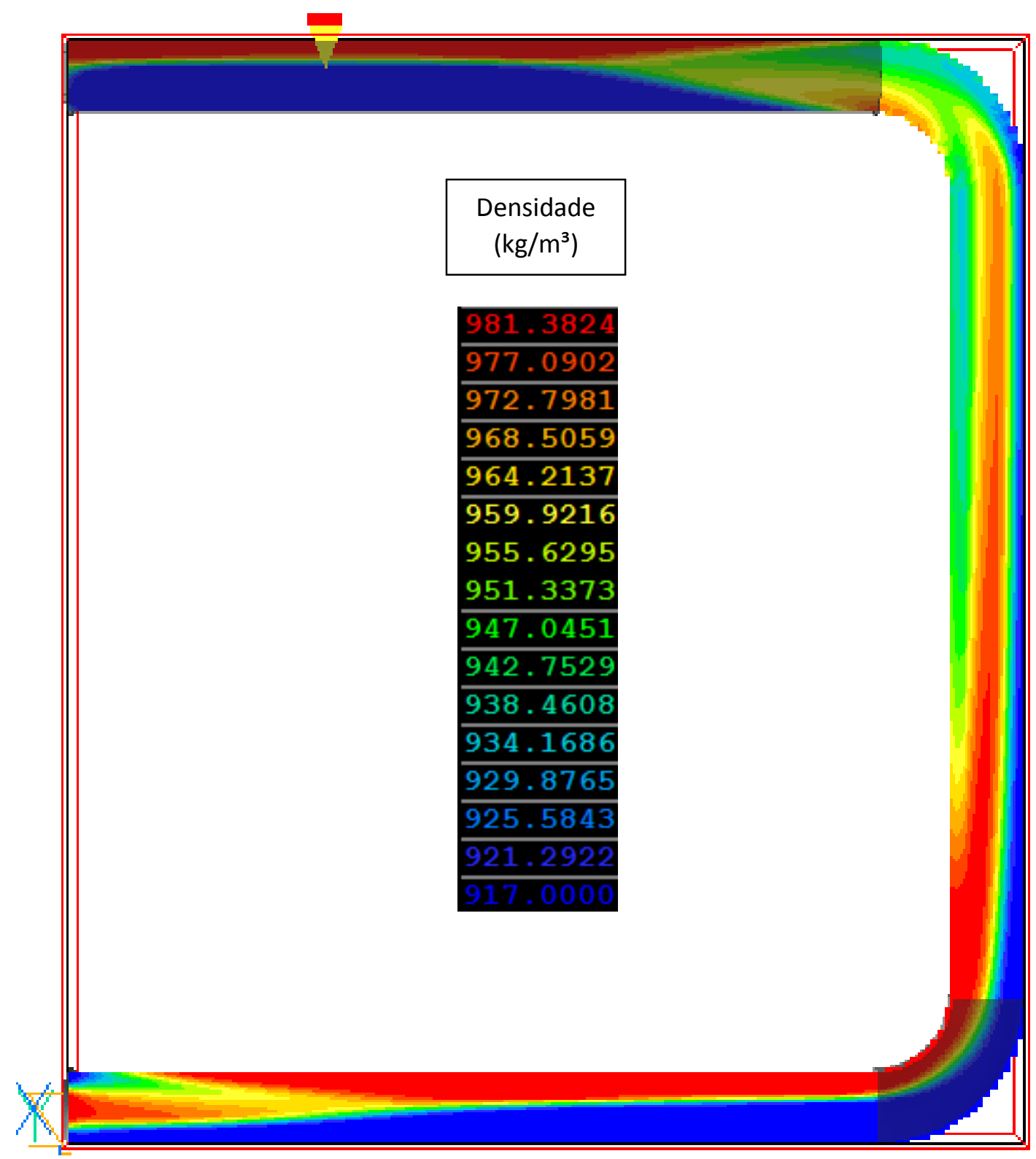

Figura 6.26 - Isosuperfíce de densidade 


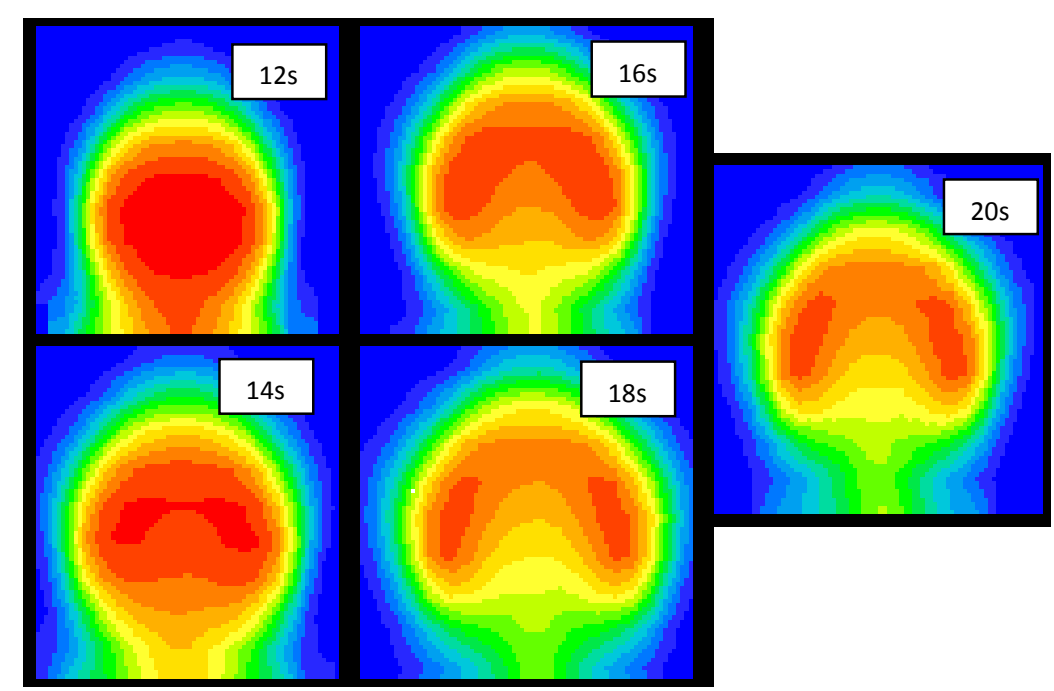

Figure 6.27 - Vista do eixo X do tubo vertical em diferente instantes

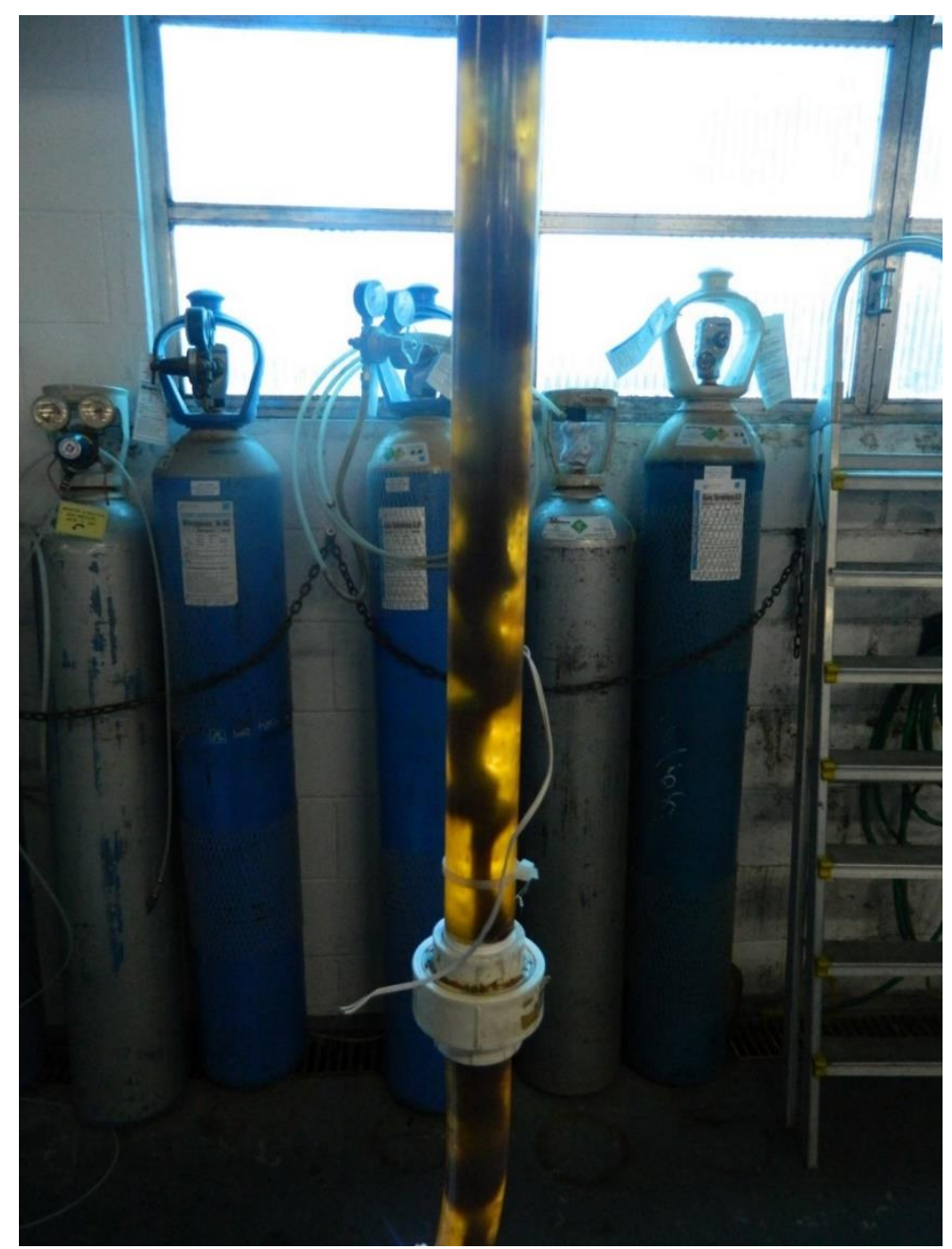

Figura 6.28 - Tubo vertical em operação 
6.2.5 Linhas de fluxo para o perfil validado

Gerando as linhas de fluxo a partir do eixo X e Y (Figura 6.28) para o perfil validado, é possível perceber uma região onde há a formação de vórtice, possivelmente gerado pela ação da diferença de densidade (Figura 6.28B), onde o óleo tende a permanecer na parte superior da tubulação e a água na parte inferior. Também é perceptível uma e somente uma rotação no fluxo ao passar pela segunda curva (Figura 6.28A), que também pode ser ocasionada devido a tendência do óleo de permanecer no topo da tubulação. 


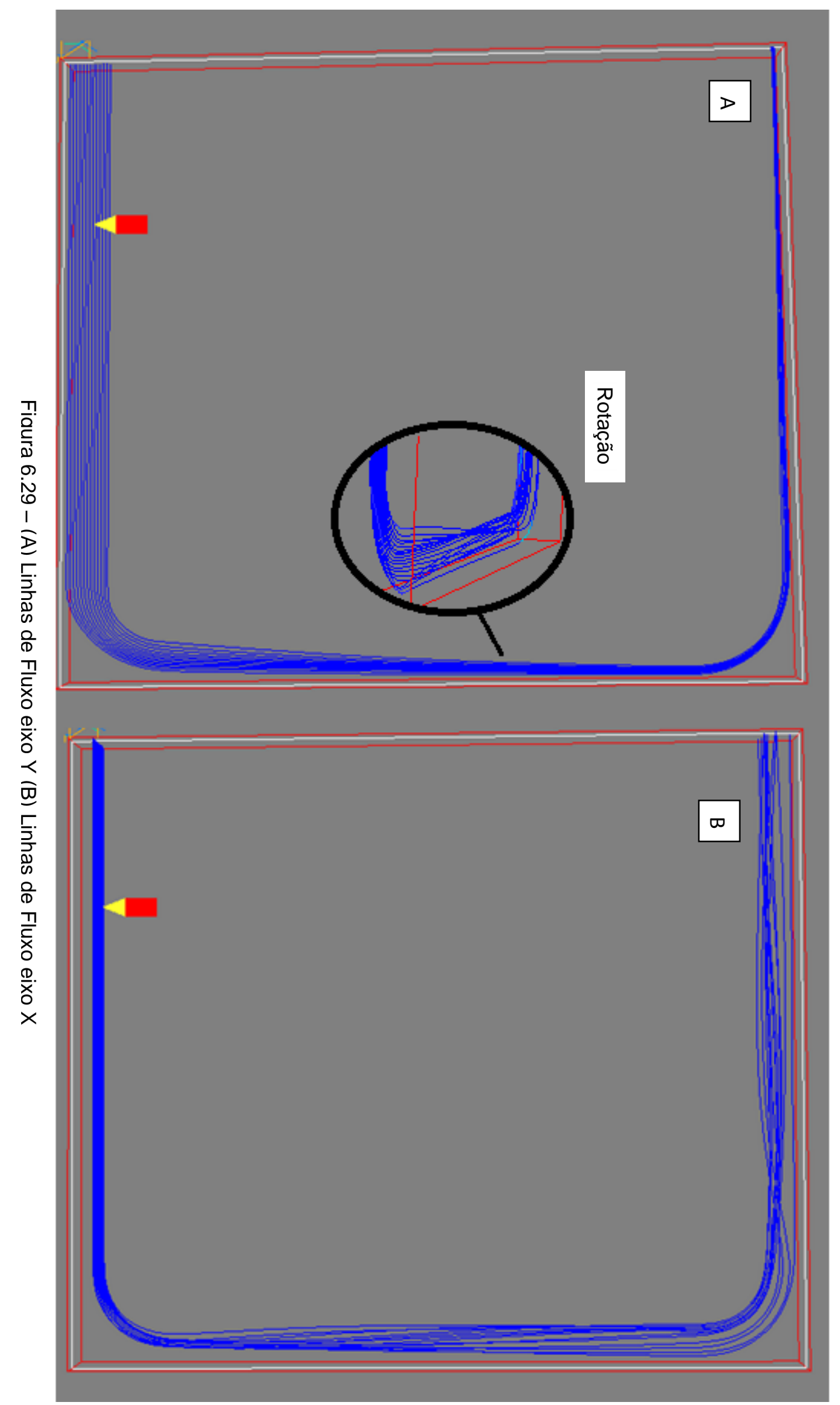




\section{Conclusões e Sugestões}

\subsection{Conclusões}

O trabalho permitiu concluir que:

a) Um campo residual com ordem de $10^{-3}$ indica que bons resultados foram obtidos para a convergência numérica;

b) O melhor modelo para o fenômeno estudado foi o Algebraic Slip com o modelo de turbulência $\mathrm{K}-\varepsilon$, já que as comparações com as figuras obtidas na unidade experimental mostram uma boa concordância, sendo as simulações consideradas como validadas;

c) O modelo IPSA não foi capaz de processar a deposição e a atomização de gotas como também o movimento da interface, com isso, ele não é o modelo adequado para o estudo do processo;

d) O modelo de turbulência K-w em conjunto com o modelo Algebraic Slip, não conseguiram prever o instante em que o óleo se desprende da parede e começa a oscilar. Uma possibilidade disso ter ocorrido é a proximidade das paredes no duto, dificultando assim o cálculo e gerando um campo residual alto;

e) Assim como na literatura, o modelo Algebraic Slip em conjunto com o modelo de turbulência $\mathrm{K}-\varepsilon$, conseguiram prever a redução da perda de carga em comparação ao fluxo monofásico de óleo;

f) Comparando os perfis de velocidade para o fluxo monofásico e multifásico, é possível perceber que houve o aumento na velocidade do óleo de $1 \mathrm{~m} / \mathrm{s}$ para aproximadamente $2,5 \mathrm{~m} / \mathrm{s}$ respectivamente;

g) A validação pode ser tida como preliminar. Apesar de ter sido validado o campo de pressão e o perfil de densidade, não foi possível obter valores experimentais para o perfil de velocidade. Mesmo assim a observação do fenômeno foi decisiva para a escolha de modelos de turbulência e de resolução de equações de transporte. 


\subsection{Sugestões}

Com o objetivo da continuidade da linha de pesquisa, é sugerido:

a) Realizar a modelagem computacional do bombeamento do equipamento em CFD;

b) Desenvolver um método para a coleta da velocidade das fases;

c) Desenvolver um método para a coleta de pressão em diferentes trechos;

d) Avaliar um injetor que tem a possibilidade de inserção de uma terceira fase gasosa para o estudo do escoamento trifásico;

e) Desenvolver equações empíricas na unidade de bancada para se prever o tipo de escoamento e a perda de carga no sistema. 


\section{Referências}

- ANGELI, P.; HEWITT, G. F.. Flow structure in horizontal oil-water flow. International Journal Of Multiphase Flow, London, UK, v. 26, p.11171140, nov. 1998.

- ARIRACHAKARAN, S.; OGLESBY, K. D.; MALINOWSKY, M. S.; SHOHAM, O., BRILL, J. P. (1989), "An Analysis of Oil-Water Flow Phenomena in Horizontal Pipes", SPE Production Operations Symposium, Oklahoma, pp. $115-167$.

- BALAKHRISNA, T. et al. Oil water flows through sudden contraction and expansion in a horizontal pipe: phase distribution and pressure drop. International Journal Of Multphase Flow, India, v. 36, p.13-24, 10 ago. 2009.

- BIRD, R. B. et al. Transport Phenomena. New York, Usa: John Miley \& Sons, Inc., 2002.

- DAVIDOV, B. I., On The Statistical Dynamics of an Incomprissible Turbulent Flow. Dokl. Akad. Nauk. SSSR, Vol. 136, pp. 47. 1961.

- Estacio, et al.. Um método Meshless para simulação de escoamento de fluidos em cavidades de moldes.16 POSMEC. 2006

- FARIAS, Irene Silva. Determinação teórica e experimental do ponto de operação de uma unidade de bombeamento com escoamento monofásico e bifásico (água-óleo). 2013. 96 f. Dissertação (Mestrado) - Curso de Engenharia Química, Instituto de Pesquisas Tecnológicas de São Paulo, São Paulo, 2014.

- Fore, L.B., et al.. Interfacial friction in gas-liquid annular flow: analogies to full and transition roughness. International friction in gas-liquid annular flow, Elmsford, v.26, n.11, p. 1755 - 1769, 2000.

- GAO, H. et al. Numerical study of stratified oil-water two-phase turbulent flow in a horizontal tube. International Journal Of Heat And Mass Transfer, Shaanxi Province, China, v. 46, p.749-754, jul. 2003.

- GONÇALVES, Nelson Daniel Ferreira. Método dos volumes finitos em malhas não estruturadas. 2007. 71 f. Dissertação (Mestrado) - Curso de Engenharia Matemática, Universidade do Porto, Portugal, 2007. 
- GOPALA, V. R.. Volume of fluid methods for immiscible-fluid and freesurface flows. Chemical Engineering Journal, Gothenburg, Sweden, v. 141, p.204-221, dez. 2007.

- GOSH, S. et al. Review of oil water core annular flow. Renewable And Sustainable Energy Reviews, India, v. 13, p.1957-1965, ago. 2008.

- GOSH, S. et al. Simulation of core annular flow in return bends: a comprehensive CFD study. Chemical Engineering Research And Design, India, v. 89, n. 89, p.2244-2253, maio 2009.

- HARLOW, F.H., NAKAYAMA P.I. Physics of Fluids: Turbulence Transport Equations., Vol. 10 (7), 2323. 1968.

- Hirt, C. W., Nichols B.. D.Volume of Fluid (VOF) Method. Journal of computational Physics. New Mexico, v. 39, p. 201 - 225, nov. 1981.

- ISAACS, J., SPEED, J. Method of piping fluids. US Patent 759374 , 1904.

- Ishii, M. One-dimensional drif-flux model and constitutive equations for relative motion between phases in various flow regimes. Argonee National Laboratory, p. 47-77, 1977.

- JOSEPH, R., CHEN, K., RENARDY, Y., Core-Annular flows. Annu. Rev. Fluid Mechanics, Vol. 29, pp 65-90, 1997.

- KAUSHIK, V. V. R. et al. CFD simulation of core annular flow through sudden contraction and expansion. Journal Of Petroleum Science And Engineering, India, v. 87, n. 86, p.153-164, 14 maio 2012.

- LAUNDER B. E., SPALDING, D.B. The numerical computation of turbulent flows. Comput. Methods Appl. Mech. Engrg. Vol. 33, pp. $269-289$. 1972.

- WILCOX, D. C., Formulation of the k-omega Turbulence Model Revisited, AIAA Journal, Vol. 46, No. 11. pp. 2823-2838.1988.

- LIU, Y.; LI, W. Z.; QUAN, S. L.. A self-standing two-fluid CFD model for vertical upward two-phase annular flow. Nuclear Engineering And Design, Liaonning Province, China, v. 241, p.1636-1642, 27 jan. 2011.

- LOOMAN MD. 1916. US Patent No. 1,192,438 
- MARINI, Fabio. Simulação de um leito fluidizado aplicando a técnica CFD baseada na teoria cinética do escoamento granular. 2008. $90 \mathrm{f}$. Dissertação (Mestrado) - Curso de Engenharia Química, Universidade Estadual de Campinas, Campinas, 2008.

- MILLER T.F., MILLER D.J., A Fourier analysis of the IPSA/PEA algorithms applied to multiphase flows with mass transfer. Computers and Fluids. v. 32, p. $197-221,2003$.

- MYDLARZ-GABRYK K. et al. Study on oil-water two phase upflow in vertical pipes. International Journal Of Heat And Mass Transfer, Wroclaw, Poland, v. 117, p.28 - 36, 2014.

- OOMS, G.; POURQUIE, M. J. B. M.; POESIO, P..Numerical Study of eccentric core-annular flow. International Journal Of Multphase Flow, Italy, v. 42, p.74-79, fev. 2012.

- PALADINO, Emilio Ernesto. Estudo do Escoamento Multifásico em Medidores de Vazão do tipo Pressão Diferencial. 2001. $90 \mathrm{f}$. Dissertação (Mestrado) - Curso de Engenharia Mecânica, Universidade Federal de Santa Catarina, Florianópolis, 2001.

- PARVARETH, A. et al. CFD and RTD investigations on two-phase flow regimes in vertical and horizontal tubes. International Communications In Heat And Mass Transfer, Iran, v. 27, p.304-311, 16 dez. 2009.

- Pauchon, C. et al. A comprehensive mechanistic model for two-phase flow. $6^{\text {th }}$ International conf. on multiphase production. Cannes: BHR Group Limited, 1993. p. 29 - 50.

- Petrobras. Perfil da Petrobras. Petrobras. 2014. Disponível em: < http://www.petrobras.com.br/pt/quem-somos/perfil/ > Acesso em: $11 \mathrm{de}$ Outubro de 2014.

- PETROBRAS. Plano de Negócios e Gestão. Petrobras. 2014. Disponível em: < http://www.petrobras.com.br/pt/quem-somos/estrategia > Acesso em: 11 de Outubro de 2014

- ROSA, Eugênio S.. Forma diferencial das equações de conservação \& transporte. 2005. 33 f. Notas de Aula. Disponível em: < http://www.fem.unicamp.br/ im450/Textos\&Transparencias/aula-1/ > 
- ROSA, Eugênio S. Aula 13 - Convergency Monotoring and Control. 2010. 50 f. Notas de Aula. Disponível em < http://www.ebah.com.br/content/ABAAAAcQcAC/aula-introdutoria-cfd>. Acesso em: 11 de outubro de 2014.

- ROSA, Eugênio S. Escoamento Multifásico Isotérmico: Modelos de Multifluidos e de Mistura. Porto Alegre: Bookman, 2012.

- RUNCHAL A.K.. Brian Spalding: CFD \& Reality. ICHMT International Symposium on Advances in Computational Heat Transfer. 2008.

- RUSSEL, T.W.F.; HODGSON, G. W.; GOVIER, G. W. Horizontal Pipeline Flow of Mixtures of Oil and Water. The Canadian Journal Of Chemica I Engineering, v. 20, n. 20, p.9-17, Fevereiro 1959.

- SAMPAIO, P. A.B. Modelling of stratified gas-liquid two-phase flow in horizontal circular pipes. International Journal Of Heat And Mass Transfer, Rio de Janeiro, Brasil, v. 51, p.2752-2761, dez. 2008.

- SILVA, L. F. L. R.. Introdução a Fluidodinâmica Computacional: Aplicação em Processos Químicos. 2009. 30 f. Notas de Aula. Disponível em < http://www.ebah.com.br/content/ABAAAAcQcAC/aula-introdutoriacfd > Acesso em: 11 de outubro de 2014.

- SPALDING D.B. PHOENICS Encyclopedia. Algebraic Slip Model in PHOENICS. 1992. Disponível em: < www.cham.co.uk/asmlec.htm. > Acesso em: 11 de outubro de 2014.

- SPALDING D.B., PHOENICS Encyclopedia, Models in PHOENICS. 1996. Disponivel em: < http://www.cham.co.uk/ChmSupport/polis.php > Acesso em 10 de setembro de 2014.

- VAN WACHEM, B.G.M. et al. Methods for multiphase computational fluid dynamics. Chemical Engineering Journal, Gothenburg, Sweden, v. 96, p.81-98, nov. 2003.

- VARA, R. M. O. Hidrodinâmica do Escoamento Bifásico Óleo Pesado - Água em um Tubo Horizontal. 2001. 182 f. Dissertação (Mestrado) Curso de Engenharia Mecânica, Universidade Estadual de Campinas, Campinas, 2001. 
- Versteeg, H. K.; MALALASEKERA, W.. An Introduction to Computational Fluid Dynamics. England: Pearson Education Limited, 2007.

- WALVEKAR, R.G.. Numerical study of dispersed oil-water turbulent flow in horizontal tube. Journal of Petroleum Science and Engineering, Malaysia, v. 65, p.123-128, dez. 2009.

- WALVEKAR, Rashmi G. et al. Numerical Study of dispersed oil-water turbulent flow in horizontal tube. Journal of Petroleum Science and Engineering, Malaysia, v. 65, n. 65, p.123-128, 14 dez. 2008.

- WILCOX, D. C.. Turbulence Modeling for CFD. $2^{\circ}$ ed. DCW Industries, 1998.

- XU, Xiao-xuan. Study on oil-water two-phase flow in horizontal pipelines. Journal of Petroleum Science and Engineering, Beijing, China, v. 59, p.43-58, mar. 2007. 